\title{
THE DEMAND FOR HEALTHCARE SERVICES AND RESOURCES: PATTERNS, TRENDS AND CHALLENGES IN HEALTHCARE DELIVERY
}

SOFIA CRISTINA GUEDES DE SOUSA E CRUZ GOMES

TESE DE DOUTORAMENTO APRESENTADA

À FACULDADE DE ENGENHARIA DA UNIVERSIDADE DO PORTO EM

ENGENHARIA E GESTÃO INDUSTRIAL 


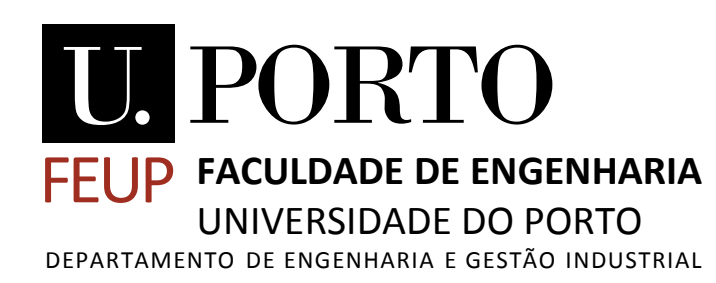

The demand for healthcare services and resources: patterns, trends and challenges in healthcare delivery

Submitted to Faculdade de Engenharia da Universidade do Porto in partial fulfillment of the requirements for the degree of Doctor of Philosophy in Industrial Engineering and Management, supervised by Bernardo Almada Lobo, Full Professor of Faculdade de Engenharia da Universidade do Porto and Mário Amorim Lopes, Invited Assistant Professor of Faculdade de Engenharia da Universidade do Porto

Department of Industrial Engineering and Management

Faculdade de Engenharia da Universidade do Porto 
This research was partially supported by the project HHRPLAN, grant

PTDC/IIMGES/4770/2014, awarded by the Portuguese Foundation for Science and Technology (FCT). 
"It is good to have an end to journey towards; but it is the journey that matters, in the end"

- Ursula Kroeber Le Guin 



\section{Acknowledgments}

The last three years have been full of experiences, challenges, opportunities, and emotions.

I was very fortunate to have the whole experience of doing a Ph.D. In addition to this thesis, I had classes, gave classes, participated in research projects, consultancy projects, participated in conferences, organized conferences, and even got married in the way! I succeed, failed, laughed, cried, and learned a lot. It was an incredible journey, and I have a lot of people to thank for it!

Firstly I want to thank my family: my reference, my inspiration, my safe haven, my everything. To Mom and Dad, for your love and education, which made me who I am. For being my role model, inspiring me in everything I do, and supporting all my choices. To Nokas, for the example of energy, resilience, willingness, and generosity. For the late-nights working together, for always saying the right words at the right time, and for always believing in me more than I ever did. For being my best friend. To Pedro, for always seeing me as a campeã , for the calmness that balances me, and for the patience and understanding of bad-moods, late dinners, and postponed celebrations. For the love and this partnership of ours. To Eduardo, Beni, and Henrique, for making my life happier and sweeter. And to Bonnie, for that tail wagging of loving happiness to see me, no matter what. For never let me feel alone.

I would also like to acknowledge the Department of Industrial Engineering and Management of FEUP, especially to Professors Maria Antónia Carravilla and José Fernando Oliveira, for the kindly accompaniment and concern that made me felt welcoming all the time. To my students, who taught me that I love teaching. And to the Professors who gave me the opportunity to work with them, Nuno Soares, Miguel Gomes, and Dulce Soares Lopes (from FEUP), and Carla Pereira (from IPP), for their trust and for all that I learned. I would further like to thank the members of IEMS and DEGI Club' organization, the Professors who gave me classes, both from FEUP and FEP, and all the colleagues, partners, and funders of the projects in which I had participated. 
To INESC-TEC, for hosting me. In particular to CEGI and its coordinators, Pedro Amorim to Ana Viana. It was my second home during these years, and I am deeply grateful to those who shared this journey with me. To Fábio, for the incredible expressions; to Gonçalo, for maintaining our faith in humanity; to Mário, for the humor and the background music; to Sara Neves and Flávia, for the friendship, help, motivation words, and genuine moments of fun; to Eduardo, for being a great drinking partner; to Xavier, for the conversations about everything and nothing; to Beatriz and Elsa, for your affection and concern; to Maria Pires, for the days when we used to sit together; to Rocha, Cristiane, Mateus, Luís Dias, Sara Martins, Maria João Santos, and so many others I can't list all. Thank you so much for making me part of this amazing group. Thanks for the daily lunches, the Soffs Caffés, the Meninas do CEGI lunches, and for the Caipirinhas $\mathcal{E}$ Comp. nights. I'm sure I'll carry friends for life. To all my old friends, thanks for cheering for me, and for the countless chill-out and party moments.

My last and most meaningful words of acknowledgement are for my supervisors, Bernardo Almada-Lobo, and Mário Amorim Lopes. I would like to thank you for your help, ideas, suggestions, reviews, and advice. For the way you managed between freedom and accompaniment, pressure and trust, supervision and friendship. But mostly, I am grateful for the opportunity you gave me. Of living all these great experiences and having those three wonderful years, which were some of the best of my life. Thank you will never be enough.

\section{Cheers!}




\begin{abstract}
Together with the significant improvement in health and longevity came a number of health and economic concerns related to the demand for healthcare services and resources: changes in the patterns of health and illness, increasing amount and complexity of healthcare services demanded, rising health expenditures and uncertainty about whether there will be enough human, physical and financial resources to deliver the healthcare services. This research aims to assist the several health stakeholders towards better decisions by providing a better understanding of the factors driving the demand for healthcare services and resources. To achieve this, we propose models and approaches to study the physician's requirements to deliver healthcare services and the health expenditures that may stem from changes in healthcare demand. Furthermore, the sustainability of healthcare delivery and alternative modes of providing care are discussed, and nursing specialization is analysed and evaluated as an option to improve care for populations with changing needs.
\end{abstract}





\section{Resumo}

Juntamente com a melhoria significativa na saúde e na longevidade, surgiu um conjunto de preocupações relacionadas com a procura por cuidados e recursos de saúde: mudanças nos padrões de saúde e de doença, aumento da quantidade e complexidade dos serviços de saúde procurados, aumento dos gastos com saúde e incerteza sobre a existência de recursos humanos, físicos e financeiros necessários para prestar os serviços de saúde procurados. Esta dissertação tem como principal objetivo auxiliar as diversas partes interessadas na área de saúde a tomar melhores decisões, através do estudo dos fatores impulsionadores da procura por serviços e recursos de saúde. Para tal, são propostas diversas abordagens e modelos para compreender e estimar a procura por cuidados de saúde, os recursos humanos necessários para prestar esses cuidados e os gastos com saúde que podem resultar de alterações nessa procura. Adicionalmente, a sustentabilidade da prestação de cuidados de saúde e os modos alternativos de prestação de cuidados são discutidos, e a especialização dos enfermeiros é avaliada enquanto medida para melhorar o atendimento de pacientes com necessidades cada vez mais complexas. 



\section{Contents}

1 Introduction 1

1.1 Context and motivation . . . . . . . . . . . . . . . . 1

1.2 Problem description . . . . . . . . . . . . . . . . . 2

1.3 Research objectives and methodological approach . . . . . . . . . . 7

1.4 Thesis synopsis $\ldots \ldots \ldots \ldots$. . . . . . . . . . . . . . . 10

Bibliography ........................ 11

2 Healthcare demand and delivery $\quad 17$

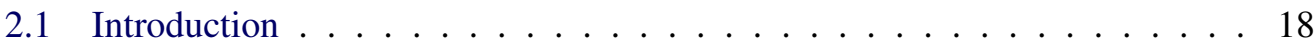

2.2 The problem . . . . . . . . . . . . . . . . . . . . . 19

2.3 Literature Review . . . . . . . . . . . . . . . . . . . . . . . . 21

2.3.1 Healthcare services . . . . . . . . . . . . . . . . . . . 21

2.3.2 Health Human Resources . . . . . . . . . . . . . . . . . . . . 23

2.3 .3 Health Expenditures . . . . . . . . . . . . . . . . . . 26

2.4 Research opportunities and the proposed approach . . . . . . . . . . . . . . 29

$2.4 .1 \quad$ Healthcare Services . . . . . . . . . . . . . . . . . . . . . 30

2.4 .2 Health Human Resources . . . . . . . . . . . . . . . . . . . . . . . 31

2.4 .3 Health Expenditures . . . . . . . . . . . . . . . . . . . 32

2.4 .4 Integrated Approach $\ldots \ldots \ldots \ldots$

2.5 Conclusion and future work . . . . . . . . . . . . . . . 35

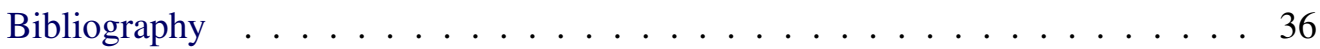

3 Health Workforce $\quad 45$

3.1 Background ......................... 46

3.2 Methods . . . . . . . . . . . . . . . . . . . 50

$3.2 .1 \quad$ Data . . . . . . . . . . . . . . . . 50

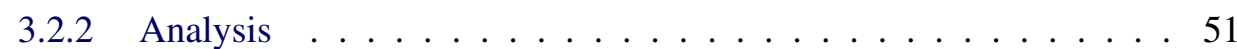


3.2 .3 Selected variables . . . . . . . . . . . . . . . . . . . 55

3.3 Results . . . . . . . . . . . . . . . . . 56

3.3.1 Descriptive statistics . . . . . . . . . . . . . . 56

3.3.2 Estimation results . . . . . . . . . . . . . . . . . . 57

3.3.3 Labor productivity . . . . . . . . . . . . . . . . . . . . 59

3.3.4 Elasticities of labor use, marginal rates of technical substitution and returns to scale $\ldots \ldots \ldots \ldots \ldots$. . . . . . . . . . 60

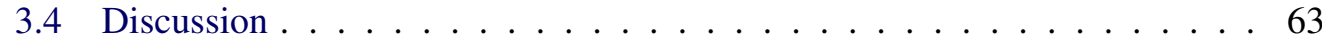

3.4.1 Limitations and further work . . . . . . . . . . . . . . . . . . 64

3.4.2 Implications for policy and practice $\ldots \ldots \ldots \ldots \ldots$

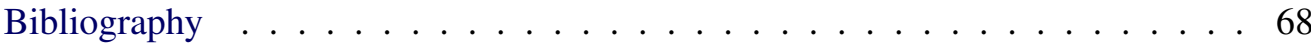

3.A Supplementary material . . . . . . . . . . . . . . . . . . 72

4 Health Expenditures $\quad 79$

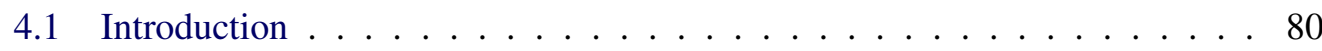

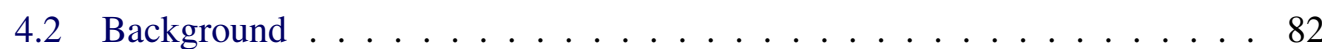

4.2.1 Methodological approaches . . . . . . . . . . . . 82

4.2.2 Determinants of Health Expenditure . . . . . . . . . . . . . . . 87

4.3 Data . . . . . . . . . . . . . . . . . 90

4.4 Methods . . . . . . . . . . . . . . . . . . . . . 91

4.4.1 Cross-section dependence . . . . . . . . . . . . . . . . . 91

4.4 .2 Stationarity . . . . . . . . . . . . . . . 93

4.4 .3 Cointegration . . . . . . . . . . . . . . . . 94

4.4.4 Long and short-run estimations _ . . . . . . . . . . 95

4.5 Results and discussion $\ldots \ldots \ldots 98$

4.5.1 Cross-section dependence, stationarity, and cointegration . . . . . 98

4.5.2 Long and short-run estimation . . . . . . . . . . . 101

4.5.3 Panel Framework Selection _ . . . . . . . . . . . . . 106

4.6 Conclusions . . . . . . . . . . . . . . . . . . . . . . . . 109 


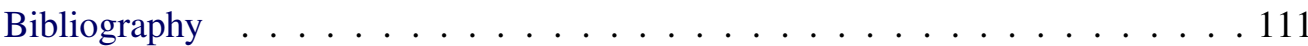

4.A Supplementary material . . . . . . . . . . . . . . . . . . . . . 121

5 Nursing specialization $\quad 127$

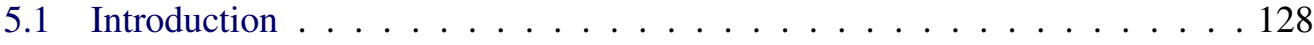

5.2 Where? The international experience . . . . . . . . . . . . . . 131

5.3 Why? The empirical evidence . . . . . . . . . . . . . . . . 133

5.3.1 Literature review design $\ldots \ldots$. . . . . . . . . . . . 134

5.3.2 Patients and population . . . . . . . . . . . 136

5.3.3 Workers and labour market . . . . . . . . . . . . . . . . 137

5.3.4 Organizations providing healthcare services . . . . . . . . . 138

5.4 How? Rolling out the role of Nurse Specialist . . . . . . . . . . . . . . . 139

5.4.1 Barriers and enablers . . . . . . . . . . . . . . . . . . 143

5.4 .2 Workforce planning . . . . . . . . . . . . . . . 144

5.4 .3 Education and training . . . . . . . . . . . . . 147

5.4.4 Payment policies . . . . . . . . . . . . . . . . . . . . 149

5.4.5 Regulation and governance . . . . . . . . . . . . . . . . . 150

5.4 .6 Economic impact . . . . . . . . . . . . . . . . 151

5.5 Conclusions . . . . . . . . . . . . . . . . . . 158

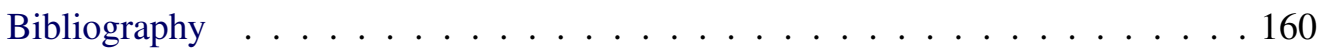

5.A Supplementary material . . . . . . . . . . . . . . . 167

6 Conclusions and future work 173

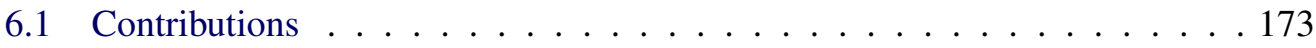

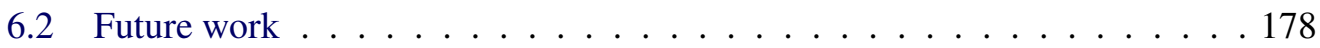





\section{List of Figures}

1.1 Healthcare demand and delivery: sub-problems $\ldots \ldots \ldots \ldots$

1.2 Evolution of life expectancy at birth . . . . . . . . . . . . 3

1.3 Evolution of health expenditures $\ldots \ldots \ldots \ldots$

1.4 Chapters overview $\ldots \ldots \ldots \ldots \ldots$

2.1 Problem Framing . . . . . . . . . . . . . . . . . . . . . . . . . 19

2.2 Integrated Approach $\ldots \ldots \ldots$. . . . . . . . . . . . . . 34

3.1 Technical change rate and cumulative technical progress in general surgery

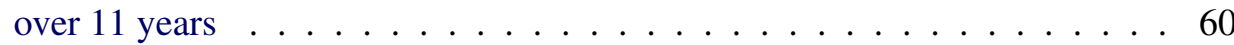

3.2 Technical change rate and cumulative technical progress in internal medicine over 11 years . . . . . . . . . . . . . . . . . . . 60

4.1 Framework for selecting the model for cointegrated macro panels . . . . . . 107

5.1 Rationale for the nursing specialization . . . . . . . . . . . . . . 129

5.2 Study selection process . . . . . . . . . . . . . . . . . 135

5.3 Framework for implementation and governance . . . . . . . . . . . . 141

5.4 Estimated evolution of the number of specialists . . . . . . . . . . 146

5.5 Forecast of the evolution of the Nursing workforce in the next 15 years. . . 147

5.6 Training and education process . . . . . . . . . . . . . . . . 148

5.7 Costs with the residency program . . . . . . . . . . . . . . 154

5.8 Estimated cost with differentiated nurse specialist remuneration . . . . . . . 155

5.9 Decomposition of savings in hospitalization costs, assuming gains of 5\% . 157

5.10 Budgetary impact of the specialty residency $\ldots \ldots \ldots 158$ 



\section{List of Tables}

3.1 Summary statistics for the variables included in the models between 1999 and $2010 \ldots \ldots \ldots \ldots \ldots \ldots \ldots \ldots \ldots$

3.2 Summary statistics for the variables included in the models between 1999 and $2010 \ldots \ldots \ldots \ldots \ldots$

3.3 Elasticities of mean-labor use, MRTS and RTS. . . . . . . . . . . . . . . 62

3.4 Mean-values of the explanatory variables . . . . . . . . . . . . . . . 77

3.5 Correlation Matrix _ . . . . . . . . . . . . . . . . . . 77

3.6 Fixed effects estimates $\ldots \ldots \ldots \ldots$. . . . . . . . . . . 77

4.1 Summary statistics for the variables included in the panel analysis . . . . 9 91

4.2 Cross-section dependence tests . . . . . . . . . . . . . . . . . . . . . . 99

4.3 Panel unit root tests (levels and first-differences) . . . . . . . . . . . . . . . 99

4.4 CIPS panel unit root tests (levels and first-differences) $\ldots . \ldots 100$

4.5 Westerlund ECM panel cointegration tests . . . . . . . . . . . . . . 100

4.6 Panel DOLS and FMOLS . . . . . . . . . . . . . . . . . . . . . . . 101

4.7 Panel ARDL (Pooled, MG and PMG) . . . . . . . . . . . . . . 103

4.8 Panel DCCE (Pooled, MG and PMG) . . . . . . . . . . . . . . 105

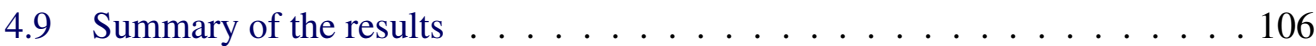

4.10 Comparison with previous literature . . . . . . . . . . . . 106

4.11 Macro panel studies of health expenditures for OECD countries . . . . . . 122

4.12 Correlation matrix . . . . . . . . . . . . . . . . . . . . 123

4.13 Hausman tests . . . . . . . . . . . . . . . . . . . . . . 123

4.14 Country-specific short-run effects (ARDL-PMG) . . . . . . . . . . . . . 124

4.15 Country-specific short-run effects (DCCE-PMG) $\ldots \ldots$. . . . . . . . . . 125

5.1 International comparison of $\mathrm{CNS}$ regulation and requirements $\ldots \ldots 133$

5.2 Targets for the ratio of Specialist Nurses in the NHS. . . . . . . . . . . . 146 
5.3 Parameters and assumptions assumed in the calculation of costs. . . . . . . 153

5.4 Parameters and assumptions assumed for benefits calculation . . . . . . 156

5.5 Summary of the papers included in the literature review. . . . . . . . . 168

5.6 Summary analysis of the budgetary impact of nursing specialization. . . . . 172 
Chapter 1

\section{Introduction}

\subsection{Context and motivation}

The improved living conditions and the advances in medical science that occurred in the past decades led to significant improvements in health and in longevity, which is now mainly due to the declining mortality among older people (WHO, 2015). However, together with this achievement came a number of changes that are raising global health and economic concerns. Healthcare systems around the world are now facing several challenges related to the demand for healthcare services and resources. Changes in patterns of health and illness among individuals, increasing amount and complexity of healthcare services demanded by the populations, rising health expenditures over time, and uncertainty about whether there will be enough resources to deliver the demanded services are some of the main current matters calling the attention of health researchers, managers and governments. Health is one of the highest priorities for people all around the world, and promotion and protection of health are crucial to both human welfare and sustained socioeconomic development (WHO, 2010). Thus, a better understanding of these topics is of major worth, as it allows for accurate planning of health systems to provide quality and timely healthcare services and to sustainably contribute to healthy populations. This thesis comes forth as an attempt to draw attention to the current health and economic concerns related to the future demand and delivery of healthcare and to show that despite the undeniable interest of the field and the growing number of studies devoted to these issues, the problem is not closed. Furthermore, it aims to provide insights, methodologies and tools to properly assess and plan for the future needs of healthcare services and resources, guid- 
ing the several health stakeholders towards better decisions. Econometric and operational research methods to understand the demand for healthcare services and resources are to be developed and used to analyse and discuss the patterns, trends and challenges in healthcare delivery.

\subsection{Problem description}

Overall, the problem of planning the demand and delivery of healthcare services can be summarized as the need to ensure that the necessary healthcare services will be provided to patients who need them. For a better understanding of this problem, we decompose it in four different sub-problems, as represented in Figure 1.1: 1) Demand for healthcare services; 2) Demand for health human resources; 3) Demand for health Expenditures; and 4) Healthcare Delivery. This decomposition is justified due to the different dimensions involved in healthcare, as ensuring that the future demand will be met depends on planning the healthcare services that will be demanded by the population, the health human resources that will be required to deliver these services, and the financial resources that will have to be available for all the inputs that are needed to produce them. Additionally, ensuring quality and timely delivery of healthcare services to all who need them is also crucial to the problem.

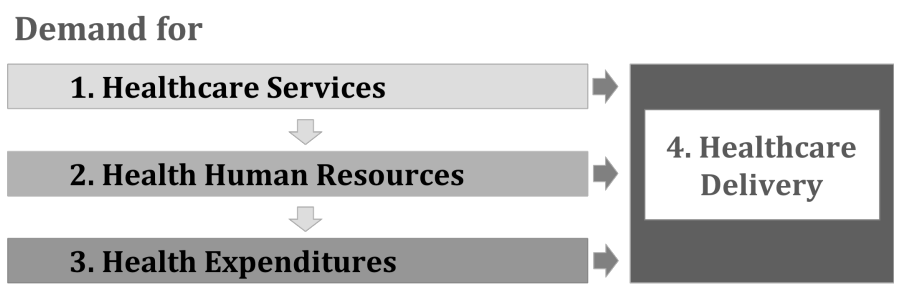

Figure 1.1 - Healthcare demand and delivery: sub-problems

The first sub-problem is related to the demand for healthcare services. Factors driving this demand have been widely studied by health and economic researchers. Within the vast list of determinants considered (socioeconomic, epidemiological and health-related, demographic, environmental, individual characteristics and behaviours), income was found 
to be negatively related with the demand for primary care services and positively associated with the use of specialist care (Pohlmeier and Ulrich, 1995; d'Uva and Jones, 2009). The price of the services, as well as the distance to providers, were found to be negatively related to the demand for healthcare (Oliveira, 2004; Sarma, 2009). Oppositely, age, pollution and unemployment were found to have a positive impact on the demand for healthcare (Schofield and Earnest, 2006; Erbsland et al., 1995; Vončina et al., 2007). Marital status, race, educational level, lifestyles, and environmental conditions were also found to have a significant effect on the demand for healthcare (Pohlmeier and Ulrich, 1995; Winkelmann, 2004). Nowadays, in a context of rising longevity (Figure 1.2) and subsequent increasing burden of disease, mostly due to the growing prevalence of chronic conditions (WHO, 2015; Alwan et al., 2010; Beaglehole et al., 2011; W Ward et al., 2014), research attempting to understand the main causes and consequences of these epidemiological changes have proliferated in the health literature.

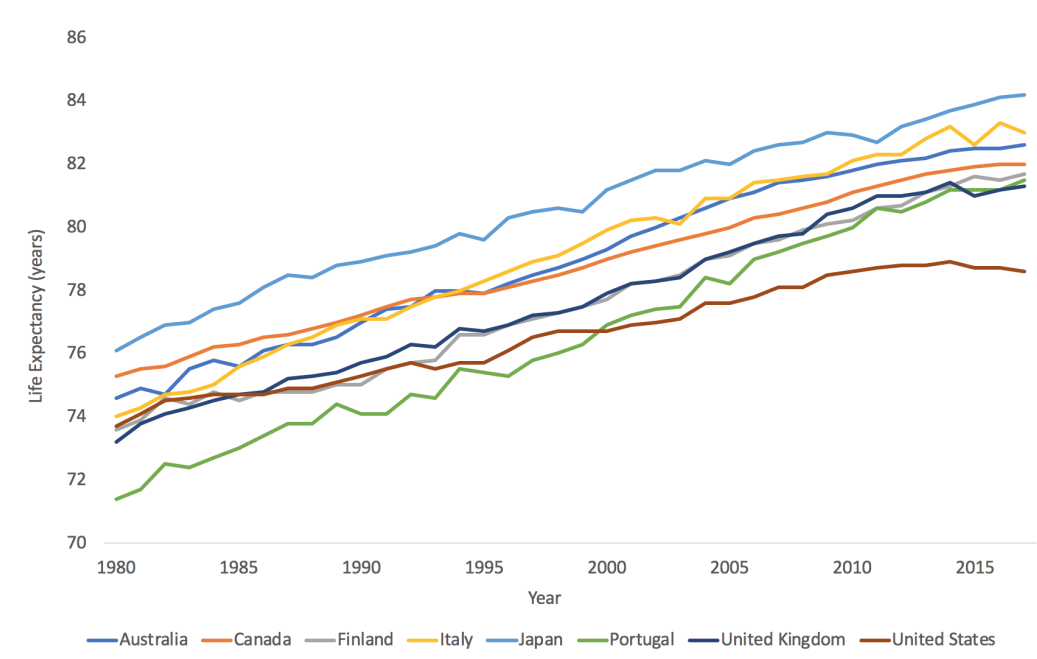

Figure 1.2 - Evolution of life expectancy at birth

Several studies have shown a positive relationship between the burden of disease and the demand for healthcare (Roberts and Charlesworth, 2012; Dall et al., 2013). It has also been revealed that increases in the prevalence of chronic diseases rise the demand for healthcare and generate new challenges on ensuring the delivery and financing of healthcare services 
(Barceló et al., 2003). Furthermore, it is known that chronic conditions tend to cluster, which drove the researchers' attention to the study of the co-existence of multiple morbidities (Fortin et al., 2005; Wolff et al., 2002; Caughey et al., 2008; Banerjee, 2015; Barnett et al., 2012; Canizares et al., 2017). Multiple morbidities are now known to be associated with a decline in health outcomes and a subsequent increase in the utilization of healthcare services and resources (Caughey et al., 2008), as people with multiple conditions tend to have a higher vulnerability to diseases and less resistance to health threats (Glynn et al., 2011). In fact, it has been shown that patients with multiple chronic diseases demand a greater array of healthcare services and professionals (Vogeli et al., 2007) and that they are more likely to seek care (and do it more often) than patients without multiple chronic diseases. Because the demand for healthcare ultimately depends on the seek for health, epidemiology and health-related factors are extremely relevant drivers of the decision to seek care. Therefore, addressing these factors and its evolution is of most importance for studying the problem of planning for healthcare services demand. Efforts should be made to understand the patterns of the demand according to these factors, especially focusing on the impact of the evolution of multiple diseases co-existence over the time, and across people from different contexts and with different individual characteristics.

The second sub-problem identified concerns to the HHR demand. Health human resources are widely recognized as the most important input of a health system (WHO, 2000a). Therefore, HHR planning is of major relevance and a popular subject among researchers, especially in more recent years (Ono et al., 2013), as imbalances in the healthcare workforce are becoming a major concern (Zurn et al., 2004) and mismatches between the demand for and the supply of HHR may lead to several economic and social problems (Lopes et al., 2015). Regarding the demand-side, there are several approaches to project future health worker requirements, such as health needs, services utilization/demand, service targets and workforce-to-population-ratio (Lopes et al., 2015; Bärnighausen and Bloom, 2009; Ono et al., 2013; WHO, 2000b; Roberfroid et al., 2009; Ansah et al., 2017). Most of them require the conversion of services into HHR requirements as a step succeeding the estimation of future healthcare services (Bärnighausen and Bloom, 2009). There are sev- 
eral methods of converting services into workforce requirements: assess the time required to complete tasks (Lipscomb et al., 1998; Hurst, 2003), apply labour productivity measures to the expected needs for healthcare services, estimate the workforce that is likely to be demanded given some known drivers of the demand for care, such as economic growth (Scheffler et al., 2008), or estimate production functions relating healthcare inputs with healthcare outputs (Pourmohammadi et al., 2014). All these approaches have pros and cons, and no consensus on the best way to translate needs in HHR requirements has been attained (Murphy G.T., 2007).

The third sub-problem represents health expenditures. The existence of both the physical and the human resources required to deliver the demanded healthcare services ultimately depend on the financial resources that are dedicated to the health sector. The rising health expenditures in the last decades (Figure 1.3) and subsequent concerns on the financial sustainability of healthcare have urged researchers to review its determinants (Getzen, 2016; Marino et al., 2017).

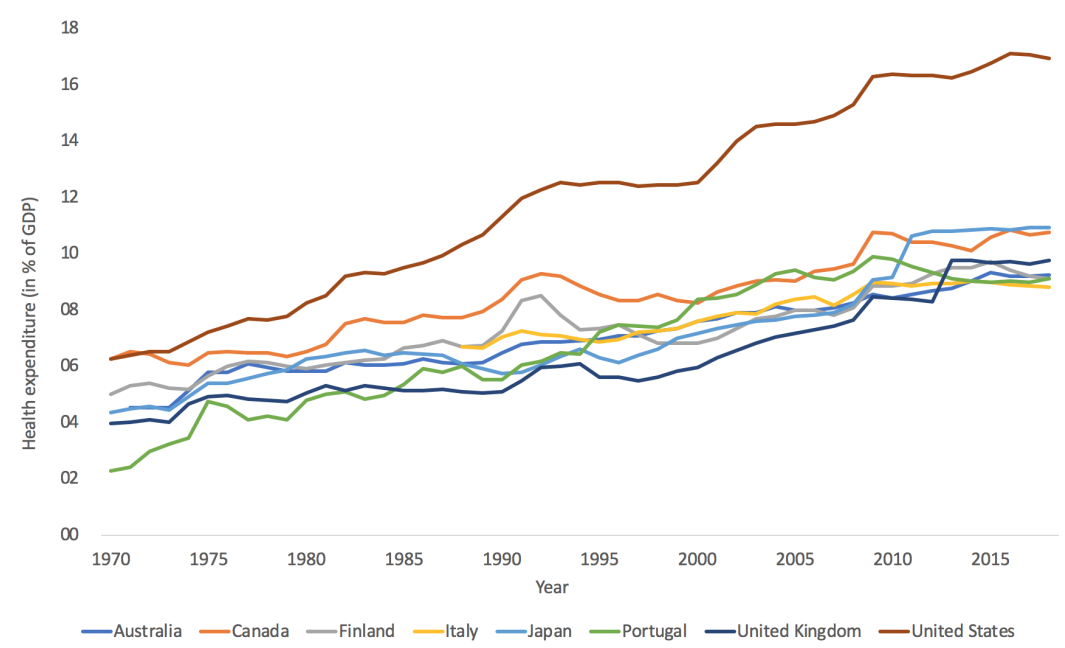

Figure 1.3 - Evolution of health expenditures

Macro analyses of the determinants of health care expenditures have been exploring the relationship between health expenditures and a diversity of possibly-related variables, both from the supply- and the demand-side. The results arising from these studies point that 
income, demography, human resources, technology and health-related factors as the main responsible for the evolution of health expenditures. However, despite the undeniable interest of the topic, the literature on health expenditures determinants and approaches reveal opportunities for contributions. First, because the factors driving health expenditures seem to remain only imperfectly understood, as their effect substantially vary according to the dataset, the variables considered and the methodological approach followed. Second, due to the lack of unanimity and consensus regarding the best methodological approach to estimate the relationship between health expenditures and its drivers, which most of the times seems to be not considering some essential characteristics of the data.

Finally, the fourth sub-problem deals with the challenges in healthcare delivery. An ageing population with chronic diseases and multiple morbidities, along with the technological developments in healthcare delivery and organizational changes aiming to promote a higher quality of and access to healthcare services led to a growing complexity of healthcare, and health systems are currently facing pressures both in the levels of care and in the resources needed (Fagerström, 2012; CNA, 2008; Parker and Hill, 2017). Therefore, finding ways of dealing with the current challenges and of providing adequate and sustainable care to a population with changing needs have been calling the attention of researchers, managers, and governments. Currently, it is recognized that a redefinition of HHR management policies - in terms of intervention roles, qualifications, number, and distribution - capable of meeting the new societal challenges may be required to ensure that timely and quality healthcare services are delivered in a sustainable way (Kabene et al., 2006). Investing in human capital, through the specialization of providers, fostering economies of scale and knowledge and improving both the productivity of HHR and the quality of healthcare is very relevant. Within the possible ways to deal with the rising demand and complexity of healthcare, the nursing specialization is presented as an alternative mode of delivering care, which is claimed to help to ensure the quality, access, and sustainability of healthcare delivery. Search and evaluate alternatives to deal with the challenges arising from the lack of physicians, the need to contain expenditures, to reduce waiting times, to serve the underprivileged, to manage chronic diseases and to care for older people with multiple 
morbidities is therefore crucial in the current context (Sheer and Wong, 2008).

A more detailed description of the problem and a literature review and discussion regarding each of the sub-problems identified here is presented in the next chapter, where some gaps are also recognized, and an integrated approach is proposed.

\subsection{Research objectives and methodological approach}

In the previous subsection, the problem of planning the demand and delivery of healthcare was characterized and an overview of the four interrelated sub-problems identified was provided: three of them directly related to demand planning - for healthcare services, HHR and HE - and the other deriving from the previous ones, representing the challenges in healthcare delivery that come from a rising pressure on these demands.

With this thesis, we firstly aim to show that despite the undeniable interest of the field and the growing number of studies devoted to such issues, the problem is not closed, as there is no consensus on the main subjects, nor established preferred methodologies to approach it. Therefore, the main goal of this research is to contribute to the field with economic, econometric, and operational research methods to properly assess and plan the future needs for healthcare services and resources. Furthermore, it aims to provide useful insights about the patterns and trends of healthcare delivery, helping the several health stakeholders facing the challenges of delivering care and guiding them towards better decisions.

Three main research questions (RQ) were postulated in order to guide the work of this research. Research questions 1 and 2 are explicitly concerned with the sub-problems 2 and 3 composing the research problem: demand for both health human resources and health expenditures, respectively. Research question 3 is related to healthcare delivery, and to the need for finding alternative modes of delivering care for populations with changing needs. The methodological approach to answer each RQ is briefly exposed. 


\section{Research question 1}

How to translate healthcare services into HHR requirements in a multi-output context (e.g., hospitals)?

- What has been the impact of labour productivity on healthcare delivery?

- Which allocation options are available for the current levels of HHR?

Ensuring the delivery of healthcare services is crucially dependent on planning for the HHR needed to deliver these services. To empirically quantify the relation between healthcare services and HHR requirements, we propose a Labour Requirements Function relating the number of physicians with a set of speciality-specific workload and capital variables. Elasticities of mean labour-use, marginal rates of technical substitutions between healthcare services, and returns to scale are also analysed to provide further insights on opportunity costs of labour and different possibilities for allocating the existing HHR.

\section{Research question 2}

Out of the main supply- and demand-side drivers of healthcare expenditures identified in the literature, which are the most significant for the OECD countries?

- What are the shapes of long- and short-run relationships among health care expenditures and these drivers?

- Which are the most suitable models for detecting the existence of long-run relationships among healthcare spending and its determinants? Do the different methodologies most commonly applied lead to similar results and conclusions?

The rising health expenditures and the uncertainty about whether there will be enough resources to deliver the demanded services in the future have been calling the attention of health researchers, managers, and policy-makers. To investigate the long-run relationship between health expenditures and the main spending drivers identified in the literature, several econometric models and techniques are applied. The suitability of the different 
methodologies is exposed, and the results are compared. A framework guiding the selection of the adequate methodological approach according to the characteristics of the data is also proposed.

\section{Research question 3}

Within healthcare delivery, can nursing specialization help with the main challenges arising from the recent changes in the demand for healthcare?

- What is the theoretical rationale supporting the specialization of nurses? Do the main empirical results reported by countries where nursing specialization was implemented support this rationale?

- How to roll-out nursing specialization in a specific country? What can be the expected budgetary impact of implementing specialized nursing roles?

Specialized nursing care has been pointed out as one of the ways to deal with the rising volume and complexity on the demand for healthcare. It has been defended the relevance of their role in chronic diseases management and care for older people with multiple morbidities. We review both the theoretical arguments and the empirical results of specialization, to check if there is evidence supporting these arguments. This research question is answered through a literature review on the effects of specialized nursing roles, and through a policy framework for the creation and governance of such roles, which provides insights regarding the main barriers and enablers, the regulation guiding the main aspects of the measure, the estimation and plan for the workforce that should be specialized and hired as a specialist, the education and training required, the payment policies, and the economic impact of both the specialization process and the maintenance of a specialized workforce in the health system. 


\subsection{Thesis synopsis}

We have chosen to elaborate this thesis as a collection papers, which are published or submitted in international peer-reviewed journals. This format has the advantage of reporting some work that was already subject to peer review and improvements, with the drawback being that some of the introductory parts may be repetitive.

The work is divided into six chapters. Each of the chapters 2 to 5 correspondent to a paper, and the final chapter (6) concludes. Figure 1.4 provides an overview of how the chapters collate.

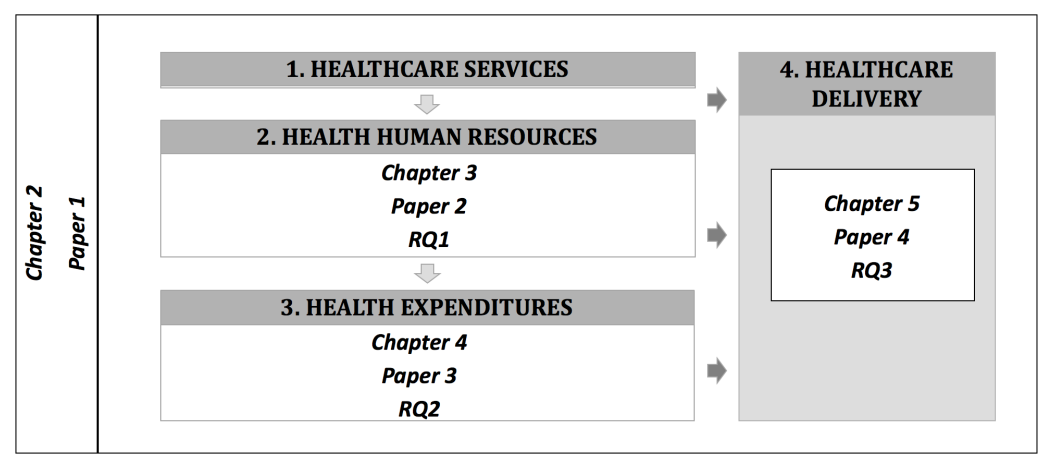

Figure 1.4 - Chapters overview

The remainder of the thesis is as follows. Chapter 2 provides a self-contained review and discussion of the demand for healthcare problem. It is the aim of the chapter to highlight the importance of planning the demand for healthcare in the challenging current health and economic environment, to enhance some research opportunities and create awareness for the need for a comprehensive study on the different dimensions of the demand for healthcare services and resources. The chapter ends with the proposal of an integrated approach for planning healthcare services and resources, which intends to produce the necessary knowledge to inform both managers and policy-makers on what can be the main challenges on assuring healthcare delivery in the future.

Chapter 3 presents a Labor Requirements Function to empirically quantify the relation between healthcare services and Health Human Resources requirements, aiming to assist the challenging task of translating healthcare services into workforce requirements. This 
chapter seeks to answer RQ1.

In Chapter 4, the long-run relationship between health expenditures and some of its main determinants, both from the supply- and the demand-side, is investigated, and the questions raised in RQ2 are answered. The sensibility of the results to the econometric models and techniques is analysed, and guidelines for the selection of the methodological approach according to the characteristics of the data are provided.

Chapter 5, which is devoted to answering RQ3, sheds some light on the nursing specialization rationale, international trends, and empirical evidence on the effects of having a specialized nursing workforce. Moreover, it provides a policy framework for the creation and governance of specialized nursing roles, and presents the analysis performed to support the discussion and negotiation of the implementation of this role in Portugal.

Finally, Chapter 6 synthesizes the main contributions of the thesis and presents some future work that may be done in the field.

\section{Bibliography}

A. Alwan, D. R. MacLean, L. M. Riley, E. T. d'Espaignet, C. D. Mathers, G. A. Stevens, and D. Bettcher. Monitoring and surveillance of chronic non-communicable diseases: progress and capacity in high-burden countries. The Lancet, 376(9755):1861-1868, 2010.

J. Ansah, V. Koh, D. De Korne, S. Bayer, C. Pan, T. Jayabaskar, D. Matchar, and D. Quek. Comparing health workforce forecasting approaches for healthcare planning: the case for ophthalmologists. International Journal of Healthcare, 3(1):84-96, 2017.

S. Banerjee. Multimorbidity-older adults need health care that can count past one. The Lancet, 385(9968):587-589, 2015.

A. A. M. Barceló, C. Aedo, S. N. Rajpathak, and S. Robles. The cost of diabetes in latin america and the caribbean. Bulletin of the World Health Organization, 81 1:19-27, 2003.

K. Barnett, S. W. Mercer, M. Norbury, G. Watt, S. Wyke, and B. Guthrie. Epidemiology 
of multimorbidity and implications for health care, research, and medical education: a cross-sectional study. The Lancet, 380(9836):37-43, 2012.

T. Bärnighausen and D. E. Bloom. Changing research perspectives on the global health workforce. Technical report, National Bureau of Economic Research, 2009.

R. Beaglehole, R. Bonita, R. Horton, C. Adams, G. Alleyne, P. Asaria, V. Baugh, H. Bekedam, N. Billo, S. Casswell, et al. Priority actions for the non-communicable disease crisis. The Lancet, 377(9775):1438-1447, 2011.

M. Canizares, S. Hogg-Johnson, M. A. Gignac, R. H. Glazier, and E. M. Badley. Increasing trajectories of multimorbidity over time: birth cohort differences and the role of changes in obesity and income. The Journals of Gerontology: Series B, 73(7):1303-1314, 2017.

G. E. Caughey, A. I. Vitry, A. L. Gilbert, and E. E. Roughead. Prevalence of comorbidity of chronic diseases in australia. BMC public health, 8(1):221, 2008.

CNA. Advanced nursing practice a national framework. Canadian Nurses Association., pages $1-53,2008$.

T. M. Dall, P. D. Gallo, R. Chakrabarti, T. West, A. P. Semilla, and M. V. Storm. An aging population and growing disease burden will require alarge and specialized health care workforce by 2025. Health affairs, 32(11):2013-2020, 2013.

T. B. d'Uva and A. M. Jones. Health care utilisation in europe: new evidence from the echp. Journal of health economics, 28(2):265-279, 2009.

M. Erbsland, W. Ried, and V. Ulrich. Health, health care, and the environment. econometric evidence from german micro data. Health Economics, 4(3):169-182, 1995.

L. Fagerström. The impact of advanced practice nursing in healthcare: Recipe for developing countries. Annals of neurosciences, 19(1):1, 2012.

M. Fortin, G. Bravo, C. Hudon, A. Vanasse, and L. Lapointe. Prevalence of multimorbidity among adults seen in family practice. The Annals of Family Medicine, 3(3):223-228, 2005. 
T. E. Getzen. Measuring and forecasting global health expenditures. In World Scientific Handbook of Global Health Economics and Public Policy: Volume 1: The Economics of Health and Health Systems, pages 177-215. World Scientific, 2016.

L. G. Glynn, J. M. Valderas, P. Healy, E. Burke, J. Newell, P. Gillespie, and A. W. Murphy. The prevalence of multimorbidity in primary care and its effect on health care utilization and cost. Family practice, 28(5):516-523, 2011.

K. Hurst. Selecting and applying methods for estimating the size and mix of nursing teams selecting and applying methods for estimating the size and mix of nursing teams. 2003.

S. M. Kabene, C. Orchard, J. M. Howard, M. A. Soriano, and R. Leduc. The importance of human resources management in health care: a global context. Human resources for health, 4(1):20, 2006.

J. Lipscomb, G. Parmigiani, and V. Hasselblad. Combining expert judgment by hierarchical modeling: an application to physician staffing. Management Science, 44(2):149-161, 1998.

M. A. Lopes, Á. S. Almeida, and B. Almada-Lobo. Handling healthcare workforce planning with care: where do we stand? Human Resources for Health, 13(1):38, May 2015. ISSN 1478-4491.

A. Marino, D. Morgan, L. Lorenzoni, and C. James. Future trends in health care expenditure: A modelling framework for cross-country forecasts. OECD Health Working Papers, 5(95), 2017.

M. A. Murphy G.T., Birch S. Needs-based health human resources planning: The challenge of linking needs to provider requirements. 2007.

M. D. Oliveira. Modelling demand and supply influences on utilization: a flow demand model to predict hospital utilization at the small area level. Applied Economics, 36(20): 2237-2251, 2004. 
T. Ono, G. Lafortune, and M. Schoenstein. Health workforce planning in oecd countries. 2013.

J. M. Parker and M. N. Hill. A review of advanced practice nursing in the united states, canada, australia and hong kong special administrative region (sar), china. International Journal of Nursing Sciences, 4(2):196-204, 2017.

W. Pohlmeier and V. Ulrich. An econometric model of the two-part decisionmaking process in the demand for health care. Journal of Human Resources, pages 339-361, 1995.

K. Pourmohammadi, N. Hatam, P. Bastani, and F. Lotfi. Estimating production function: a tool for hospital resource management. Shiraz E-Medical Journal, 15(4), 2014.

D. Roberfroid, C. Leonard, and S. Stordeur. Physician supply forecast: better than peering in a crystal ball? Human Resources for Health, 7(1):10, Feb 2009. ISSN 1478-4491.

A. Roberts and A. Charlesworth. Future demand for health care: a modelling study. The Lancet, 380:S20, 2012.

S. Sarma. Demand for outpatient healthcare. Applied health economics and health policy, 7(4):265-277, 2009.

R. M. Scheffler, J. X. Liu, Y. Kinfu, and M. R. Dal Poz. Forecasting the global shortage of physicians: an economic-and needs-based approach. Bulletin of the World Health Organization, 86:516-523B, 2008.

D. J. Schofield and A. Earnest. Demographic change and the future demand for public hospital care in australia, 2005 to 2050. Australian Health Review, 30(4):507-515, 2006.

B. Sheer and F. K. Y. Wong. The development of advanced nursing practice globally. Journal of Nursing Scholarship, 40(3):204-211, 2008.

C. Vogeli, A. E. Shields, T. A. Lee, T. B. Gibson, W. D. Marder, K. B. Weiss, and D. Blumenthal. Multiple chronic conditions: prevalence, health consequences, and implications for quality, care management, and costs. Journal of general internal medicine, 22 (3):391-395, 2007. 
L. Vončina, I. Pristaš, M. Mastilica, O. Polašek, Z. Šošić, and R. Stevanović. Use of preventive health care services among unemployed in croatia. Croatian medical journal, 48(5):0-0, 2007.

B. W Ward, J. S Schiller, and R. A Goodman. Multiple chronic conditions among u.s. adults: A 2012 update. Preventing chronic disease, 11:E62, 042014.

WHO. Health systems: Improving performance. World Health Organization., 78(1):1215, 2000a.

WHO. World health organization. models and tools for health workforce planning and projections. world heal rep. World Health Organization., $2000 \mathrm{~b}$.

WHO. Health systems financing - the path to universal coverage. World Health Organization., pages 1-128, 2010.

WHO. World report on ageing and health. World Health Organization., pages 1-260, 2015.

R. Winkelmann. Health care reform and the number of doctor visits-an econometric analysis. Journal of Applied Econometrics, 19(4):455-472, 2004.

J. L. Wolff, B. Starfield, and G. Anderson. Prevalence, expenditures, and complications of multiple chronic conditions in the elderly. Archives of internal medicine, 162(20): 2269-2276, 2002.

P. Zurn, M. R. Dal Poz, B. Stilwell, and O. Adams. Imbalance in the health workforce. Human resources for health, 2(1):13, 2004. 



\title{
Healthcare demand and delivery
}

\section{The demand for healthcare: patterns, trends and chal- lenges in healthcare delivery}

\author{
Sofia Cruz-Gomes* · Mário Amorim Lopes * · Bernardo Almada-Lobo*
}

Published in Springer Proceedings in Mathematics \& Statistics vol. 278, pp 91-106, 2019

\begin{abstract}
Together with the significant improvement in health and longevity came a number of health and economic concerns related to the demand for healthcare services and resources: changes in the patterns of health and illness, increasing amount and complexity of healthcare services demanded, rising health expenditures and uncertainty about whether there will be enough human, physical and financial resources to deliver the healthcare services needed. This paper aims to draw attention to the importance of planning the demand for healthcare in the aforementioned context, to create awareness of the need for a comprehensive study on the demand for healthcare services and resources and to propose an integrated approach for planning them, to inform managers and policy-makers on what can be the main challenges on assuring healthcare delivery in the future.
\end{abstract}

Keywords Healthcare $\cdot$ Demand $\cdot$ Integrated framework $\cdot$ planning

${ }^{*}$ INESC TEC, Faculdade de Engenharia, Universidade do Porto, Rua Dr. Roberto Frias, 4200-465, Porto, Portugal 


\subsection{Introduction}

The improved living conditions and the advances in medical science that occurred in the past decades led to significant improvements in health and in longevity, which is now mainly due to the declining mortality among older people (WHO, 2015). However, together with this achievement came a number of changes that are raising global health and economic concerns. Healthcare systems around the world are now facing several challenges related to the demand for healthcare services and resources. Changes in patterns of health and illness among individuals, increasing amount and complexity of healthcare services demanded by the populations, rising health expenditures over time and uncertainty about whether there will be enough resources to deliver the demanded services are some of the main current matters calling the attention of health researchers, managers and governments.

Health is one of the highest priorities for people all around the world and promotion and protection of health are crucial to both human welfare and sustained socioeconomic development (WHO, 2010a). Thus, a better understanding of these topics - allowing an accurate planning that can help to ensure that health systems can continue to provide quality and timely healthcare services and to contribute to healthy populations in a sustainable way - is of major worth.

This paper aims to highlight the importance of planning the demand for healthcare in the challenging current health and economic environment, to create awareness of the need for a comprehensive study on the demand for healthcare services and resources and to propose an integrated approach for planning them, to inform both managers and policy-makers on what can be the main challenges on assuring healthcare delivery in the future.The remainder of the paper is organized as follows. The next section presents and describes the problem under consideration. In section 3, the scientific literature on the different problem dimensions is briefly revised and some research opportunities on assessing and planning for the future needs of healthcare services and resources are pointed out. Section 4 proposes an integrated approach to address the identified gaps and the main contributions that 
may result from such work. The last section is devoted to conclusions and final remarks.

\subsection{The problem}

Overall, the problem can be summarized as the need to ensure that the necessary healthcare services will be provided to patients who need them. However, ensuring that future demand will be met depends on planning the different dimensions of the problem: 1) the healthcare services that will be demanded by the population; 2) the health human resources that will be required to deliver these services; 3 ) the financial resources that will have to be available for all the inputs that are needed to produce them; and 4) the quality and timely delivery of healthcare to all who need them. Thus, for a better understanding of the problem of planning the demand and delivery of healthcare services, we decompose it in four different blocks, as represented in Figure 2.1. Each block represents one of the aforementioned dimensions of the problem, which are logically and sequentially connected as the figure shows.

The first block represents the sub-problem of planning the demand for healthcare services. There are many factors driving this demand, which have been hardly studied by health and economic researchers, theoretically and empirically: socio-economic, epidemiological and health-related, demographic and individual characteristics and behaviors. Nowadays, in a context of rising co-existence of multiple health conditions, it is recognized that epidemiological factors are extremely relevant on driving the decision of seek for care. Efforts should be made on understanding the patterns of the demand according to these factors,

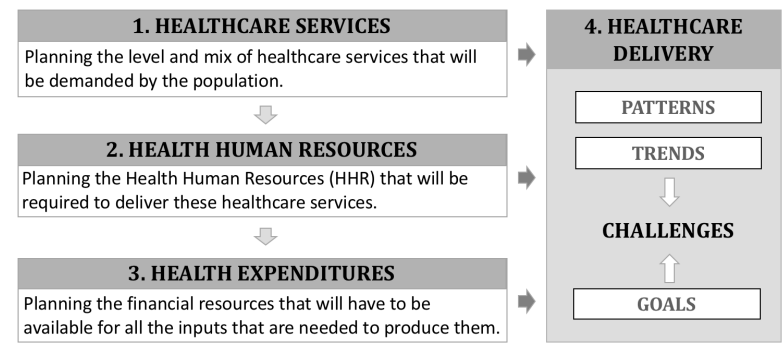

Figure 2.1 - Problem Framing 
specially focusing on the impact of the evolution of multiple diseases co-existence over the time and across people from different contexts and with different individual characteristics. The understanding of these complex and dynamic interrelations is of most interest to produce accurate forecasts on the demand for healthcare evolution, which are crucial to several purposes, such as planning for the capacity needed, inform on regional disparities and serve as basis for the sub-problem represented on the next block, where knowing the outputs to be produced is imperative to determine the inputs that may be needed.

The second block respects to the HHR demand planning sub-problem. Here, the main issue is to translate the healthcare services demanded in HHR requirements. There are many interesting insights arising from the study of this topic. In addition to the more obviously useful information on the future demand for HHR, so that an adequate planning avoids future imbalances and their consequences, a deeper knowledge on the effect of the productivity in the delivery of healthcare over time and on several possible allocations of the existent HHR between different healthcare services are some of the useful information that can be used by health managers on pursuing their goals. Additionally, since the human resources bill is usually the largest single item in the budget for health, the requirements of HHR have a preponderant influence in health expenditures, to which the following block is dedicated.

In the third block, the sub-problem of forecasting health expenditures is represented. Ultimately, the healthcare services delivery is dependent on the availability of the financial resources needed to provide all the necessary inputs to produce these services - physical and human. The expenditures depend on a range of factors, whose relevance should be assessed and integrated in forecast models. Planning for the future health expenditures is critical at government level, as they are ultimately responsible for ensuring the continuity and sustainability of healthcare services delivery.

Finally, the fourth block represents the sub-problem of dealing with the challenges in healthcare delivery. From the three previous blocks, insights on what can be these main challenges arise from the analysis of the main trends in health and in healthcare, and from the study on the demand for healthcare services, on the subsequent HHR requirements 
and on the financial sustainability of healthcare. In a context of growing incidence of chronic diseases and existence of multiple morbidities, patients have changing needs and the volume and complexity of healthcare is rising, as well as health expenditures. A better understanding of the main trends and challenges should culminate in the study and evaluation of different modes of delivering care, ensuring that access, quality and sustainability of healthcare delivery are safe.

\subsection{Literature Review}

This section is divided in three distinct sub-sections, each one of them directly related to one of the sub-problems 1 to 3 previously described.

\subsubsection{Healthcare services}

In his seminal work, (Grossman, 1972) presents a health production model establishing the relation between the demand for health and for healthcare, arguing that the demand for healthcare is a derived demand, as it derives from the demand for 'good health'. By recognizing health as a capital good and that individuals have an initial stock of health that depreciates with time and that can be enlarged by investment, he synthesized that when purchasing healthcare services, consumers are not demanding these services per se: rather, they want to produce 'good health' (the commodity) using healthcare services (the market goods) and their own time as inputs. This insight revolutionized the way economists studied health related topics: it turns the attentions to health determinants, marking the begin of health economics as a sub-discipline by replacing the healthcare economics that prevailed until then, where the demand for healthcare services was studied as being a regular demand for a final consumption good (Linddren, 1972).

Since then, studies analyzing the determinants of healthcare demand started to include both types of factors: the ones that are known to drive the demand for consumption goods, such as the income, the prices and the individual preferences, and others related to the demand for the investment good: health. It is now recognized that the demand for healthcare ul- 
timately depends on the seek for health and that addressing epidemiological factors and its evolution is of most importance for studying the problem of planning the demand for healthcare services.

In the last decades, the improved socio-economic conditions and the advances in medical science led to significant improvements in health and longevity (WHO, 2015), responsible for a significant demographic transformation and a subsequent drastic change in the epidemiological profiles and in the patterns of health and illness. Chronic diseases are now the world's leading causes of death, and their burden is increasing rapidly (Alwan et al., 2010; Beaglehole et al., 2011). As the prevalence of chronic conditions continues to rise (Ashman and Beresovsky, 2013), several attempts on understanding main causes and consequences of these epidemiological changes have been made, which are reflected in a vast scientific literature on the topic. It is now known the prevalence of the most common chronic diseases and the main factors on which it depends. It has also been showed that increases in the prevalence of chronic diseases rise the demand for healthcare and generate new challenges on ensuring the delivery and financing of healthcare services (Barceló et al., 2003). Furthermore, it is known that chronic conditions tend to cluster, as people with one chronic condition are more likely to also have others (Fortin et al., 2005; Wolff et al., 2002). This fact drove the researchers' attention to the study of the co-existence of multiple morbidities, which got a huge attention in last years, resulting in undeniable interesting knowledge on this field.

Due to the efforts that have been made on getting a better understanding of the main determinants of the co-existence of multiple morbidities, we now know that age and the cooccurrence of multiple morbidities are significant and positively related (Banerjee, 2015; Canizares et al., 2017), which helps to explain the recent rising of multiple morbidities. Studies also show that prevalence of multiple morbidities is higher in women than in men (Glynn et al., 2011; Smith et al., 2008), maybe because women are generally more affected by non-fatal conditions than men (Marengoni et al., 2011), and that socio-economic conditions are inversely associated with multiple morbidities (Barnett et al., 2012). In this context, interesting studies on the effect of socio-economic conditions were undertaken 
considering a space component. Overall, they conclude that multiple chronic conditions occur earlier and more frequently in deprived areas, a conclusion that can be very helpful to plan for the resources needed in each location, according to their different healthcare needs. Multiple morbidity is known to be associated with a decline in health outcomes and a subsequent increase in the utilization of healthcare services and resources (Caughey et al., 2008), as people with multiple conditions tend to have a higher vulnerability to diseases and less resistance to health threats (Glynn et al., 2011). In fact, it has been shown that patients with multiple chronic diseases demand for a greater array of healthcare services and professionals (Vogeli et al., 2007) and that they are more likely to seek care (and do it more often) than patients without multiple chronic diseases. This fact was observed for all different types of healthcare services: primary care, inpatient care, ambulatory care and emergency care (Boyd and Fortin, 2010).

However, although the impact of different health conditions on healthcare demand have been widely studied, the combined impact of multiple co-existent disease is yet less well understood (Roos et al., 1998). As an higher prevalence of multiple conditions increases the demand for healthcare services and heightens its complexity (Fortin et al., 2005), a deeper analysis on the interacting influences that lead to the complex pattern in the use of health services, addressing the evolution on morbidity patterns and planning for the necessary healthcare services are of most importance for clinicians, researchers, managers and policy-makers to improve healthcare delivery.

\subsubsection{Health Human Resources}

Since human resources account is usually the largest single item in the healthcare budget, and that no health system can deliver healthcare services without them, health human resources are widely recognized as the most important input of the health system (WHO, 2000).Although health workforce planning is not new, the attention and resources allocated to workforce planning have increased in recent years (Ono et al., 2013), as imbalances in the healthcare workforce are becoming a major concern in both developed and developing countries (Zurn et al., 2004). 
HHR planning comprises the study and analysis of four key elements: supply, demand, a potential gap, and possible solutions to solve imbalances (Murphy G.T., 2007; Al-Sawai and Al-Shishtawy, 2015). Typically, most HHR planning studies address the supply of HHR, the demand for healthcare services, or a combination of both. Studies focused on the supply-side aim to forecast the future HHR, analyzing factors that influence the movement of professionals into, through and out of the healthcare workforce, as well as their motivation and organization (WHO, 2010b). On the other hand, studies approaching the demand-side aim to predict the HHR that will be needed, or demanded, in the future. These studies focus on the evolution of factors driving the demand for healthcare services and on the estimation of HHR required to efficiently deliver these services. Perhaps due to the relative simplicity of the data required to address the supply-side of the problem, considerable attention has been placed on supply approaches, with fewer endeavors on the demand-side (O’Brien-Pallas et al., 2001).

On the demand-side, four main approaches to project future health worker requirements can be identified in the literature: health needs, services utilization/demand, service targets and workforce-to-population-ratio (Lopes et al., 2015; Bärnighausen and Bloom, 2009; Ono et al., 2013; Roberfroid D., 2009). These four approaches differ in the way the required healthcare services are identified: approaches based on health needs use epidemiological information to estimate the effect of future diseases' incidence and prevalence in the demand for healthcare services; approaches based on the effective demand for healthcare consider the current levels of services' utilization, assuming a constant relation between the demand and its drivers, with only the drivers' level changing over time; service target approaches aim to identify future needs for services by establishing targets to the production and delivery of healthcare services; and population-ratio approaches predict future health workforce requirements using demographic projections and desired health workerto-population ratios that can be derived from benchmarks, studies or policy-makers' deliberations (Dreesch et al., 2005). From the four main approaches to project future health worker requirements, only the latter directly estimate the healthcare workforce requirements; the other three require the estimation of HHR requirements as a step succeeding the 
estimation of future healthcare services (Bärnighausen and Bloom, 2009).

Several methods of converting services into workforce requirements can be found in the literature. The most commonly used consists of assessing the time required to complete tasks, measured by direct observation (time-motion studies, activity sampling techniques and patient flow analysis) or by expert's opinion (Lipscomb et al., 1998; Hurst, 2003). This method has some advantages: it is not very demanding in terms of data and it is the only one involving the healthcare providers. However, defining the necessary tasks can be difficult and time-consuming, and there is the risk of over-estimating the HHR requirements (Dreesch et al., 2005). Another method, based on productivity patterns, consists in applying labor productivity measures to the expected needs for healthcare services. This approach can be based both on the maintenance of productivity levels and on the productivity benchmarks to be achieved (Hurst, 2003; Dall T., 2015; Hall, 1971). Contrastingly, some authors applied methods not directly related to healthcare services delivery by trying to estimate the workforce that is likely to be demanded given some known drivers of the demand for care, such as economic growth (Scheffler et al., 2008).

Involving theoretical economic fundamentals in HHR planning has also become popular. Economics, which is ultimately about studying the allocation of limited resources to unlimited necessities, can bring useful insights to the problem, namely on the opportunity cost of human resources allocation between alternative productive processes (Scott 2 nd et al., 2001). In this context, the estimation of production functions relating healthcare inputs (HHR and capital in health facilities) to healthcare outputs (delivered services) has become a widely used method in HHR planning (Pourmohammadi et al., 2014). Although the economic concepts and assumptions underlying the use of production functions are suitable to the problem (Santías et al., 2011), the complexity of handling production functions with multiple outputs contributed to a rising interest in the creation of indexes combining outputs (Castelli et al., 2015), and also in nonparametric approaches for the estimation of production frontiers, such as Data Envelopment Analysis (DEA) (Newhouse, 1994; Hollingsworth et al., 1999; Kumbhakar and Lovell, 2003). An inverse production function can also be used to model the production of healthcare services (Diewert, 1974). This function, commonly 
known as Input Requirements Function (IRF), is another way of overcoming the limitation of handling multiple outputs (Lipscomb et al., 1995), keeping the key economical concepts of the production functions. Using IRF to understand the demand for labour has been a very popular approach in several sectors, including banking (Battese et al., 2000; Heshmati, 2001), insurance (Kumbhakar and Hjalmarsson, 1995), manufacturing (Kumbhakar and Zhang, 2013), electricity (Kumbhakar and Hjalmarsson, 1998), railways (Gathon and Pestieau, 1995) and agriculture (Guan et al., 2009). However, despite the strengths and adequacy of using IRF and besides its popularity in other fields, the use of IRF in the healthcare field is almost inexistent.

\subsubsection{Health Expenditures}

Within the literature on health expenditures (HE) two different types of studies can be found: the ones that want to provide a better understanding on the determinants of health expenditure and the ones that intend to forecast health expenditures (Zhao, 2015). The first type of studies urged from the rising interest on understanding the main factors causing the rapid increase of health expenditures in many developed countries by 1960 (Getzen, 2016). More recently, the concerns on the financial sustainability of the upward trend in national health expenditures in recent decades boosted the development of forecasting models to project health expenditure evolution and inform on its sustainability (Marino et al., 2017). Overall, most of the health expenditure literature still only tries to understand past drivers of health expenditure, rather than project health expenditures into the future.

The models to forecast health expenditures can be classified according to the aggregation level of the unit of analysis. Hollenbeck (Hollenbeck, 1995) distinguished between disaggregate models, where a micro unit such as individuals or households is considered, and aggregate models, which are dedicated to the analysis of a macro unit, such as a cohort of individuals or a whole country or region. Later, Astofi et al. (Astolfi et al., 2012) refined this classification by considering both the aggregation level and the level of detail of the health expenditure projected. Three different classes of forecast models were identified: micro, component-based, and macro. Although the choice between the available models 
must always be driven by the policy questions that need to be answered, while their main merits and constraints are also considered, some authors believe that the evolution in both the data availability and the computing power will lead the forecasts of health expenditures to complicated micro-level models (Astolfi et al., 2012). However, Zhao (Zhao, 2015) showed that when the main goal is to accurately forecast aggregate health expenditure, these models require considerably more data and effort, and projections may be worse than the ones obtained with macro-level models.

In the past decades, macro analyses of the determinants of health care expenditures have been exploring the relation between health expenditures and a diversity of possibly-related variables. The first health expenditures studies only examined the relationship between income and health expenditures (Newhouse, 1977). However, it has been later recognized that this approach may omit relevant variables and therefore bias the income effects. Thus, several studies have then tried to address the determinants of health expenditure in a more comprehensive way, including multiple non-income macroeconomic indicators to explain health expenditures. The determinants of health expenditures have been grouped according to their nature in several categories, such as macroeconomic, organizational, technological, demographic, lifestyle and environmental. More succinctly, some authors (Schulz, 2005) and (De la Maisonneuve and Martins, 2013) distinguished the factors influencing the future trajectory of health expenditures as demand factors, such as aging, health status and income; and supply factors, such as technological progress, productivity and health prices. Within the wide range of health expenditures determinants, income was the first to be related to health expenditures (Newhouse, 1977) and it is still considered the most important factor in explaining differences in the level and growth of health expenditures (Newhouse, 1992). In his seminal work, Newhouse (Newhouse, 1974) found the GDP to be statistically and economically significant on explaining health expenditures, a fact that is nowadays generally accepted, after several other authors confirmed the existence of a positive correlation between variations in national income and variations in health expenditures. These findings show that national health expenditure is highly related to a country's state of economic development, which according to Wagner's law (Musgrave and Peacock, 1958) 
states that government spending increases as the national income increases, mainly due to an increase in demand for public services. Population aging, for also being considered as a major determinant of health expenditures (Przywara et al., 2010), is another of the most studied factors in this field. The literature on this topic, however, is not unanimous on the relevance of this factor. While some authors argue that health expenditures largely depend on the size and structure of the population and tend to rise due to an increase in life expectancy and consequent decline of the health status of the population, expansion of morbidity and burden of healthcare (Fogel, 2009), others give preference to the argument that aging, per se, is not that relevant: health expenditures are considerably higher in the period preceding death and increases on the life expectancy only postpone the expenditures, rather than raise them (De la Maisonneuve and Martins, 2013). These two opposite theoretical standpoints result on different factors considered in empirical analysis: while the first approach leads to the study of demographic indicators, such as the share of elderly population or the life expectancy, the latter includes pure health-related variables translating the needs for care, such as the health-status or morbidity (Schulz, 2005).

Besides the most obvious demand-side factors, the supply of healthcare services and resources have also been pointed as a relevant driver of health expenditures. The inclusion of factors such as the number of physicians or the number of beds per 1.000 inhabitants can be explained by the direct dependency between health expenditures and physical and human resources' levels of a health system. The number of physicians is the most considered explanatory variable in this class for three main reasons: first, because healthcare is a labor-intensive industry, where the human resources are more representative of health expenditures than the physical resources (Belay, 2013); second, the number of physicians has been the indicator selected to capture the supply-induced demand (SID) effect, as it is known that supply and demand for healthcare are not independent from each other and that asymmetric information exists between physicians and patients (Gerdtham and Löthgren, 2000); and third, because from a higher access to healthcare usually comes a higher utilization, specially in the presence of unmet needs (San E., 2005). Overall, these studies found a positive and statistically significant relation between the number of doctors and the aggre- 
gate health expenditures. Also from the supply-side, technological progress has also been citetd as a major driver of health expenditures. The pioneer work of Newhouse (Newhouse, 1992), considering the relevance of technological change on health expenditures, has been extended by several other authors (Dreger and Reimers, 2005; Okunade and Murthy, 2002; Matteo, 2005) studying the impact of technological advances on the evolution of the health expenditures. Many proxies for changes in health technology have been used, such as surgical procedures performed (Bodenheimer, 2005), life expectancy (Dreger and Reimers, 2005), pharmaceutical spending (Atella et al., 2012) or R\&D expenditures (Okunade and Murthy, 2002). In most of the time-series studies, the authors considered as technological progress the whole or part of the unexplained component of the econometric models: a time trend (Blomqvist and Carter, 1997) or a time effect (Matteo, 2005) that is not explained by the other considered explanatory variables. Overall, these studies confirmed that technological progress is, in fact, a major determinant of health expenditures.

Several other factors can be found in the literature. The vast list of health expenditures determinants studied so far includes many other less studied drivers and variables with lower demonstrated relevance, such as health prices, inflation rates, insurance coverages, total or young population, dependency rates, education expenditures, life-style factors, utilization indicators and indicators related to the health system itself, as the share of public health expenditure or the out-of-pocket payments.

\subsection{Research opportunities and the proposed approach}

This section presents some of the gaps identified in the literature and proposes research directions both to assess and plan the future needs for healthcare services and resources and to provide insights on the patterns and trends of healthcare delivery, helping the several health stakeholders facing the challenges on healthcare delivery. Despite the undeniable interest of the field and the growing number of studies devoted to such issues, the problem is not closed, as there are no established preferred methodologies to approach it. 


\subsubsection{Healthcare Services}

Despite the rising interest on understanding the complexity inherent to the co-existence of multiple health conditions and its impact on the demand for healthcare services, there is clearly space to contribute to the knowledge on this topic. First, the analysis of multiple co-existent conditions is usually made considering only the chronic conditions, and a better understanding on the interaction between chronic and non-chronic disease is also of major interest. Second, most of the studies intended to provide knowledge for a specific disease (or selected group of diseases) and its association with other conditions that are previously known to be related, which can hide less obvious relations between conditions. Third, studies dedicated to the analysis of co-existent diseases and their evolution over time consider a simple count of conditions or, more succinctly, if the individual has or not two or more chronic diseases at the same time. Forth, studies analyzing longitudinal changes in morbidity over time and through the life course are limited, as well as analysis considering cohorts effects on the co-existence of health conditions. Finally, most of the research that has been done is only focused on the analysis of historical data and does not go further in assessing for the future healthcare services demanded to contribute to a more informed planning.

The literature reviewed points to several topics worthy of investigation, where it stands out the lack of a wider approach, capable of dealing with the complexity of the problem as a whole. Such approach should be able to describe patterns of healthcare services utilization, analyzing the complex interaction between both chronic and non-chronic diseases, while also capturing the influence of other relevant characteristics, such as age, gender and geographical location. Additionally, to be useful for planning the demand for healthcare services, this approach should also consider 1) a space dimension, to plan for the resources needed in each location, according to their different healthcare needs and 2) a time dimension, to describe how illnesses evolve over time: due to the dynamic character of health status and its main drivers, time, age and cohorts should also be included.

With the main goal of understanding and describe how the demand for healthcare ser- 
vices change due to the expected evolution in morbidity, we propose the development of an agent based simulation model. This model is intended to detect the complex patterns on the evolution of multiple epidemiological conditions through their association with the co-occurrence of other current or previous conditions, as well as of other relevant factors, such as age, gender, and residence location. These patterns may then be used to simulate how will illness and morbidity evolve and the subsequent services utilization, using projections for some relevant variables (e.g., demographic) and considering specific 'what if' scenarios (e.g., representing a change in the prevalence of a specific epidemiological condition). Furthermore, the results on the expected utilization of healthcare services may allow to infer if the current physical capacity will be enough to provide the expected volume of healthcare services and, as this simulation model may include a space dimension, it also allows for a further assessment of the geographical distribution of the demand for healthcare and eventual regional asymmetries.

\subsubsection{Health Human Resources}

Ensuring the delivery of healthcare services is also crucially dependent on planning for the HHR needed to properly deliver these services. The literature reviewed on this topic shows there is still room to contribute to the extension and diversity of the available methods to forecast the HHR demand. In fact, while there is a growing agreement that planning the demand for HHR should be based on healthcare needs, less accordance exists on the best way to translate needs in HHR requirements (Murphy G.T., 2007).

A new approach to empirically quantify the relation between healthcare services and workforce requirements, modeling the relation between services and human resources, may result in an interesting contribution to the challenging task of translating healthcare services to HHR requirements if conjoining five main aspects: 1) analyze healthcare services by medical specialty, which have the advantage of capturing some relevant specificities that otherwise pass unnoticed; 2) analyze labor productivity evolution and its impact on the healthcare services delivered over time; 3) consider a specification that assumes that labor can be planned and sized according to the needs; 4) consider a flexible functional form for 
the specification; and 5) analyze HHR requirements for different types of healthcare services. This approach may rend in an efficient tool for the estimation of the HHR required to meet expected variations in the demand for healthcare services. It may also contribute to a deeper knowledge of the healthcare delivery process by revealing possible options for HHR allocation and opportunity costs of labor. Furthermore, by accounting for the technological progress and for the productivity of health professionals, this approach may allow the analysis of the labor productivity evolution and its impact on the healthcare services delivered over time, which is critical to plan for the future needs of HHR.

To empirically quantify the relation between healthcare services and the HHR requirements in a multi-output context we propose a Labor Requirements Function relating the number of physicians with a set of specialty specific workload and capital variables, a methodology based on the assumption that health decision makers do not control the demand for healthcare services, but they can size and adjust the level of HHR in response to a given expected demand. By using period fixed effects, this methodology allows to infer on the impact of labor productivity and technological progress on healthcare delivery. Furthermore, elasticities of mean labor use, marginal rates of technical substitutions between healthcare services and returns to scale can be analyzed to provide further insights on opportunity costs of labor and different possibilities for allocate the existing HHR.

\subsubsection{Health Expenditures}

Planning the future health expenditure is of major interest, specially for the decision makers responsible for assuring that quality and timely healthcare services are provided, and that this provision is sustainable. The rising health expenditures experienced over the last decades have urged researchers to review the determinants of health expenditures and to try to anticipate it evolution. Despite the undeniable interest of the topic, the literature on health expenditures models, approaches and determinants clearly revealed opportunities for contributions. In fact, the factors driving health expenditures remain only imperfectly understood and empirical explanatory forecasts applying time-series approaches are almost inexistent. 
A contribution to the field must compile both the existent knowledge on health expenditure drivers and the main insights on the adequacy of the models and approaches in a countrylevel forecast of health expenditures to inform governments and managers on their expected evolution and on the sustainability of healthcare delivery. An interesting contribution may rely in an explanatory forecast of health expenditures associating the following main characteristics: 1) Macro-level analysis of health expenditures at the single-country level to provide an aggregate view and identify national specificities and trends; 2) Multi-variable approach, considering the most relevant drivers of health expenditures, both on the demandside, represented by socio-economic and demographic variables; and on the supply-side, including the technology and the number of physicians; 3) Time series techniques to detect non-stationarity and long-run relationships between the variables; 4) Multi-equation time-series model estimation, exploring and describing both the long-run relationships and the short-run dynamics between the variables; 5)Forecast health expenditures using the estimated model.

To infer on how much will the health expenditures reach in the short- and long-run future if no actions are taken, we propose the use of a Vector Error Correction (VEC) model: a multi equation time series econometric model relating health expenditures and some other relevant macro indicators. This model will allow to account for both non stationarity of the data and possible existence of cointegration. Through this model, the main factors driving the changes in health expenditures, as well as both the long-run relations and the short run dynamics between health expenditures and its drivers may be investigated. Furthermore, it is possible to use the estimated model to forecast health expenditures for the future, based on the projections available for the main determinants that are found to impact health expenditures.

\subsubsection{Integrated Approach}

To approach the research opportunities identified, we propose an integrated framework to the problem of planning the demand and delivery of healthcare services. This four-steps framework, represented in Figure 2.2, aims to help ensuring that healthcare services will be 


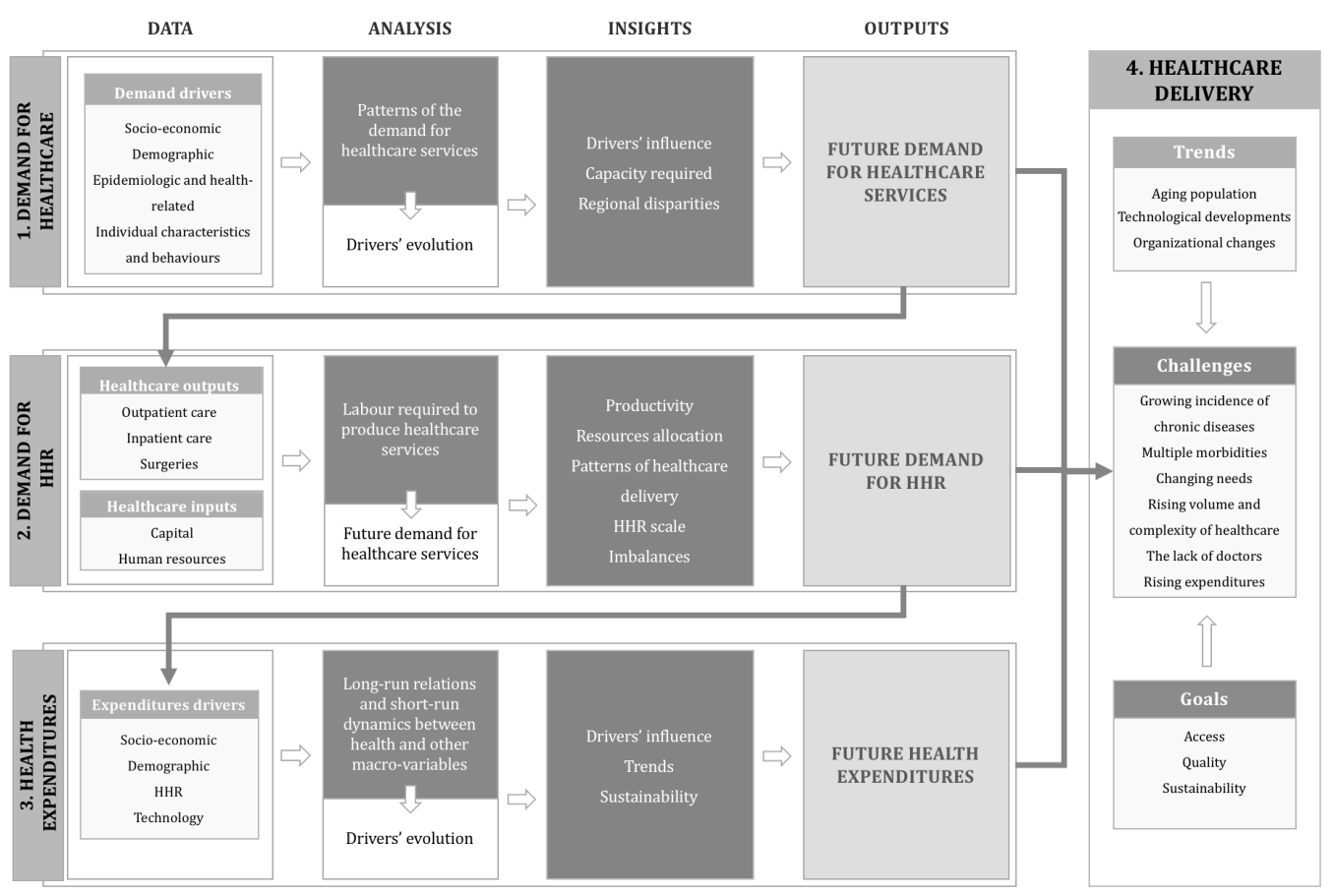

Figure 2.2 - Integrated Approach

provided to whom may need them. Each of the four steps is directly related to one the four dimensions identified in the problem: 1) the healthcare services that will be demanded by the population; 2) the health human resources that will be required to deliver these services; 3) the financial resources that will have to be available for all the inputs that are needed to produce them; and 4) the quality and timely delivery of healthcare.

For each of the three fists steps, the data required, the core analysis suggested and the main insights and outputs resulting from this analysis are described in the figure, as well as the connection between the outputs of one step and the data required to perform the step following.

The fourth step consists on the joint analysis and evaluation of the insights and outputs resulting from the three previous steps, on the main trends and patterns of healthcare delivery. This information should be used to infer about what can be the main challenges on the future of healthcare delivery, and to provide knowledge and tools to deal with them, enabling alternative modes of healthcare delivery and ensuring the continuity and sustainability of healthcare services delivery. 


\subsection{Conclusion and future work}

This paper draws attention to the current health and economic concerns related to the future demand for healthcare services and resources, as changes in the patterns of health and illness, increasing amount and complexity of healthcare services demanded, rising health expenditures and uncertainty about whether there will be enough human resources to deliver the healthcare services have been calling the attention of health researchers, managers and governments.

As we attempted to prove, and despite the undeniable interest of the field and the growing number of studies devoted to these issues, the problem is not closed. By pointing out to some research opportunities we hope to stimulate future research focused both on providing a better understanding on the factors driving the demand for healthcare services and resources and on developing models to accurately forecast their expected evolution for the future: the healthcare services that will be demanded by the population, the health human resources that will be required to deliver these services and the financial resources that will be needed for all the inputs that are required to produce them.

Furthermore, we plan to apply the proposed four-steps framework, making use of econometric and operational research methods, to assess and plan the future needs for healthcare services and resources. As so, we hope to contribute for this undeniably interesting field of research and to make a fruitful contribution to society by providing useful insights on the patterns and trends of healthcare delivery, which may help on the challenging task of planning for the future demand and delivery of healthcare services.

\section{Acknowledgements}

This work is financed by the ERDF - European Regional Development Fund through the Operational Programme for Competitiveness and Internationalisation - COMPETE 2020 Programme and by National Funds through the Portuguese funding agency, FCT - Fundação para a Ciência e a Tecnologia within project POCI-01-0145-FEDER-016738. 


\section{Bibliography}

A. Al-Sawai and M. M. Al-Shishtawy. Health workforce planning: An overview and suggested approach in oman. Sultan Qaboos University medical journal, 15(1):27-33, 2015.

A. Alwan, D. R. MacLean, L. M. Riley, E. T. d'Espaignet, C. D. Mathers, G. A. Stevens, and D. Bettcher. Monitoring and surveillance of chronic non-communicable diseases: progress and capacity in high-burden countries. The Lancet, 376(9755):1861-1868, 2010.

J. J. Ashman and V. Beresovsky. Multiple chronic conditions among us adults who visited physician offices: data from the national ambulatory medical care survey, 2009. Preventing chronic disease, 10:E64-E64, 2013.

R. Astolfi, L. Lorenzoni, and J. Oderkirk. Informing policy makers about future health spending: A comparative analysis of forecasting methods in oecd countries. Health Policy, 107(1):1 - 10, 2012.

V. Atella, J. Bhattacharya, and L. Carbonari. Pharmaceutical price controls and minimum efficacy regulation: Evidence from the u nited s tates and i taly. Health services research, 47(1pt1):293-308, 2012.

S. Banerjee. Multimorbidity—older adults need health care that can count past one. The Lancet, 385(9968):587 - 589, 2015.

A. A. M. Barceló, C. Aedo, S. N. Rajpathak, and S. Robles. The cost of diabetes in latin america and the caribbean. Bulletin of the World Health Organization, 81 1:19-27, 2003.

K. Barnett, S. W. Mercer, M. Norbury, G. Watt, S. Wyke, and B. Guthrie. Epidemiology of multimorbidity and implications for health care, research, and medical education: a cross-sectional study. The Lancet, 380(9836):37-43, 2012.

G. E. Battese, A. Heshmati, and L. Hjalmarsson. Efficiency of labour use in the swedish banking industry: a stochastic frontier approach. Empirical Economics, 25(4):623-640, Dec 2000. 
R. Beaglehole, R. Bonita, R. Horton, C. Adams, G. Alleyne, P. Asaria, V. Baugh, H. Bekedam, N. Billo, S. Casswell, et al. Priority actions for the non-communicable disease crisis. The Lancet, 377(9775):1438-1447, 2011.

M. Belay. Determinants of Demand for Health Care Services in Mekelle City. PhD thesis, Mekelle University, 2013.

A. Blomqvist and R. Carter. Is health care really a luxury? Journal of Health Economics, 16(2):207 - 229, 1997.

T. Bodenheimer. High and Rising Health Care Costs. Part 2: Technologic Innovation. Annals of Internal Medicine, 142(11):932-937, 062005.

C. M. Boyd and M. Fortin. Future of multimorbidity research: How should understanding of multimorbidity inform health system design? Public Health Reviews, 32(2):451-474, Dec 2010.

T. Bärnighausen and D. E. Bloom. Changing research perspectives on the global health workforce. Working Paper 15168, National Bureau of Economic Research, July 2009.

M. Canizares, S. Hogg-Johnson, M. A. Gignac, R. H. Glazier, and E. M. Badley. Increasing trajectories of multimorbidity over time: birth cohort differences and the role of changes in obesity and income. The Journals of Gerontology: Series B, 45(0):387-416, 2017.

A. Castelli, A. Street, R. Verzulli, and P. Ward. Examining variations in hospital productivity in the english nhs. The European Journal of Health Economics, 16(3):243-254, Apr 2015.

G. E. Caughey, A. I. Vitry, A. L. Gilbert, and E. E. Roughead. Prevalence of comorbidity of chronic diseases in australia. BMC Public Health, 8(1):221, Jun 2008.

C. R. I. W. . Dall T., West T. The complexities of physician supply and demand: Projections from 2013 to 2025. Final Report Association of American Medical Colleges, pages 1-68, 2015. 
C. De la Maisonneuve and J. O. Martins. Public spending on health and long-term care. 6 (6):1-39, 2013.

W. E. Diewert. Functional forms for revenue and factor requirements functions. International Economic Review, 15(1):119-130, 1974.

N. Dreesch, C. Dolea, M. R. D. Poz, A. Goubarev, O. Adams, M. Aregawi, K. Bergstrom, H. Fogstad, D. Sheratt, J. Linkins, R. W. Scherpbier, and M. Youssef-Fox. An approach to estimating human resource requirements to achieve the millennium development goals. Health policy and planning, 20 5:267-276, 2005.

C. Dreger and H.-E. Reimers. Health care expenditures in oecd countries: a panel unit root and cointegration analysis. 2005 .

R. W. Fogel. Forecasting the cost of us health care in 2040. Journal of Policy Modeling, 31(4):482-488, 2009.

M. Fortin, G. Bravo, C. Hudon, A. Vanasse, and L. Lapointe. Prevalence of multimorbidity among adults seen in family practice. The Annals of Family Medicine, 3(3):223-228, 2005.

H.-J. Gathon and P. Pestieau. Decomposing efficiency into its managerial and its regulatory components: The case of european railways. European Journal of Operational Research, 80(3):500-507, 1995.

U.-G. Gerdtham and M. Löthgren. On stationarity and cointegration of international health expenditure and gdp. Journal of Health Economics, 19(4):461-475, 2000.

T. E. Getzen. Measuring and forecasting global health expenditures. In World Scientific Handbook of Global Health Economics and Public Policy: Volume 1: The Economics of Health and Health Systems, pages 177-215. World Scientific, 2016.

L. G. Glynn, J. M. Valderas, P. Healy, E. Burke, J. Newell, P. Gillespie, and A. W. Murphy. The prevalence of multimorbidity in primary care and its effect on health care utilization and cost. Family practice, 28(5):516-523, 2011. 
M. Grossman. On the concept of health capital and the demand for health. Journal of Political Economy, 80(2):223-255, 1972.

Z. Guan, S. C. Kumbhakar, R. J. Myers, and A. O. Lansink. Measuring Excess Capital Capacity in Agricultural Production. American Journal of Agricultural Economics, 91 (3):765-776, 082009.

T. L. Hall. Chile health manpower study: methods and problems. International Journal of health services, 1(2):166-184, 1971.

A. Heshmati. Labour demand and efficiency in swedish savings banks. Applied Financial Economics, 11(4):423-433, 2001.

K. Hollenbeck. A review of retirement income policy models. 95(38), 1995.

B. Hollingsworth, P. Dawson, and N. Maniadakis. Efficiency measurement of health care: a review of non-parametric methods and applications. Health Care Management Science, 2(3):161-172, Jul 1999.

K. Hurst. Selecting and applying methods for estimating the size and mix of nursing teams selecting and applying methods for estimating the size and mix of nursing teams. 2003.

S. Kumbhakar and R. Zhang. Labor-use efficiency and employment elasticity in chinese manufacturing. Economia e Politica Industriale, 2013.

S. C. Kumbhakar and L. Hjalmarsson. Labour-use efficiency in swedish social insurance offices. Journal of Applied Econometrics, 10(1):33-47, 1995.

S. C. Kumbhakar and L. Hjalmarsson. Relative performance of public and private ownership under yardstick competition: electricity retail distribution. European Economic Review, 42(1):97-122, 1998.

S. C. Kumbhakar and C. K. Lovell. Stochastic frontier analysis. Cambridge university press, 2003. 
B. Linddren. Foreword to the 2017 edition. The Demand for Health, M. Grossman, pages xi-xxvi, 1972.

J. Lipscomb, K. E. Kilpatrick, K. L. Lee, and K. S. Pieper. Determining va physician requirements through empirically based models. Health services research, 29(6):697$717,1995$.

J. Lipscomb, G. Parmigiani, and V. Hasselblad. Combining expert judgment by hierarchical modeling: an application to physician staffing. Management Science, 44(2):149-161, 1998.

M. A. Lopes, Á. S. Almeida, and B. Almada-Lobo. Handling healthcare workforce planning with care: where do we stand? Human Resources for Health, 13(1):38, May 2015.

A. Marengoni, S. Angleman, R. Melis, F. Mangialasche, A. Karp, A. Garmen, B. Meinow, and L. Fratiglioni. Aging with multimorbidity: a systematic review of the literature. Ageing research reviews, 10(4):430-439, 2011.

A. Marino, D. Morgan, L. Lorenzoni, and C. James. Future trends in health care expenditure: A modelling framework for cross-country forecasts. OECD Health Working Papers, 5(95), 2017.

L. D. Matteo. The macro determinants of health expenditure in the united states and canada: assessing the impact of income, age distribution and time. Health Policy, 71(1):23 - 42, 2005.

M. A. Murphy G.T., Birch S. Needs-based health human resources planning: The challenge of linking needs to provider requirements. 2007.

R. A. Musgrave and A. T. Peacock. Classics in the theory of public finance. Springer, 1958.

J. P. Newhouse. Forecasting demand for medical care for the purpose of planning health services. 1974. 
J. P. Newhouse. Medical-care expenditure: a cross-national survey. The Journal of Human Resources, 12(1):115-125, 1977.

J. P. Newhouse. Medical care costs: How much welfare loss? Journal of Economic Perspectives, 6(3):3-21, September 1992.

J. P. Newhouse. Frontier estimation: How useful a tool for health economics? Journal of Health Economics, 13(3):317 - 322, 1994.

L. O'Brien-Pallas, A. Baumann, G. Donner, G. T. Murphy, J. Lochhaas-Gerlach, and M. Luba. Forecasting models for human resources in health care. Journal of Advanced Nursing, 33(1):120-129, 2001.

A. A. Okunade and V. N. Murthy. Technology as a 'major driver'of health care costs: a cointegration analysis of the newhouse conjecture. Journal of health economics, 21(1): 147-159, 2002.

T. Ono, G. Lafortune, and M. Schoenstein. Health workforce planning in oecd countries. (62), 2013.

K. Pourmohammadi, N. Hatam, P. Bastani, and F. Lotfi. Estimating production function: a tool for hospital resource management. Shiraz E-Medical Journal, 15(4), 2014.

B. Przywara et al. Projecting future health care expenditure at european level: drivers, methodology and main results. Technical report, Directorate General Economic and Financial Affairs (DG ECFIN), 2010.

S. S. . Roberfroid D., Leonard C. Physician supply forecast: better than peering in a crystal ball? Hum Resour Health, 7:10, 2009.

N. P. Roos, K. C. Carriere, and D. Friesen. Factors influencing the frequency of visits by hypertensive patients to primary care physicians in winnipeg. Canadian Medical Association Journal, 159(7):777-783, 1998. 
P. W. San E., Mar O. The effects of an ageing population and other factors on aggregate health care expenditure in singapore. ICEB-15, 2005.

F. R. Santías, C. Cadarso-Suárez, and M. X. Rodríguez-Álvarez. Estimating hospital production functions through flexible regression models. Mathematical and Computer Modelling, 54(7-8):1760-1764, 2011.

R. M. Scheffler, J. X. Liu, Y. Kinfu, and M. R. Dal Poz. Forecasting the global shortage of physicians: an economic-and needs-based approach. Bulletin of the World Health Organization, 86:516-523B, 2008.

E. Schulz. The influence of supply and demand factors on aggregate health care expenditure with a specific focus on age composition. ENEPRI Res Rep, 16:45, 2005.

R. Scott 2nd, S. L. Solomon, and J. E. McGowan Jr. Applying economic principles to health care. Emerging Infectious Diseases, 7(2):282-285, 2001.

S. M. Smith, A. Ferede, and T. O'Dowd. Multimorbidity in younger deprived patients: An exploratory study of research and service implications in general practice. BMC Family Practice, 9(1):6, Jan 2008.

C. Vogeli, A. E. Shields, T. A. Lee, T. B. Gibson, W. D. Marder, K. B. Weiss, and D. Blumenthal. Multiple chronic conditions: prevalence, health consequences, and implications for quality, care management, and costs. Journal of general internal medicine, 22 (3):391-395, 2007.

WHO. Health systems: Improving performance. World Health Organization., 78(1):1$215,2000$.

WHO. Health systems financing - the path to universal coverage. World Health Organization., pages 1-128, 2010a.

WHO. Hmodels and tools for health workforce planning and projections. World Health Organization., (3):1-19, $2010 \mathrm{~b}$. 
WHO. World report on ageing and health. World Health Organization., pages 1-260, 2015.

J. L. Wolff, B. Starfield, and G. Anderson. Prevalence, Expenditures, and Complications of Multiple Chronic Conditions in the Elderly. JAMA Internal Medicine, 162(20):2269$2276,112002$.

J. Zhao. Forecasting health expenditure: Methods and applications to international databases. Centre for Health Economics and Policy Analysis (CHEPA), McMaster University, 2015.

P. Zurn, M. R. Dal Poz, B. Stilwell, and O. Adams. Imbalance in the health workforce. Human resources for health, 2(13):1-12, 2004. 



\title{
Health Workforce
}

\section{A Labor Requirements Function for Sizing the Health Workforce}

\author{
Sofia Cruz-Gomes* · Mário Amorim Lopes * · Bernardo Almada-Lobo*
}

Published in Human Resources for Health, dec 2018

\begin{abstract}
Background. Ensuring healthcare delivery is dependent both on the prediction of the future demand for healthcare services and on the estimation and planning for the Health Human Resources needed to properly deliver these services. Although the Health Human Resources planning is a fascinating and widely researched topic, and despite the number of methodologies that have been used, no consensus on the best way of planning the future workforce requirements has been reported in the literature. This paper aims to contribute to the extension and diversity of the range of available methods to forecast the demand for Health Human Resources and assist in tackling the challenge of translating healthcare services to workforce requirements.
\end{abstract}

Methods. A method to empirically quantify the relation between healthcare services and Health Human Resources requirements is proposed. For each one of the three groups of specialties identified - Surgical specialties, Medical specialties and Diagnostic specialties (e.g. pathologists) - a Labor Requirements Function relating the number of physicians

\footnotetext{
*INESC TEC, Faculdade de Engenharia, Universidade do Porto, Rua Dr. Roberto Frias, 4200-465, Porto, Portugal
} 
with a set of specialty-specific workload and capital variables is developed. This approach, which assumes that health managers and decision-makers control the labour levels more easily than they control the amount of healthcare services demanded, is then applied to a panel dataset comprising information on 142 public hospitals, during a twelve-year period. Results. This method provides interesting insights on healthcare services delivery: the number of physicians required to meet expected variations in the demand for healthcare, the effect of the technological progress on healthcare services delivery, the time spent on each type of care, the impact of Human Resources concentration on productivity, and the possible resource allocations given the opportunity cost of the physicians' labor.

Conclusions. The empirical method proposed is simple, flexible, and produces statistically strong models to estimate Health Human Resources requirements. Moreover, it can enable a more informed allocation of the available resources and help to achieve a more efficient delivery of healthcare services.

Keywords Health Human Resources $\cdot$ Labor Requirements Function $\cdot$ Labor Productivity $\cdot$ Opportunity Costs

\subsection{Background}

Ideally, a health system provides quality and timely care services, contributing to a healthy population. However, most health systems have been facing rising care volumes and health expenditures, which is a significant problem considering that resources are scarce. As human resources usually represent the largest item in the healthcare budget, and since no health system can deliver healthcare services without them, Health Human Resources (HHR) are widely recognized as the most important input of a health system (WHO, 2000a).

Planning the healthcare workforce has long been a major challenge for health policymakers. Although the widely-recognized relevance of HHR planning is not new, attention 
and resources allocated to workforce planning has increased in recent years (Ono et al., 2013). Imbalances in the health workforce (disequilibrium between the demand for and the supply of health professionals) are becoming a major concern for both developed and developing countries (Scheffler et al., 2018; Zurn et al., 2004), increasing the need to achieve a balance between the available and the required workforce to provide healthcare services (Lopes et al., 2015).

HHR planning comprises the study and analysis of four key-elements: supply, demand, potential gap, and possible solutions to solve imbalances (Al-Sawai and Al-Shishtawy, 2015; Murphy GT, 2007). Typically, most HHR planning studies address the supply-side, the demand-side, or a combination of both. Studies focusing on the supply-side aim to forecast the HHR that will exist in the future, analyzing factors that influence the movement of professionals into, through and out of the healthcare workforce, as well as their motivations and organization (WHO, 2000b). On the other hand, studies approaching the demand-side aim to predict the HHR that will be needed or demanded in the future. These studies focus on the evolution of factors driving the demand for health services and on the estimation of the HHR required to deliver these services (Jiménez-Martín et al., 2004). Perhaps due to the relative simplicity of the data required to address the supply-side, considerable attention has been placed on supply approaches, with fewer endeavours on the demand-side (O’Brien-Pallas et al., 2001). In fact, most specialty workforce studies limited their scope of analysis to the supply-side, with only about $20 \%$ addressing the demand (CGME, 2000). On the demand-side, four main approaches to project future HHR requirements can be identified in the literature: health needs, service utilization/demand, service-targets and workforce-to-population ratios (Ono et al., 2013; Lopes et al., 2015; WHO, 2000b; Roberfroid et al., 2009; Ansah et al., 2017; Bärnighausen and Bloom, 2009). These approaches differ in the way the required healthcare services are identified: approaches based on health needs use epidemiological information to estimate the effect of diseases' incidence and prevalence in the future demand for healthcare services; approaches based on demand consider the current levels of services utilization, assuming a constant relation between demand and its drivers, with only the drivers' level changing over time; service-target ap- 
proaches aim to identify future needs by establishing targets to the production and delivery of healthcare; and population-ratio approaches estimate future HHR requirements using demographic projections and desired health worker-to-population ratios that can be derived from benchmarks, studies or deliberations of policy-makers (Dreesch et al., 2005). Of these four approaches, only the worker-to-population ratio estimates directly the health workforce requirements, while the other three require the conversion of healthcare services into workforce needs (Bärnighausen and Bloom, 2009).

Although planning HHR is a fascinating and widely researched topic, and despite the number of methodologies that have been used, no consensus has been reached in the scientific literature on the best way of planning for future HHR . In fact, while there is a growing agreement that planning the demand for HHR should be based on healthcare needs (Murphy GT, 2007), less accordance exists on the best way to translate needs in HHR requirements. Several methods of converting services into workforce requirements can be found in the literature. The most commonly used consists of assessing the time required to complete tasks, measured by direct observation (time-motion studies, activity sampling techniques and patient-flow analysis) or using expert's opinion (Lipscomb et al., 1998; Hurst, 2003; Singh et al., 2018). This method is not very demanding in terms of data, but defining the necessary tasks can be difficult and time-consuming. Moreover, there is the risk of over-estimating the HHR requirements (Dreesch et al., 2005). Another method, based on productivity patterns, consists in applying labor productivity measures to the expected demand for healthcare. This approach can either assume the maintenance of the actual productivity levels or use an ideal or desirable productivity level (Hurst, 2003; Dall T, 2015). More recently, microsimulation models are also being applied to forecast the health workforce. These models have the advantage of offering information with a high level of granularity (Laurence and Karnon, 2016), but they usually apply specific staffing ratios to the health services delivered, which are assumed to remain constant over the time (DHHS, 2016). Involving economic fundamentals in HHR planning has also become popular. In this context, the estimation of Production Functions (PF) relating healthcare inputs (HHR and capital in health facilities) to healthcare outputs (delivered services) has become 
a widely used method in HHR planning (Pourmohammadi et al., 2014; Olsen et al., 2013). Although the economic concepts and assumptions underlying the use of PF are suitable to the problem (Santías et al., 2011), the complexity of handling multiple outputs contributed to a rising interest in the creation of indexes combining different outputs (Castelli et al., 2015), and in nonparametric approaches for the estimation of production frontiers, such as Data Envelopment Analysis (Hollingsworth, 2003).

An inverse PF can also be used to model this production process (Diewert, 1974). This function, commonly known as Input Requirements Function (IRF), is another way of overcoming the limitation of handling multiple outputs (Lipscomb et al., 1995), keeping the same key economic concepts. Employing IRFs to understand the demand for labor became a very popular approach in many sectors, including banking (Heshmati, 2001), manufacturing (Kumbhakar and Zhang, 2013), and agriculture (Kumbhakar et al., 2007), since labor can be sized according to needs and capacity. Despite the strengths and adequacy of using IRF and its popularity in other fields, the use of IRF in the healthcare literature is almost inexistent. In fact, to the best of our knowledge only one study applied an IRF in HHR planning context: Lipscomb et al. (Lipscomb et al., 1995) applied a Cobb-Douglas IRF to cross-sectional data on U.S. Veterans Affairs hospitals, relating the number of physicians with workload variables, number of residents and size of the hospital. This study presents two main limitations: (i) the inflexible functional form selected for the IRF, and (ii) not to consider - due to the empirical data used in the analysis - a time component to capture the technological changes and the productivity effects on the delivery of healthcare, and consequently on the physicians' requirements. Other health-related studies applied an IRF, but with different purposes: Kumbhakar (Kumbhakar and Zhang, 2013) used an IRF to estimate the minimum per capita health expenditures required to attain a particular level of Disability Adjusted Life Expectancy using panel data on World Health Organization member countries, and Gunning and Sickles (Gunning and Sickles, 2011) used a generalized Leontief IRF to perform a multi-product cost analysis, based on data from American private practices.

As such, the work hereby presented aims to introduce a method to describe and quantify 
the relation between healthcare services and workforce requirements, assisting on the challenging task of translating health services to HHR, in this way making a contribution to the extension and diversity of the available methods to forecast the demand for HHR. Our approach differs from previous studies by conjoining three main aspects. First, we consider a flexible IRF to model the relation between healthcare services and human resources, a specification based on the assumption that health managers and decision-makers can size and adjust the workforce levels in response to the expected demand. Second, we analyze hospital care by specialty. Although hospital care has been broadly researched, surprisingly not enough attention has been given to specialty-specific approaches, which have the advantage of capturing relevant specificities that otherwise pass unnoticed. Finally, we use panel-data when previous works consider a purely cross-sectional approach. Our approach may improve the statistical reliability of the results and allows for the analysis of the labor productivity and its impact on the healthcare services delivered over time.

The proposed method is meant to be used as a tool to estimate the number of physicians required to meet expected variations in the demand for healthcare. Additionally, it is our goal to contribute to a deeper knowledge on healthcare delivery process, on the possible options of HHR allocation and on the technological progress in healthcare delivery, as they may be relevant drivers for the future needs of HHR.

\subsection{Methods}

\subsubsection{Data}

We use data from the Annual Survey of Hospitals conducted by the Portuguese Institute of Statistics (INE). This data is collected through a mandatory survey and it reports hospitals' activity and resources. From the range of hospitals reporting data, we focused on public official hospitals, excluding private and non-public official hospitals, for which access is not universal (military, paramilitary and prisons hospitals). We constructed a panel dataset comprising information on 142 hospitals during a twelve-year period by compiling information from the surveys between 1999 and 2010. The period after 2010 was not con- 
sidered due to a change in coding: since 2011 the hospitals' unique identifier changed and the mapping between the two identification codes (the one used until 2010 and the one used afterwards) is unknown, which creates a discontinuity and invalidates a joint panel analysis for the periods before and after 2011. Moreover, due to recent changes that occurred in the Portuguese Health System some hospitals were closed, created or merged during the considered period. Our unbalanced panel includes all the hospitals with reported activity for at least one of the years in analysis, even if they were no longer active at the end of the period. The inclusion of hospitals that were not in activity throughout the whole period was meant to eliminate the survivorship-bias.

The final sample is composed of 1236 observations of hospitals' capacity and services utilization by medical specialty.

\subsubsection{Analysis}

The heart of our analysis is an Input Requirements Function. The IRF, first introduced by Diewert (Diewert, 1974), is an inverse Production Function (PF): while the PF gives the maximum amount of output that can be produced with a given amount of inputs, the IRF gives the minimum amount of an input that is required to attain a certain level of outputs, holding the other inputs constant. Thus, an IRF can take as dependent variable any of the inputs used in the production, which are usually divided in labor (variable inputs) and capital (fixed inputs).

Since the main purpose of our study is to provide a method to estimate the workforce needed to deliver healthcare services, we consider a labor requirements function (LRF), a specification meant to derive the minimum amount of labor that is required to produce a given level and mix of outputs, with a given level of capital. Indeed, the LRF form seems more suited to the healthcare field than the traditional PF: while the PF specification assumes the amount of labor as exogenous and the outputs as endogenous, the LRF implicitly assumes that workforce levels may be determined and changed according to a given expected demand for healthcare services. 
The production of healthcare services can generally be represented by:

$$
Y=f(L, K)
$$

where $\mathrm{f}$ denotes the production technology and $\mathrm{Y}, \mathrm{L}$ and $\mathrm{K}$ are the vectors of healthcare outputs, labor and capital variables, respectively.

The above relation can be transformed into an LRF as follows:

$$
L=f(Y, K)
$$

Of the parametric functional forms that can be used to model the healthcare services production, the traditional Cobb-Douglas and the transcendental logarithmic (translog) forms are the most popular (Coelli et al., 2005). We assumed a translog form for its flexibility, and for exhibiting several interesting benefits: it is a generalization of the Cobb-Douglas function that imposes less restrictions on the elasticities, and despite assuming a nonlinear relationship between output and inputs, it provides a second-order Taylor's approximation that can be estimated using linear models. Assuming that $n$ outputs can be produced using labor (L) and $m$ capital inputs (K), the translog LRF can then be written as follows:

$$
\begin{aligned}
\ln (L) & = \\
& \alpha_{0}+\sum_{i=1}^{n} \alpha_{i} \ln \left(Y_{i}\right)+\frac{1}{2} \sum_{i=1}^{n} \sum_{j=1}^{n} \alpha_{i j} \ln \left(Y_{i}\right) \ln \left(Y_{j}\right)+ \\
& \sum_{k=1}^{m} \beta_{k} \ln \left(K_{k}\right)+\frac{1}{2} \sum_{k=1}^{m} \sum_{l=1}^{m} \beta_{k l} \ln \left(K_{k}\right) \ln \left(K_{l}\right)+\frac{1}{2} \sum_{i=1}^{n} \sum_{k=1}^{m} \gamma_{i k} \ln \left(Y_{i}\right) \ln \left(K_{k}\right)+\mu
\end{aligned}
$$

where $L$ is the labor variable, $Y_{i}$ the output variable $i, K_{k}$ the capital variable $k, \alpha_{0}$ represents the constant term, $\alpha_{i}$ and $\beta_{k}$ stand for the coefficients of output $i$ and capital variable $k, \alpha_{i j}$, $\beta_{k} l$ and $\gamma_{i k}$ represent the parameters for the second-order terms, and $\mu$ represents the error 
term of the model.

The logarithmic transformation reduces the distributions' asymmetry and makes the statistical inference more intuitive, as the results are in the form of elasticities. Nonetheless, the use of logarithms carries the difficulty of handling observations with null-values. We opted for retaining null-valued observations by substituting them for a very low positive value $(0,00001)$, an approach typically used to overcome this issue.

We identified three main types of specialties according to the healthcare services produced: medical, surgical and diagnostic-related. Considering the differences between the specialties, we propose a different LRF model, based on Eq. 3.3, for each type of specialty (Eq. 3.4, 3.5, 3.6 in the Appendix). The main difference between the three models lies on the variables representing the outputs, which were selected according to the activities performed by each type of specialty. Medical specialties are the ones providing inpatient and outpatient care, while surgical specialties carry out the same procedures as medical specialties but also perform surgeries, and diagnostic specialties perform diagnostic and therapeutic procedures.

The public health sector has several objectives, including providing timely treatment to patients, assuring quality of the delivered care, and meeting budget and resource constraints. However, as profit-maximization is not an explicit goal, inputs and outputs are not jointly selected. Therefore, a single equation estimation perfectly fits the problem.

Additionally, understanding HHR productivity and technological progress in healthcare delivery is also of major interest, as their evolution may be relevant drivers of future HHR needs. Thus, we propose the estimation of a single LRF using period Fixed Effects (FE). The selection of a Fixed Effects (FE) model, also known as Least Squares Dummy Variable (LSDV), was due to its ability to capture the effects that are specific to the time period and common to all the entities (hospitals). Thus, these effects can be interpreted as the impact of technological change and labor productivity over the time. Also, we use robust estimators of the variance-covariance matrix to guarantee efficient estimators and ensure valid statistical inference, since the structure of our models may exhibit both heteroscedasticity and serial-correlation. 
Moreover, we perform two statistical tests: one to assess the adequacy of considering period FE in the models, and another to verify the adequacy of the functional form selected for the models (translog). In order to assess the adequacy of the FE estimation we test the FE redundancy (a test on the joint significance of the fixed effects parameters). Through the rejection of the null hypothesis it is possible to conclude that the period fixed effects are not redundant to the model and should be considered. Moreover, we perform a test on the joint significance of the second-order terms of the models to infer if the translog form is a good choice for the functional form of our models. In a similar fashion to the previous test, the rejection of the null hypothesis indicates that the second order terms of the models are not redundant, which implies that the translog form should be used instead of the traditional Cobb-Douglas function. Based on the FE estimates, we can infer about the technological change rates and the evolution of physicians' productivity over the considered period, quantify the relation between healthcare services delivery and number of physicians, and understand changes on the process of delivering healthcare over time.

The estimates for the LRF parameters do not have such a clear meaning. However, other useful insights arise from further analysis of these estimates. Elasticities of mean-labor use, which give the labor changes needed to meet a given variation in the production levels, are calculated (Eq. 3.7 in the Appendix) for each healthcare output using the mean-values of the explanatory variables (Table 3.4 in the Appendix). In turn, these elasticities are used to calculate the Marginal Rates of Technical Substitution (MRTS) of labor between the different healthcare services (Eq. 3.8 in the Appendix) and the returns to scale (RTS) of labor (Eq. 3.9 in the Appendix).

In our context, the MRTS is the rate at which one healthcare service can be substituted for another without changing the level of labor, which can be interpreted as the opportunity cost of physicians' time between the different healthcare services. The RTS represent a measure of the labor changes that are required to meet a variation of all the healthcare outputs by the same proportion, which is useful to inform about the effect of changes in the scale of labor use on productivity. 


\subsubsection{Selected variables}

Variables that represent the inputs to produce healthcare services (labor and capital), the healthcare outputs, and eventually other factors influencing the production of healthcare need to be selected for applying the LRF model.

When compared to other developed countries, healthcare in Portugal is very physicianintensive. In fact, Portugal has a relatively high ratio of physicians per 1000 population (4.6 in 2017, when the average in the OECD countries was 3.4) and a low ratio of nurses (6.3 nurses per 1000 population vs. 9.0 in the OECD countries). Additionally, and because ensuring the adequate number of physicians requires a timely planning - due to the long educational path for becoming a physician - our focus is on physicians' requirements. Hence, labor (the dependent variable) is represented only by the number of physicians. To factor in the stock of capital we use the number of rooms, a proxy to the fixed inputs available to all the production lines, including facilities that are used for outpatient care (rooms for consultations), inpatient care (wards) and surgeries (operating rooms). Finally, the main production lines are modelled as production outputs: inpatient care, measured by the number of inpatient discharges; outpatient care, measured by the number of outpatient visits; surgeries, measured by the number of procedures; and diagnostic and therapeutic procedures, also measured by the number of procedures. Except for the variable used as a proxy for capital, all the others are specialty-specific.

Other factors capable of influencing the process of healthcare production and physicians' productivity can also be included in the model, such as the number of nurses, residents and other health-staff working in hospitals, or additional variables related to other fixed inputs, such as the number of beds. However, a correlation analysis (Table 3.5 in the Appendix) shows these variables to be redundant, as they are extremely correlated to the other variables already factored in in the model (e.g. high correlation between the number of nurses and the size of the hospital, measured by the number of rooms, or between the number of beds and the number of inpatient discharges). Therefore, in order to avoid multicollinearity problems, such as imprecise estimates and invalid statistical inference, 
we omit these variables from the estimated models without any prejudice to the generality of the results. However, we also present the original LRF models for each type of specialty, which can be used in contexts where these variables are not that correlated (Eq. 3.10, 3.11 and 3.12 in the Appendix). Of the fifty-two specialties, we selected three for the statistical analysis, one from each specialty group: General Surgery (surgical), Internal Medicine (medical) and Anatomical Pathology (diagnostic).

\subsection{Results}

\subsubsection{Descriptive statistics}

The descriptive statistics of the variables included in each model are presented in Table 1. The General Surgery LRF estimation uses 956 observations, comprising 112 different hospitals between 1999 and 2010. Portuguese hospitals have, on average, 13 general surgeons, each one producing around 700 outpatient visits, 145 inpatient discharges and 140 surgeries per year. The sample used on the Internal Medicine LRF estimation includes 1014 observations from 128 hospitals. Portuguese hospitals with an Internal Medicine department have, on average, 15 specialists providing this type of care. On average, each internal medicine specialist produces about 360 outpatient visits and 120 inpatient discharges per year.

For both the surgical and the medical specialties we observed that all hospitals provide outpatient consultations, but not all deliver inpatient care. This is due to the Portuguese hospital structure, where smaller hospitals are not able to provide inpatient care and patients with these needs are referred to larger facilities. It is possible to find hospitals where only 1 specialist provides healthcare services, as well as hospitals with more than 70 specialists in activity. Likewise, the discrepancy of capital levels in Portuguese hospitals is quite substantial: hospitals have an average of 50 rooms, but this number varies from 2 to more than 200.

The workload of Portuguese physicians may seem low when compared to other developed countries. In fact, in 2017, the annual number of overall consultations per physician in 
Portugal was only about 1000 consultations per physician, a low number when compared to the number of the average consultations per physician in the OECD countries (around 2300 consultations). The physicians' workload for inpatient care is also below the OECD average, when measured by the number of inpatient discharges per 1000 population (110 in Portugal vs 156 in OECD countries) (OECD, 2018). Although these workloads may suggest an under-utilization of the specialist workforce, it does not seem to be case of Portugal, where waiting times and waiting lists have been a concern for both health managers and decision-makers in the past two decades, and where several efforts have been made to devise and implement several recovery programmes (Christiansen and Bech, 2013).

Additionally, this low workload can be justified by a number of factors, such as the low nurse ratio per population, which may suggest more physicians are required to deliver healthcare than in countries where the nurse ratio is higher. The lower number of hospital beds per 1000 population in Portugal (3.4 beds) when compared to the OECD average (4.7 beds) and the higher average length to stay (of 8.8 days in 2017, when the average for OECD countries was of 7.8 days) may also help to explain the lower number of discharges per physician in Portugal (OECD, 2018).

The production variable considered in the LRF for the diagnostic specialty comprises all the diagnostic procedures performed by anatomical pathologists (exams and clinical autopsies). The sample contains 469 observations from 55 different hospitals. Portuguese hospitals with an Anatomical Pathology department are the larger ones: 75 rooms, compared to an average of less than 50 for the other specialties. These hospitals employ, on average, 4 anatomical pathologists producing, on average, more than 22,000 diagnostic procedures per year.

\subsubsection{Estimation results}

The results of the LRF estimations, as well as the tests performed on the functional form and on the FE estimators are presented in Table 2. Overall, workload and capital variables included in the models are statistically relevant and the goodness-of-fit of the models is high: the LRF can explain $86 \%, 83 \%$ and $61 \%$ of the variation in the number of physicians 
Table 3.1 - Summary statistics for the variables included in the models between 1999 and 2010.

\begin{tabular}{|c|c|c|c|c|c|c|c|c|c|c|c|c|}
\hline \multirow{2}{*}{ Variable } & \multicolumn{4}{|c|}{ General Surgery } & \multicolumn{4}{|c|}{ Internal Medicine } & \multicolumn{4}{|c|}{ Anatomical Pathology } \\
\hline & Mean & Std. Dev. & Min. & Max. & Mean & Std. Dev. & Min. & Max. & Mean & Std. Dev. & Min. & Max. \\
\hline PHY & 13 & 0.4 & 1 & 73 & 15 & 0.5 & 1 & 109 & 4 & 0.2 & 1 & 25 \\
\hline ROO & 48 & 1.6 & 3 & 229 & 47 & 1.6 & 2 & 305 & 75 & 2.5 & 9 & 229 \\
\hline OUT & 8989 & 226.2 & 340 & 39228 & 5510 & 161.3 & 70 & 31730 & - & - & - & - \\
\hline INP & 1890 & 43.3 & 0 & 6564 & 1862 & 53.7 & 0 & 11499 & - & - & - & - \\
\hline SUR & 1847 & 47 & 0 & 7785 & - & - & - & - & - & - & - & - \\
\hline DIA & - & - & - & - & - & - & - & - & 22233 & 1237.7 & 57 & 289038 \\
\hline $\begin{array}{c}\text { Number of } \\
\text { hospitals }(i)\end{array}$ & 112 & & & & 128 & & & & 55 & & & \\
\hline $\begin{array}{c}\text { Number of } \\
\text { years }(t)\end{array}$ & 12 & & & & 12 & & & & 12 & & & \\
\hline $\begin{array}{c}\begin{array}{c}\text { Number of } \\
\text { observations }(n)\end{array} \\
\end{array}$ & 956 & & & & 1014 & & & & 469 & & & \\
\hline
\end{tabular}

in surgical, medical and diagnostic specialties, respectively. However, individually, the estimated parameters do not have any useful interpretation and further analysis is required to obtain meaningful inferences, such as the Elasticities of mean-labor use with respect to each healthcare output, the Marginal Rates of Technical Substitution of labor between the different healthcare services, and the Returns to Scale of labor.

The test on the joint significance of the second-order terms shows that these terms are statistically significant and relevant to the model, which we confirm by rejecting the null hypothesis of redundancy of the second-order terms with a significance level of 5\%. This means that the flexible functional form considered is superior to the traditional Cobb-Douglas form, for all specialties.

Additionally, we confirm that considering year FE is a valid approach for the medical and the surgical specialties: at the 5\% significance level, the test on the FE redundancy shows that FE are statistically different from zero, thus affecting the production of healthcare services in these specialties. As no statistically significant FE were found (at the 5\% significance level) for Anatomical Pathology, we did not go further with the productivity analysis for this specialty.

All the estimations and tests were performed using the statistical software EViews@8. 
Table 3.2 - Summary statistics for the variables included in the models between 1999 and 2010 .

\begin{tabular}{|c|c|c|c|c|c|c|c|}
\hline \multirow[t]{2}{*}{ Parameter } & \multirow[t]{2}{*}{ Variable } & \multicolumn{2}{|c|}{$\begin{array}{c}\text { General Surgery } \\
(\mathrm{n}=956)\end{array}$} & \multicolumn{2}{|c|}{$\begin{array}{c}\text { Internal Medicine } \\
(\mathrm{n}=1014)\end{array}$} & \multicolumn{2}{|c|}{$\begin{array}{c}\text { Anatomical Pathology } \\
(\mathrm{n}=469)\end{array}$} \\
\hline & & Coefficient & Std. Error & Coefficient & Std. Error & Coefficient & Std. Error \\
\hline$\alpha_{0}$ & $\mathrm{C}$ & $0.5607^{*}$ & 0.2475 & $0.1583 *$ & 0.0603 & $1.9218 * *$ & 0.7578 \\
\hline$\alpha_{\text {OUT }}$ & $\ln (\mathrm{OUT})$ & $-0.4272 * * *$ & 0.0733 & $-0.9266^{* * * *}$ & 0.1203 & - & - \\
\hline$\alpha_{I N P}$ & $\ln (\mathrm{INP})$ & $-0.1499^{* *}$ & 0.0759 & $0.3064 * * *$ & 0.0437 & - & - \\
\hline$\alpha_{S U R}$ & $\ln$ (SUR) & 0.0615 & 0.0683 & 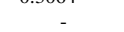 & - & - & - \\
\hline$\alpha_{D I A}$ & $\ln$ (DIA) & - & - & - & - & $-0.2574 * * *$ & 0.1176 \\
\hline$\beta_{R O O}$ & $\ln (\mathrm{ROO})$ & $0.2804^{* * *}$ & 0.1069 & $0.9156 * * *$ & 0.1418 & $-1.2782 * *$ & 0.1993 \\
\hline$\gamma_{R O O, I N P}$ & $\frac{1}{2} \ln (\mathrm{ROO}) * \ln (\mathrm{INP})$ & $0.0113^{* *}$ & 0.0043 & 0.0230 & 0.0165 & - & - \\
\hline$\gamma_{R O O, O U T}$ & $\frac{1}{2} \ln (\mathrm{ROO}) * \ln (\mathrm{OUT})$ & -0.0094 & 0.0125 & $-0.3937 * * *$ & 0.0633 & - & - \\
\hline$\gamma_{O U T, I N P}$ & $\frac{1}{2} \ln (\mathrm{OUT}) * \ln (\mathrm{INP})$ & $0.0076 *$ & 0.0030 & $-0.1046 * * *$ & 0.0168 & - & - \\
\hline$\gamma_{R O O, S U R}$ & $\frac{1}{2} \ln (\mathrm{ROO}) * \ln (\mathrm{SUR})$ & -0.0084 & 0.0198 & - & - & - & - \\
\hline$\gamma_{S U R, I N P}$ & $\frac{1}{2} \ln (\mathrm{SUR}) * \ln (\mathrm{INP})$ & $-0.0190 * * *$ & 0.0060 & - & - & - & - \\
\hline$\gamma_{S U R, O U T}$ & $\frac{1}{2} \ln (\mathrm{SUR}) * \ln (\mathrm{OUT})$ & 0.0034 & 0.0126 & - & - & - & - \\
\hline$\gamma_{R O O, D I A}$ & $\frac{1}{2} \ln (\mathrm{ROO}) * \ln (\mathrm{DIA})$ & - & - & - & - & $-0.3709^{* * *}$ & 0.0857 \\
\hline$\beta_{R O O, R O O}$ & $\frac{1}{2}[\ln (\mathrm{ROO})]^{2}$ & 0.0240 & 0.0297 & $0.2967 * * *$ & 0.0407 & $0.8270^{* * *}$ & 0.0713 \\
\hline$\alpha_{\text {OUT, OUT }}$ & $\frac{1}{2}[\ln (\text { OUT })]^{2}$ & $0.0847 * * *$ & 0.0083 & $0.2753^{* * *} *$ & 0.0279 & - & - \\
\hline$\alpha_{I N P, I N P}$ & $\frac{1}{2}[\ln (\mathrm{INP})]^{2}$ & $0.0488^{* * *}$ & 0.0110 & $0.0629 * * *$ & 0.0062 & - & - \\
\hline$\alpha_{S U R, S U R}$ & $\frac{1}{2}[\ln (\mathrm{SUR})]^{2}$ & $0.0331 * * *$ & 0.0117 & - & - & - & - \\
\hline$\alpha_{D I A, D I A}$ & $\frac{1}{2}[\ln (\mathrm{DIA})] 2$ & - & - & - & - & $0.1537 * * *$ & 0.0175 \\
\hline R-squared & & 0.8621 & & 0.8326 & & 0.6100 & \\
\hline Adjusted R-squared & & 0.8584 & & 0.8293 & & 0.6057 & \\
\hline F-statistic & & $232.6221 * * *$ & & $247.0297 * * *$ & & $144.7795^{* * * *}$ & \\
\hline Redundant Fixed Effects test & & & & & & & \\
\hline F-statistic & & $5.7358 * * *$ & & $1.8425^{* * *}$ & & $1.6236^{*}$ & \\
\hline $\begin{array}{l}\text { Redundant (2nd order) variables test } \\
\text { F-statistic }\end{array}$ & & $38.0364 * * *$ & & $39.9792 * * *$ & & $44.6099 * * *$ & \\
\hline
\end{tabular}

\subsubsection{Labor productivity}

To analyze the technical progress and the labor productivity we used the FE estimates (Table 3.6 in the Appendix). FE decreases can be interpreted as technical progress (decreasing labor demand) and increases as technical regress (increasing demand for labor). Results on both the annual technical change rate and the cumulative technological progress in healthcare delivery are presented in Figure 3.1 (General Surgery) and Figure 3.2 (Internal Medicine).

There were only two periods of regression for the surgical specialty (2007-2008 and 20092010 ) and three for the medical specialty (2000-2001, 2003-2004 and 2009-2010), where a decreasing labor productivity was apparent. The 2009-2010 period, however, had a sharper reduction in productivity. This decrease may be related to the evolution of the mean number of physicians and the possible existence of economies of scale, as it is further explained in the discussion section. Increasing RTS would help to explain this phenomenon, as no other structural or political change occurred that could explain significant changes in productivity.

Our results show also that healthcare delivery has benefited from an increasing productivity 


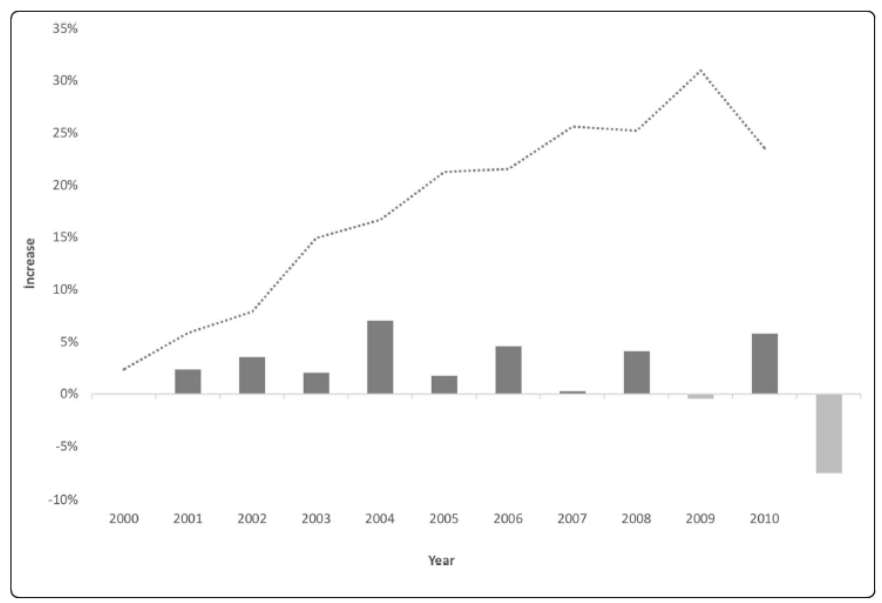

Figure 3.1 - Technical change rate and cumulative technical progress in general surgery over 11 years

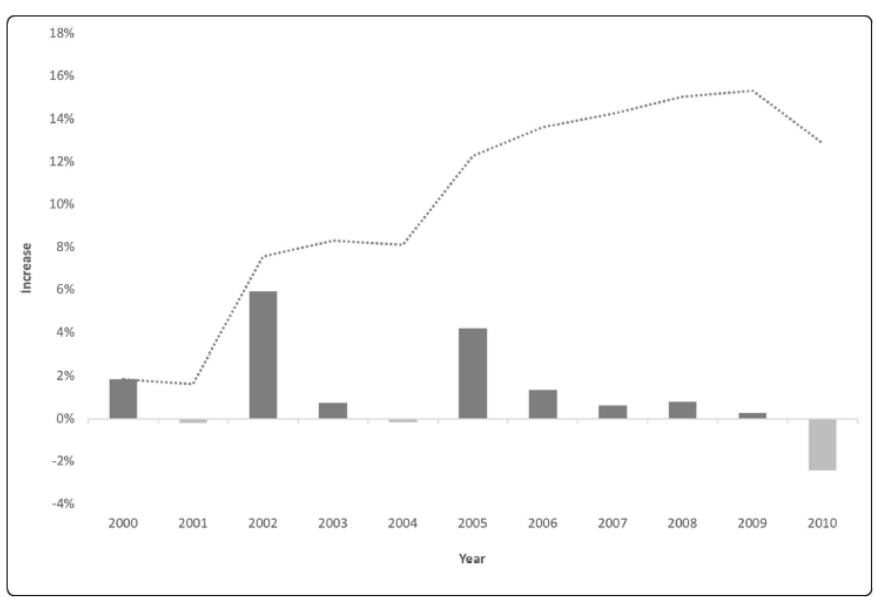

Figure 3.2 - Technical change rate and cumulative technical progress in internal medicine over 11 years

of physicians' labor of around $2.14 \%$ per year for General Surgery. In the case of Internal Medicine the improvement was smaller, of around $1.20 \%$.

\subsubsection{Elasticities of labor use, marginal rates of technical substitution and returns to scale}

The estimation results were used to further analyze the healthcare services delivered by physicians. The elasticities of labor use for each production line, the marginal rates of 
technical substitution (MRTS) between healthcare services and the labor RTS are presented in Table 3. Results show that, for all specialties under analysis, elasticities of mean laboruse are relatively stable over the years, although it was verified a slight increase of surgeries and outpatient visits and a decrease of inpatient discharges' weight over time.

The General Surgery elasticities for the overall period show that, ceteris paribus, increasing outpatient visits by $1 \%$ requires $0.35 \%$ more physicians; increasing the number of inpatient discharges by $1 \%$ requires $0.16 \%$ additional specialists delivering care; and increasing the surgeries by $1 \%$ requires $0.16 \%$ more general surgeons. These results mean that one additional physician is needed to increase the outpatient care by 1975 visits, the inpatient care by 909 discharges or the surgeries by 888 surgeries.

From the MRTS, which can be interpreted as the opportunity costs of the physicians' time, we found that increasing the outpatient visits delivered by $1 \%$ (90 visits) would imply a reduction of $2.17 \%$ in inpatient discharges (41 discharges) or, alternatively, the sacrifice of $2.20 \%$ of surgeries (4 surgeries).

The Internal Medicine results suggest that, ceteris paribus, an increase in the outpatient visits by $1 \%$ requires $0.31 \%$ more specialists delivering care and an increase in the number of inpatient discharges by $1 \%$ requires $0.32 \%$ additional physicians. These results mean that one additional physician would be able to increase the outpatient care by 1184 visits or the inpatient care by 388 discharges. The MRTS between outpatient visits and inpatient discharges for this specialty shows that increasing the outpatient visits by $1 \%$ (55 visits) would reduce inpatient care in $0.97 \%$ (18 discharges) as a trade-off.

For the diagnostic specialty we found that, ceteris paribus, increasing the number of diagnose procedures by $1 \%$ requires $0.63 \%$ additional physicians: one additional physician would increase the number of procedures performed by 8823 .

Additionally, results show RTS for the overall period of 1.48 for the surgical specialty, and of 1.58 for both the medical and the diagnostic specialties, meaning that the production of healthcare services has increasing RTS. As a result, increasing all healthcare services produced by $1 \%$ would lead to an additional requirement of physicians less than proportional: $0.68 \%$ for the surgical specialty and $0.63 \%$ for the other specialities. 


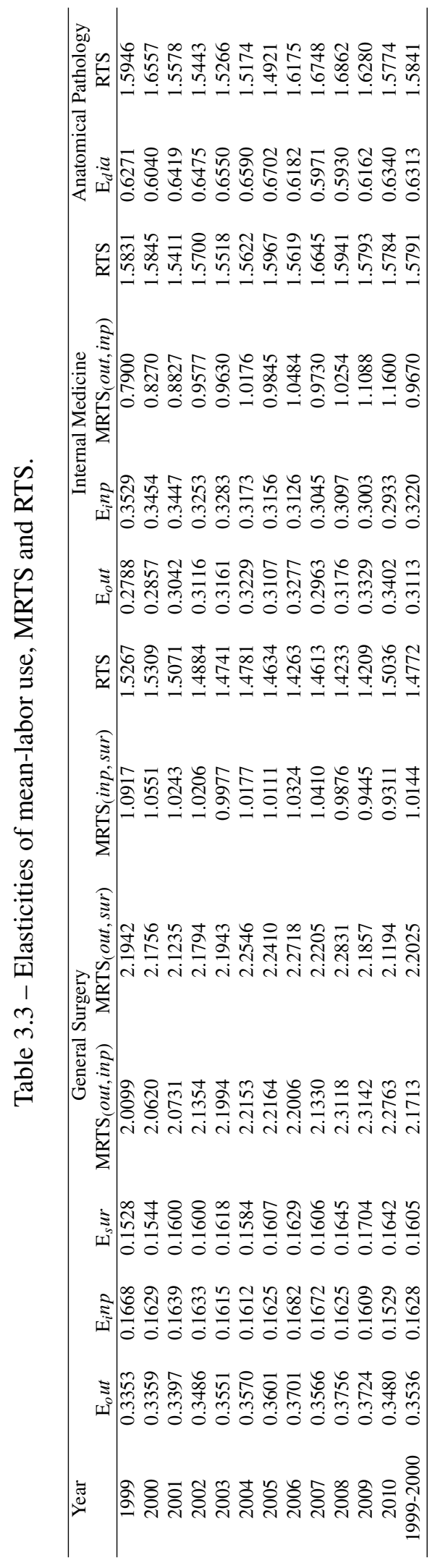




\subsection{Discussion}

Ensuring an efficient delivery of healthcare services is crucially dependent on both the prediction of the future demand for healthcare services and on planning the HHR needed to properly deliver these services. Considering this, we proposed an LRF relating the number of physicians with a set of specialty-specific workload and capital variables to empirically quantify and describe the relation between healthcare services and the HHR needed. The method is based on the assumption that health managers and decision-makers can size and adjust the level of the HHR in response to a given expected demand, which is a very realistic assumption.

We considered a flexible form, which we also found to be superior to the traditional CobbDouglas form, confirming the results obtained by other authors (Kwietniewski et al., 2017). Additionally, we use period FE estimation to account for the technological progress, concluding that there are statistically significant time effects affecting the production of healthcare services, which allows for the analysis of labor productivity and its impact on the healthcare services delivered over time. Key findings

Most of the health workforce planning models include productivity as a factor influencing the future workforce needs, usually by making some arbitrary assumptions regarding productivity growth rates (Ono et al., 2013). Our models estimate these rates, and overall results show that the delivery of healthcare has benefited from an increasing productivity of physicians' labor. These results are in line with other international studies on healthcare productivity, suggesting that the positive impact of technological innovations on labor productivity exceeds the negative effect that may derive from the increased patient complexity experienced in the healthcare sector (Kwietniewski et al., 2017; Nolan, 2007). For the medical specialty the improvement was smaller, which can be explained by the larger dependency of surgical specialties on technology (Gurtner and Soyez, 2015) and by a programme recently implemented in Portugal to reduce the waiting times for surgeries, which is based on additional financial incentives to hospitals that perform the surgeries on time, and penalties for those which do not. The production of healthcare services in Portugal has 
increasing returns to scale: increasing the health workforce tends to originate a more than proportional increase in the level of healthcare services delivered, which is in line with previous results for Portugal (Gonçalves and Barros, 2013) and with several other studies that showed increasing returns to scale among median-size hospitals (Nolan, 2007). These results suggest that the Portuguese specialists would be more productive on delivering healthcare services if hospitals had an higher HHR concentration, which is interesting regarding that the largest hospitals are usually the ones dealing with the higher diversity, severity and complexity of cases. Additionally, the interaction between returns to scale and the evolution of the mean number of physicians may also explain changes in productivity: in case of increasing returns to scale, increasing the amount of labor increases the labor productivity and decreasing the amount of labor leads to a productivity decrease, while in case of decreasing returns to scale, the changes in the labor levels have exactly the opposite effect in productivity. Thus, these results explain the decreasing productivity registered between 2009 and 2010, where the average number of specialists decreased due to retirements, followed by a significant decrease in productivity.

The elasticities of mean labor-use, which reflect the portion of time that a physician spends on each type of activity, are relatively stable over the years. Notwithstanding, it is possible to verify a slight increase of surgeries and outpatient visits and a decrease of inpatient discharges' weight over time. These changes follow the efforts that have been made in Portugal for substituting inpatient care with outpatient care, with the aim of controlling both health expenditures and avoidable hospital infections (MOH, 2004). Additionally, they are also a consequence of the recent increase in the number of surgical procedures carried out on a same-day basis (ambulatory surgery), similar to what happened in other countries (OECD, 2018).

\subsubsection{Limitations and further work}

The application of this method to other datasets would be interesting for comparing resources allocation patterns across countries, regions or health systems. Further applications of the proposed method in different contexts (e.g., where some of the explanatory 
variables are not so highly correlated as in the Portuguese case), or assuming the number of nurses as the dependent variable of the models (e.g., for cases where the health system is characterized by higher nursing ratios and lower physician ratios per population) would also be interesting. Notwithstanding, future empirical studies applying the proposed method should have present the main limitations of our empirical data: Full-Time Equivalents (FTE) should be used instead of the number of HHR and the volume of healthcare services provided can be adjusted to account for diversity and complexity, using relative measures such as the Case Mix Index (CMI). Moreover, further work on HHR productivity can be undertaken to provide a better understanding on the main factors driving the changes in productivity that were found.

\subsubsection{Implications for policy and practice}

The proposed method yields simple yet powerful models to understand and quantify the relation between healthcare services and HHR needed. Estimation of HHR requirements based on our models can be performed as the second step - that aims to translate services to HHR - on the different demand approaches to HHR planning. These models can be applied both for a single medical specialty and for a group of specialties, at international, national or regional level.

Additionally, by empirically quantifying the relation between HHR and healthcare services produced, this method can be used to complement several other existent approaches aiming to translate healthcare services in HHR, which require the use of service standards measured in unit time or rate of work - as an input, to further estimate the HHR requirements (e.g. WHO Workload Indicators of Staffing Needs - WISN) (WHO, 1999). These service standards, which may be derived from an empirical method like the one proposed in this paper, may also be used: i) to conduct international or regional comparisons of HHR productivity; ii) as a benchmark for specific hospitals; or iii) to measure and monitor the distance to some ideal/desirable productivity pattern.

Our approach provides several interesting insights that can be very useful to health managers and policy-makers, such as: 
- The variation in the number of physicians that is required to meet fluctuations in the demand for healthcare, to ensure that enough resources will exist to provide healthcare services to the patients who need them;

- The proportion of time spent by physicians in each type of care provided, both to elucidate about the distribution of HHR workload, and to assist in the implementation and monitoring of specific strategies related to healthcare delivery (e.g., reduce the inpatient care, increase ambulatory surgeries);

- The feasible allocations of the available physicians between different healthcare services, based on the opportunity cost of physicians' labor, informing on the allocations that most benefits the population and the organizations;

- The effect of the HHR concentration in hospitals. Based on the returns to scale of labor provided, this method informs on the effect of changes in the scale of hospitals' labor use and points the HHR concentration changes that may lead to a higher productivity of human resources on delivering healthcare services;

- The evolution of the labor productivity in hospitals. The time fixed-effects estimates are useful to predict the adjustments in the human resources levels that may be required over the time, due to the evolution of labor productivity.

Overall, this method can be used to enable a more informed sizing and allocation of human resources and to achieve a better HHR management in hospitals, which is highly dependent on reliable HHR estimations; to inform on the right scale of health facilities and HHR concentration; and to foster a deeper knowledge on the evolution of the labor productivity and on the opportunity costs of labor in different healthcare services.

\section{List of abbreviations}

CMI - Case Mix Index

FE - Fixed Effects 
FTE - Full-Time Equivalent

HHR - Health Human Resources

INE - Portuguese Institute of Statistics

IRF - Input Requirements Function

LRF - Labor Requirements Function

MRTS - Marginal Rate of Technical Substitution

PF - Production Function

RTS - Returns to Scale

\section{Declarations}

\section{Ethics approval and consent to participate}

Not applicable.

\section{Consent for publication}

Not applicable.

\section{Availability of data and materials}

The data that support the findings of this study are available from Statistics Portugal, but restrictions apply to the availability of these data, which were used under license for the current study, and so are not publicly available. Data are however available from the authors upon reasonable request and with permission of Statistics Portugal.

\section{Competing interests}

The authors declare that they have no competing interests. 


\section{Funding}

This work is financed by the ERDF European Regional Development Fund through the

Operational Programme for Competitiveness and Internationalisation - COMPETE 2020

Programme and by National Funds through the Portuguese funding agency, Foundation for

Science and Technology Portugal (FCT) within project POCI-01-0145-FEDER-016738.

\section{Authors' contributions}

SCG developed the models, applied them to the dataset and further analyzed the results and drafted the paper, with MAL and BAL providing guidance, critical assessment and review of the writing. The three authors conceived the idea, read, reviewed and approved the final manuscript.

\section{Acknowledgements}

The authors would like to thank both the Statistics Portugal institute, for sharing the data, and the Portuguese funding agency Foundation for Science and Technology Portugal (FCT), for financing the project POCI-01-0145-FEDER-016738 (HHRPLAN).

\section{Bibliography}

A. Al-Sawai and M. M. Al-Shishtawy. Health workforce planning: An overview and suggested approach in oman. Sultan Qaboos University medical journal, 15(1):e27, 2015.

J. P. Ansah, V. Koh, D. F. de Korne, S. Bayer, C. Pan, J. Thiyagarajan, D. B. Matchar, and D. T.-L. Quek. Comparing health workforce forecasting approaches for healthcare planning: The case for ophthalmologists. 2017.

T. Bärnighausen and D. E. Bloom. Changing research perspectives on the global health workforce. Technical report, National Bureau of Economic Research, 2009. 
A. Castelli, A. Street, R. Verzulli, and P. Ward. Examining variations in hospital productivity in the english nhs. The European Journal of Health Economics, 16(3):243-254, 2015.

CGME. Evaluation of specialty physician workforce methodologies. Council On Graduate Medical Education., 2000.

T. Christiansen and M. Bech. Waiting time policies in the health care sector. what works?: Denmarkdanmark. In Oecd Health Policy Studies, pages 115-131. OECD, 2013.

T. J. Coelli, D. S. P. Rao, C. J. O’Donnell, and G. E. Battese. An introduction to efficiency and productivity analysis. Springer Science \& Business Media, 2005.

C. R. I. W. Dall T, West T. The complexities of physician supply and demand: Projections from 2013 to 2025. Final Report Association of American Medical Colleges. Assoc Am Med Coll., pages 1-68, 2015.

DHHS. National and regional projections of supply and demand for primary care practitioners: 2013-2025. ealth Resources and Services Administration National, Center for Health Workforce Analysis., 2016.

W. E. Diewert. Functional forms for revenue and factor requirements functions. International Economic Review, 15(1):119-130, 1974. ISSN 00206598, 14682354.

N. Dreesch, C. Dolea, M. R. Dal Poz, A. Goubarev, O. Adams, M. Aregawi, K. Bergstrom, H. Fogstad, D. Sheratt, J. Linkins, et al. An approach to estimating human resource requirements to achieve the millennium development goals. Health policy and planning, 20(5):267-276, 2005.

R. Gonçalves and P. P. Barros. Economies of scale and scope in the provision of diagnostic techniques and therapeutic services in portuguese hospitals. Applied Economics, 45(4): 415-433, 2013.

T. S. Gunning and R. C. Sickles. A multi-product cost function for physician private practices. Journal of Productivity Analysis, 35(2):119-128, Apr 2011. ISSN 1573-0441. 
S. Gurtner and K. Soyez. Challenges and opportunities in health care management. Springer, 2015.

A. Heshmati. Labour demand and efficiency in swedish savings banks. Applied Financial Economics, 11(4):423-433, 2001.

B. Hollingsworth. Non-parametric and parametric applications measuring efficiency in health care. Health care management science, 6(4):203-218, 2003.

K. Hurst. 2 selecting and applying methods for estimating the size and mix of nursing teams selecting and applying methods for estimating the size and mix of nursing teams. 2003.

S. Jiménez-Martín, J. M. Labeaga, and M. Martínez-Granado. An empirical analysis of the demand for physician services across the european union. The European Journal of Health Economics, formerly: HEPAC, 5(2):150-165, 2004.

S. Kumbhakar and R. Zhang. Labor-use efficiency and employment elasticity in chinese manufacturing. Economia e Politica Industriale, 2013.

S. C. Kumbhakar, Z. Guan, and A. G. Oude Lansink. Excess Capital in Agricultural Production. Technical report, 2007.

L. Kwietniewski, M. Heimeshoff, and J. Schreyögg. Estimation of a physician practice cost function. The European Journal of Health Economics, 18(4):481-494, 2017.

C. O. M. Laurence and J. Karnon. Improving the planning of the gp workforce in australia: a simulation model incorporating work transitions, health need and service usage. Human resources for health, 14:13, 2016.

J. Lipscomb, K. E. Kilpatrick, K. L. Lee, and K. S. Pieper. Determining va physician requirements through empirically based models. Health services research, 29(6):697, 1995. 
J. Lipscomb, G. Parmigiani, and V. Hasselblad. Combining expert judgment by hierarchical modeling: an application to physician staffing. Management Science, 44(2):149-161, 1998.

M. A. Lopes, Á. S. Almeida, and B. Almada-Lobo. Handling healthcare workforce planning with care: where do we stand? Human Resources for Health, 13(1):38, May 2015. ISSN 1478-4491.

MOH. National health plan 2004-2010, volume i - priorities. Ministry Of Health, 2004.

M. A. Murphy GT, Birch S. Needs-based health human resources planning: The challenge of linking needs to provider requirements. Can Nurses Assoc Can Med Assoc., pages $1-31,2007$.

B. Nolan. The provision and use of health services, health inequalities and health and social gain. ESRI, 2007.

OECD. Health at a glance 2017: Oecd indicators. Ministry Of Health, 2018.

K. R. Olsen, D. Gyrd-Hansen, T. H. Sørensen, T. Kristensen, P. Vedsted, and A. Street. Organisational determinants of production and efficiency in general practice: a populationbased study. The European Journal of Health Economics, 14(2):267-276, 2013.

T. Ono, G. Lafortune, and M. Schoenstein. Health workforce planning in oecd countries. 2013.

L. O'Brien-Pallas, A. Baumann, G. Donner, G. T. Murphy, J. Lochhaas-Gerlach, and M. Luba. Forecasting models for human resources in health care. Journal of Advanced Nursing, 33(1):120-129, 2001.

K. Pourmohammadi, N. Hatam, P. Bastani, and F. Lotfi. Estimating production function: a tool for hospital resource management. Shiraz E-Medical Journal, 15(4), 2014.

D. Roberfroid, C. Leonard, and S. Stordeur. Physician supply forecast: better than peering in a crystal ball? Human Resources for Health, 7(1):10, Feb 2009. ISSN 1478-4491. 
F. R. Santías, C. Cadarso-Suárez, and M. X. Rodríguez-Álvarez. Estimating hospital production functions through flexible regression models. Mathematical and Computer Modelling, 54(7-8):1760-1764, 2011.

R. M. Scheffler, J. Campbell, G. Cometto, A. Maeda, J. Liu, T. A. Bruckner, D. R. Arnold, and T. Evans. Forecasting imbalances in the global health labor market and devising policy responses. Human resources for health, 16(1):5, 2018.

S. Singh, S. Upadhyaya, P. R. Deshmukh, A. R. Dongre, N. Dwivedi, D. K. Dey, and V. Kumar. Time motion study using mixed methods to assess service delivery by frontline health workers from south india: methods. In Human resources for health, 2018.

WHO. Workload indicators of staffing need (wisn) - user manual. World Health Organization., 1999.

WHO. Health systems: Improving perfomance. world heal rep. World Health Organization., 2000a.

WHO. World health organization. models and tools for health workforce planning and projections. world heal rep. World Health Organization., $2000 \mathrm{~b}$.

P. Zurn, M. R. Dal Poz, B. Stilwell, and O. Adams. Imbalance in the health workforce. Human resources for health, 2(1):13, 2004.

\section{Appendix 3.A Supplementary material}

\section{Model for surgical specialties}

$$
\begin{aligned}
& \ln \left(P H Y_{i t}\right)= \\
& \alpha_{0}+\alpha_{1} \ln \left(O U T_{i, t}\right)+\alpha_{2} \ln \left(I N P_{i, t}\right)+\alpha_{3} \ln \left(S U R_{i, t}\right)+\beta_{1} \ln \left(R O O_{i, t}\right)+ \\
& \frac{1}{2} \gamma_{1,1} \ln \left(R O O_{i, t}\right) * \ln \left(O U T_{i, t}\right)+\frac{1}{2} \gamma_{1,2} \ln \left(R O O_{i, t}\right) * \ln \left(I N P_{i, t}\right)+\frac{1}{2} \gamma_{1,3} \ln \left(R O O_{i, t}\right) * \ln \left(S U R_{i, t}\right)+ \\
& \frac{1}{2} \alpha_{1,2} \ln \left(O U T_{i, t}\right) * \ln \left(I N P_{i, t}\right)+\frac{1}{2} \alpha_{1,3} \ln \left(O U T_{i, t}\right) * \ln \left(S U R_{i, t}\right)+\frac{1}{2} \alpha_{2,3} \ln \left(I N P_{i, t}\right) * \ln \left(S U R_{i, t}\right)+
\end{aligned}
$$




$$
\frac{1}{2} \alpha_{1,1}\left[\ln \left(O U T_{i, t}\right)\right]^{2}+\frac{1}{2} \alpha_{2,2}\left[\ln \left(I N P_{i, t}\right)\right]^{2}+\frac{1}{2} \alpha_{3,3}\left[\ln \left(S U R_{i, t}\right)\right]^{2}+\frac{1}{2} \beta_{1,1}\left[\ln \left(R O O_{i, t}\right)\right]^{2}+\delta_{t}+\mu_{i, t}
$$

\section{Model for medical specialties}

$$
\begin{aligned}
& \ln \left(\text { PHY }_{i t}\right)= \\
& \alpha_{0}+\alpha_{1} \ln \left(O U T_{i, t}\right)+\alpha_{2} \ln \left(I N P_{i, t}\right)+\beta_{1} \ln \left(R O O_{i, t}\right)+ \\
& \frac{1}{2} \gamma_{1,1} \ln \left(\text { ROO }_{i, t}\right) * \ln \left(O U T_{i, t}\right)+\frac{1}{2} \gamma_{1,2} \ln \left(R O O_{i, t}\right) * \ln \left(I N P_{i, t}\right)+\frac{1}{2} \alpha_{1,2} \ln \left(O U T_{i, t}\right) * \ln \left(I N P_{i, t}\right)+ \\
& \frac{1}{2} \alpha_{1,1}\left[\ln \left(O U T_{i, t}\right)\right]^{2}+\frac{1}{2} \alpha_{2,2}\left[\ln \left(I N P_{i, t}\right)\right]^{2}+\frac{1}{2} \beta_{1,1}\left[\ln \left(R O O_{i, t}\right)\right]^{2}+\delta_{t}+\mu_{i, t}
\end{aligned}
$$

\section{Model for medical specialties}

$$
\begin{aligned}
& \ln \left(P H Y_{i t}\right)= \\
& \alpha_{0}+\alpha_{1} \ln \left(D I A_{i, t}\right)+\beta_{1} \ln \left(R O O_{i, t}\right)+\frac{1}{2} \gamma_{1,1} \ln \left(R O O_{i, t}\right) * \ln \left(D I A_{i, t}\right)+ \\
& \frac{1}{2} \alpha_{1,1}\left[\ln \left(D I A_{i, t}\right)\right]^{2}+\frac{1}{2} \beta_{1,1}\left[\ln \left(R O O_{i, t}\right)\right]^{2}+\delta_{t}+\mu_{i, t}
\end{aligned}
$$

where PHY is the number of physicians, ROO is the number of rooms (consultation rooms, operating rooms and yards), OUT is the number of outpatient visits, INP is the number of inpatient discharges, SUR is the number of surgeries, DIA is the number of diagnostic and therapeutic procedures, $\delta$ stands for a set of binary year variables (each multiplied by their respective regression coefficients ), $\mu$ represents the error term of the model, $i$ the index for the hospital and $t$ the index for the period.

\section{Elasticity of mean labor used in the production of output $Y_{i}$}

$$
E_{i}=\frac{\partial \ln (L)}{\partial \ln \left(Y_{i}\right)}=\alpha_{i}+\frac{1}{2} \sum_{j=1}^{n} \alpha_{i, j} \ln \left(Y_{j}\right)+\sum_{k=1}^{m} \gamma_{i, k} \ln \left(K_{k}\right)
$$




\section{Marginal Rate of Technical Substitution between two HS, $i$ and $j$}

$$
\operatorname{MRTS}_{i, j}=\frac{E_{i}}{E_{j}}
$$

\section{Returns to scale (RTS) of labor}

$$
R T S=\left(\sum_{i=1}^{n} E_{i}\right)^{-1}
$$

\section{Original model for surgical specialties}

$$
\begin{aligned}
& \ln \left(P H Y_{i t}\right)= \\
& \alpha_{0}+\alpha_{1} \ln \left(O U T_{i, t}\right)+\alpha_{2} \ln \left(I N P_{i, t}\right)+\alpha_{3} \ln \left(S U R_{i, t}\right)+ \\
& \beta_{1} \ln \left(R O O_{i, t}\right)+\beta_{2} \ln \left(N U R_{i, t}\right)+\beta_{3} \ln \left(R E S_{i, t}\right)+\beta_{4} \ln \left(O T H_{i, t}\right)+\beta_{5} \ln \left(B E D_{i, t}\right)+ \\
& \frac{1}{2} \gamma_{1,2} \ln \left(R O O_{i, t}\right) * \ln \left(I N P_{i, t}\right)+\frac{1}{2} \gamma_{2,2} \ln \left(N U R_{i, t}\right) * \ln \left(I N P_{i, t}\right)+\frac{1}{2} \gamma_{3,2} \ln \left(R E S_{i, t}\right) * \ln \left(I N P_{i, t}\right)+ \\
& \frac{1}{2} \gamma_{4,2} \ln \left(O T H_{i, t}\right) * \ln \left(I N P_{i, t}\right)+\frac{1}{2} \gamma_{5,2} \ln \left(B E D_{i, t}\right) * \ln \left(I N P_{i, t}\right)+\frac{1}{2} \gamma_{1,1} \ln \left(R O O_{i, t}\right) * \ln \left(O U T_{i, t}\right)+ \\
& \frac{1}{2} \gamma_{2,1} \ln \left(N U R_{i, t}\right) * \ln \left(O U T_{i, t}\right)+\frac{1}{2} \gamma_{3,1} \ln \left(R E S_{i, t}\right) * \ln \left(O U T_{i, t}\right)+\frac{1}{2} \gamma_{4,1} \ln \left(O T H_{i, t}\right) * \ln \left(O U T_{i, t}\right)+ \\
& \frac{1}{2} \gamma_{5,1} \ln \left(B E D_{i, t}\right) * \ln \left(O U T_{i, t}\right)+\frac{1}{2} \gamma_{1,3} \ln \left(R O O_{i, t}\right) * \ln \left(S U R_{i, t}\right)+\frac{1}{2} \gamma_{2,3} \ln \left(N U R_{i, t}\right) * \ln \left(S U R_{i, t}\right)+ \\
& \frac{1}{2} \gamma_{3,3} \ln \left(R E S_{i, t}\right) * \ln \left(S U R_{i, t}\right)+\frac{1}{2} \gamma_{4,3} \ln \left(O T H_{i, t}\right) * \ln \left(S U R_{i, t}\right)+\frac{1}{2} \gamma_{5,3} \ln \left(B E D_{i, t}\right) * \ln \left(S U R_{i, t}\right)+ \\
& \frac{1}{2} \alpha_{1,2} \ln \left(O U T_{i, t}\right) * \ln \left(I N P_{i, t}\right)+\frac{1}{2} \alpha_{1,3} \ln \left(O U T_{i, t}\right) * \ln \left(S U R_{i, t}\right)+\frac{1}{2} \alpha_{2,3} \ln \left(I N P_{i, t}\right) * \ln \left(S U R_{i, t}\right)+ \\
& \frac{1}{2} \beta_{1,2} \ln \left(R O O_{i, t}\right) * \ln \left(N U R_{i, t}\right)+\frac{1}{2} \beta_{1,3} \ln \left(R O O_{i, t}\right) * \ln \left(R E S_{i, t}\right)+\frac{1}{2} \beta_{1,4} \ln \left(R O O_{i, t}\right) * \ln \left(O T H_{i, t}\right)+ \\
& \frac{1}{2} \beta_{1,5} \ln \left(R O O_{i, t}\right) * \ln \left(B E D_{i, t}\right)+\frac{1}{2} \beta_{2,3} \ln \left(N U R_{i, t}\right) * \ln \left(R E S_{i, t}\right)+\frac{1}{2} \beta_{2,4} \ln \left(N U R_{i, t}\right) * \ln \left(O T H_{i, t}\right)+ \\
& \frac{1}{2} \beta_{2,5} \ln \left(N U R_{i, t}\right) * \ln \left(B E D_{i, t}\right)+\frac{1}{2} \beta_{3,4} \ln \left(R E S_{i, t}\right) * \ln \left(O T H_{i, t}\right)+\frac{1}{2} \beta_{3,5} \ln \left(R E S_{i, t}\right) * \ln \left(B E D_{i, t}\right)+ \\
& \frac{1}{2} \beta_{4,5} \ln \left(O T H_{i, t}\right) * \ln \left(B E D_{i, t}\right)+\frac{1}{2} \alpha_{1,1}\left[\ln \left(O U T_{i, t}\right)\right]^{2}+\frac{1}{2} \alpha_{2,2}\left[\ln \left(I N P_{i, t}\right)\right]^{2}+\frac{1}{2} \alpha_{3,3}\left[\ln \left(S U R_{i, t}\right)\right]^{2}+ \\
& \frac{1}{2} \beta_{1,1}\left[\ln \left(R O O_{i, t}\right)\right]^{2}+\frac{1}{2} \beta_{2,2}\left[\ln \left(I N P_{i, t}\right)\right]^{2}+\frac{1}{2} \beta_{3,3}\left[\ln \left(R E S_{i, t}\right)\right]^{2}+\frac{1}{2} \beta_{4,4}\left[\ln \left(O T H_{i, t}\right)\right]^{2}+ \\
& \frac{1}{2} \beta_{5,5}\left[\ln \left(B E D_{i, t}\right)\right]^{2}+\delta_{t}+\mu_{i, t}
\end{aligned}
$$




\section{Original model for medical specialties}

$$
\begin{aligned}
& \ln \left(\text { PHY }_{i t}\right)= \\
& \alpha_{0}+\alpha_{1} \ln \left(O U T_{i, t}\right)+\alpha_{2} \ln \left(I N P_{i, t}\right)+ \\
& \beta_{1} \ln \left(R O O_{i, t}\right)+\beta_{2} \ln \left(N U R_{i, t}\right)+\beta_{3} \ln \left(R E S_{i, t}\right)+\beta_{4} \ln \left(O T H_{i, t}\right)+\beta_{5} \ln \left(B E D_{i, t}\right)+ \\
& \frac{1}{2} \gamma_{1,2} \ln \left(R O O_{i, t}\right) * \ln \left(I N P_{i, t}\right)+\frac{1}{2} \gamma_{2,2} \ln \left(N U R_{i, t}\right) * \ln \left(I N P_{i, t}\right)+\frac{1}{2} \gamma_{3,2} \ln \left(R E S_{i, t}\right) * \ln \left(I N P_{i, t}\right)+ \\
& \frac{1}{2} \gamma_{4,2} \ln \left(O T H_{i, t}\right) * \ln \left(I N P_{i, t}\right)+\frac{1}{2} \gamma_{5,2} \ln \left(B E D_{i, t}\right) * \ln \left(I N P_{i, t}\right)+\frac{1}{2} \gamma_{1,1} \ln \left(R O O_{i, t}\right) * \ln \left(O U T_{i, t}\right)+ \\
& \frac{1}{2} \gamma_{2,1} \ln \left(N U R_{i, t}\right) * \ln \left(O U T_{i, t}\right)+\frac{1}{2} \gamma_{3,1} \ln \left(R E S_{i, t}\right) * \ln \left(O U T_{i, t}\right)+\frac{1}{2} \gamma_{4,1} \ln \left(O T H_{i, t}\right) * \ln \left(O U T_{i, t}\right)+ \\
& \frac{1}{2} \gamma_{5,1} \ln \left(B E D_{i, t}\right) * \ln \left(O U T_{i, t}\right)+\frac{1}{2} \alpha_{1,2} \ln \left(O U T_{i, t}\right) * \ln \left(I N P_{i, t}\right)+\frac{1}{2} \beta_{1,2} \ln \left(R O O_{i, t}\right) * \ln \left(N U R_{i, t}\right)+ \\
& \frac{1}{2} \beta_{1,3} \ln \left(R O O_{i, t}\right) * \ln \left(R E S_{i, t}\right)+\frac{1}{2} \beta_{1,4} \ln \left(R O O_{i, t}\right) * \ln \left(O T H_{i, t}\right)+\frac{1}{2} \beta_{1,5} \ln \left(R O O_{i, t}\right) * \ln \left(B E D_{i, t}\right)+ \\
& \frac{1}{2} \beta_{2,3} \ln \left(N U R_{i, t}\right) * \ln \left(R E S_{i, t}\right)+\frac{1}{2} \beta_{2,4} \ln \left(N U R_{i, t}\right) * \ln \left(O T H_{i, t}\right)+\frac{1}{2} \beta_{2,5} \ln \left(N U R_{i, t}\right) * \ln \left(B E D_{i, t}\right)+ \\
& \frac{1}{2} \beta_{3,4} \ln \left(R E S_{i, t}\right) * \ln \left(O T H_{i, t}\right)+\frac{1}{2} \beta_{3,5} \ln \left(R E S_{i, t}\right) * \ln \left(B E D_{i, t}\right)+\frac{1}{2} \beta_{4,5} \ln \left(O T H_{i, t}\right) * \ln \left(B E D_{i, t}\right)+ \\
& \frac{1}{2} \alpha_{1,1}\left[\ln \left(O U T_{i, t}\right)\right]^{2}+\frac{1}{2} \alpha_{2,2}\left[\ln \left(I N P_{i, t}\right)\right]^{2}+\frac{1}{2} \beta_{1,1}\left[\ln \left(R O O_{i, t}\right)\right]^{2}+\frac{1}{2} \beta_{2,2}\left[\ln \left(I N P_{i, t}\right)\right]^{2}+ \\
& \frac{1}{2} \beta_{3,3}\left[\ln \left(R E S_{i, t}\right)\right]^{2}+\frac{1}{2} \beta_{4,4}\left[\ln \left(O T H_{i, t}\right)\right]^{2}+\frac{1}{2} \beta_{5,5}\left[\ln \left(B E D_{i, t}\right)\right]^{2}+\delta_{t}+\mu_{i, t}
\end{aligned}
$$

\section{Original model for diagnostic specialties}

$\ln \left(P H Y_{i t}\right)=$

$\alpha_{0}+\alpha_{1} \ln \left(D I A_{i, t}\right)+\beta_{1} \ln \left(R O O_{i, t}\right)+\beta_{2} \ln \left(N U R_{i, t}\right)+\beta_{3} \ln \left(R E S_{i, t}\right)+\beta_{4} \ln \left(O T H_{i, t}\right)+\beta_{5} \ln \left(B E D_{i, t}\right)+$ $\frac{1}{2} \gamma_{1,1} \ln \left(R O O_{i, t}\right) * \ln \left(D I A_{i, t}\right)+\frac{1}{2} \gamma_{2,1} \ln \left(N U R_{i, t}\right) * \ln \left(D I A_{i, t}\right)+\frac{1}{2} \gamma_{3,1} \ln \left(R E S_{i, t}\right) * \ln \left(D I A_{i, t}\right)+$ $\frac{1}{2} \gamma_{4,1} \ln \left(O T H_{i, t}\right) * \ln \left(D I A_{i, t}\right)+\frac{1}{2} \gamma_{5,1} \ln \left(B E D_{i, t}\right) * \ln \left(D I A_{i, t}\right)+\frac{1}{2} \beta_{1,2} \ln \left(R O O_{i, t}\right) * \ln \left(N U R_{i, t}\right)+$ $\frac{1}{2} \beta_{1,3} \ln \left(R O O_{i, t}\right) * \ln \left(R E S_{i, t}\right)+\frac{1}{2} \beta_{1,4} \ln \left(R O O_{i, t}\right) * \ln \left(O T H_{i, t}\right)+\frac{1}{2} \beta_{1,5} \ln \left(R O O_{i, t}\right) * \ln \left(B E D_{i, t}\right)+$ $\frac{1}{2} \beta_{2,3} \ln \left(N U R_{i, t}\right) * \ln \left(R E S_{i, t}\right)+\frac{1}{2} \beta_{2,4} \ln \left(N U R_{i, t}\right) * \ln \left(O T H_{i, t}\right)+\frac{1}{2} \beta_{2,5} \ln \left(N U R_{i, t}\right) * \ln \left(B E D_{i, t}\right)+$ $\frac{1}{2} \beta_{3,4} \ln \left(R E S_{i, t}\right) * \ln \left(O T H_{i, t}\right)+\frac{1}{2} \beta_{3,5} \ln \left(R E S_{i, t}\right) * \ln \left(B E D_{i, t}\right)+\frac{1}{2} \beta_{4,5} \ln \left(O T H_{i, t}\right) * \ln \left(B E D_{i, t}\right)+$ $\frac{1}{2} \alpha_{1,1}\left[\ln \left(D I A_{i, t}\right)\right]^{2}+\frac{1}{2} \beta_{1,1}\left[\ln \left(R O O_{i, t}\right)\right]^{2}+\frac{1}{2} \beta_{2,2}\left[\ln \left(I N P_{i, t}\right)\right]^{2}+\frac{1}{2} \beta_{3,3}\left[\ln \left(R E S_{i, t}\right)\right]^{2}+$ 


$$
\frac{1}{2} \beta_{4,4}\left[\ln \left(O T H_{i, t}\right)\right]^{2}+\frac{1}{2} \beta_{5,5}\left[\ln \left(B E D_{i, t}\right)\right]^{2}+\delta_{t}+\mu_{i, t}
$$

where PHY is the number of physicians, ROO is the number of rooms (consultation rooms, operating rooms and yards), OUT is the number of outpatient visits, INP is the number of inpatient discharges, SUR is the number of surgeries, DIA is the number of diagnostic and therapeutic procedures, NUR is the number of nurses, RES is the number of residents, OTH is the number of other health professionals, BED is the number of inpatient beds, $\delta$ stands for a set of binary year variables (each multiplied by their respective regression coefficients ), $\mu$ represents the error term of the model, $i$ the index for the hospital and $t$ the index for the period. 
Table 3.4 - Mean-values of the explanatory variables

\begin{tabular}{cccccccccc}
\hline \multicolumn{9}{c}{ General Surgery } & \multicolumn{3}{c}{ Internal Medicine } & \multicolumn{2}{c}{ Anatomical Pathology } \\
\hline & $\ln ($ OUT) & $\ln ($ INP) & $\ln ($ ROO) & $\ln ($ SUR) & $\ln ($ OUT) & $\ln ($ INP) & $\ln ($ ROO) & $\ln ($ ROO) & $\ln$ (DIA) \\
\hline 1999 & 8,4345 & 7,1038 & 3,043 & 6,7608 & 7,8646 & 6,7161 & 3,0897 & 3,1354 & 9,5373 \\
\hline 2000 & 8,4563 & 7,0084 & 3,1013 & 6,7665 & 7,918 & 6,6306 & 3,1521 & 3,2272 & 9,4974 \\
\hline 2001 & 8,4919 & 7,0963 & 3,1747 & 7,0002 & 8,0159 & 6,6953 & 3,1775 & 3,2619 & 9,7862 \\
\hline 2002 & 8,6056 & 7,0482 & 3,1973 & 6,9668 & 8,01 & 6,376 & 3,2167 & 3,2735 & 9,8368 \\
\hline 2003 & 8,6948 & 6,9923 & 3,2791 & 7,003 & 8,135 & 6,5051 & 3,3342 & 3,3491 & 9,9767 \\
\hline 2004 & 8,734 & 6,9157 & 3,3155 & 6,8591 & 8,1316 & 6,3258 & 3,3429 & 3,3512 & 10,0052 \\
\hline 2005 & 8,7682 & 6,9681 & 3,3735 & 6,9719 & 8,1292 & 6,2844 & 3,4122 & 3,4139 & 10,1535 \\
\hline 2006 & 8,8815 & 7,0998 & 3,5047 & 7,1353 & 8,3178 & 6,3643 & 3,5685 & 3,4299 & 9,8348 \\
\hline 2007 & 8,7428 & 7,0522 & 3,631 & 7,0845 & 8,1896 & 6,1215 & 3,6134 & 3,5786 & 9,8766 \\
\hline 2008 & 8,9849 & 6,9167 & 3,6898 & 7,1161 & 8,3374 & 6,3192 & 3,6592 & 3,7287 & 10,0313 \\
\hline 2009 & 8,9459 & 6,9581 & 3,7896 & 7,3472 & 8,4628 & 6,2519 & 3,7745 & 3,7523 & 10,1977 \\
\hline 2010 & 8,6552 & 6,7738 & 3,5017 & 7,01 & 8,1541 & 5,9558 & 3,3844 & 3,5639 & 10,0988 \\
\hline $1999-2010$ & 8,6859 & 6,9973 & 3,3612 & 6,9885 & 8,1252 & 6,389 & 3,3757 & 3,4074 & 9,8925 \\
\hline
\end{tabular}

Table 3.5 - Correlation Matrix

\begin{tabular}{|c|c|c|c|c|c|c|c|c|c|c|c|c|c|c|c|c|}
\hline & BEDS & BEDS GS & BEDS IM & ROO & $\begin{array}{c}\text { PHY } \\
\text { AP }\end{array}$ & $\begin{array}{c}\text { PHY } \\
\text { GS }\end{array}$ & $\begin{array}{c}\text { PHY } \\
\text { IM }\end{array}$ & RES & NUR & OTH & $\begin{array}{l}\text { INP } \\
\text { GS }\end{array}$ & $\begin{array}{l}\text { INP } \\
\text { IM }\end{array}$ & $\begin{array}{c}\text { OUT } \\
\text { GS }\end{array}$ & $\begin{array}{c}\text { OUT } \\
\text { IM }\end{array}$ & $\begin{array}{c}\text { SUR } \\
\text { GS }\end{array}$ & $\begin{array}{l}\text { DIA } \\
\text { AP } \\
\end{array}$ \\
\hline BEDS & 1 & & & & & & & & & & & & & & & \\
\hline BEDS GS & 0,927 & 1 & & & & & & & & & & & & & & \\
\hline BEDS IM & 0,849 & 0,885 & 1 & & & & & & & & & & & & & \\
\hline ROO & 0,902 & 0,784 & 0,705 & 1 & & & & & & & & & & & & \\
\hline PHY AP & 0,697 & 0,652 & 0,649 & 0,793 & 1 & & & & & & & & & & & \\
\hline PHY GS & 0,799 & 0,843 & 0,824 & 0,79 & 0,754 & 1 & & & & & & & & & & \\
\hline PHY IM & 0,772 & 0,785 & 0,856 & 0,751 & 0,693 & 0,786 & 1 & & & & & & & & & \\
\hline RES & 0,826 & 0,764 & 0,712 & 0,941 & 0,783 & 0,785 & 0,773 & 1 & & & & & & & & \\
\hline NUR & 0,882 & 0,826 & 0,766 & 0,921 & 0,715 & 0,804 & 0,769 & 0,831 & 1 & & & & & & & \\
\hline OTH & 0,87 & 0,813 & 0,771 & 0,927 & 0,772 & 0,835 & 0,806 & 0,844 & 0,89 & 1 & & & & & & \\
\hline INP GS & 0,817 & 0,948 & 0,854 & 0,705 & 0,567 & 0,838 & 0,783 & 0,686 & 0,77 & 0,752 & 1 & & & & & \\
\hline INP IM & 0,781 & 0,817 & 0,954 & 0,641 & 0,522 & 0,78 & 0,728 & 0,675 & 0,736 & 0,72 & 0,763 & 1 & & & & \\
\hline OUT GS & 0,737 & 0,784 & 0,833 & 0,74 & 0,636 & 0,822 & 0,786 & 0,672 & 0,727 & 0,732 & 0,718 & 0,736 & 1 & & & \\
\hline OUT IM & 0,691 & 0,726 & 0,74 & 0,702 & 0,536 & 0,697 & 0,731 & 0,655 & 0,697 & 0,685 & 0,732 & 0,7 & 0,721 & 1 & & \\
\hline SUR GS & 0,811 & 0,795 & 0,775 & 0,774 & 0,664 & 0,829 & 0,761 & 0,722 & 0,753 & 0,763 & 0,786 & 0,727 & 0,768 & 0,736 & 1 & \\
\hline DIA AP & 0,465 & 0,431 & 0,417 & 0,517 & 0,575 & 0,495 & 0,479 & 0,492 & 0,477 & 0,514 & 0,407 & 0,39 & 0,435 & 0,32 & 0,448 & 1 \\
\hline
\end{tabular}

Table 3.6 - Fixed effects estimates

\begin{tabular}{ccc}
\hline Year & \multicolumn{2}{c}{ Fixed Effects } \\
\hline & General surgery & Internal Medicine \\
\hline 1999 & 0,1548 & 0,0904 \\
2000 & 0,1413 & 0,0719 \\
2001 & 0,096 & 0,074 \\
2002 & 0,0759 & 0,0129 \\
2003 & 0,0053 & 0,0056 \\
2004 & $-0,0121$ & 0,0074 \\
2005 & $-0,0576$ & $-0,0352$ \\
2006 & $-0,0604$ & $-0,0489$ \\
2007 & $-0,1014$ & $-0,0552$ \\
2008 & $-0,097$ & $-0,063$ \\
2009 & $-0,155$ & $-0,0658$ \\
2010 & $-0,0803$ & $-0,0416$ \\
\hline
\end{tabular}





\title{
Health Expenditures
}

\section{Health Expenditures in OECD countries: An Econo- metric Analysis}

\author{
Sofia Cruz-Gomes* · Mário Amorim-Lopes* · Bernardo Almada-Lobo*
}

Submitted to Health Economics, 2019

\begin{abstract}
Rising health expenditures and uncertainty about whether there will be enough resources to deliver the demanded services in the future have been calling the attention of health researchers, managers, and policy-makers. Applied econometric studies of health expenditures have recently proliferated in the health economics literature. The research community is now faced with a large body of knowledge that, mainly due to the rapid development of econometric techniques, is characterized by an enormous diversity regarding the econometric approach, the drivers considered and the results about their impact on the trajectory of health expenditures. The majority of the studies are based on single-model approaches, which are known not to deliver consistent results, even if applied to the same datasets. Therefore, we question the suitability of those models, exposing the differences and similarities, and comparing the results of different approaches pointed out in recent works as appropriate for studying health expenditures. We rely on a long and recent (19802014) panel on 34 OECD countries to investigate the long-run relationship between health expenditures and the main determinants of health expenditures identified in the literature,

\footnotetext{
*INESC TEC, Faculdade de Engenharia, Universidade do Porto, Rua Dr. Roberto Frias, 4200-465, Porto, Portugal
} 
both from the supply- (technology and human resources) and the demand-side (economic, demographic and health-related factors). Results show that distinct econometric models and techniques lead to different conclusions about the effect of the considered determinants on health expenditures. Thus, this paper also provides a framework and guidelines for the adequate selection of the methodological approach according to the characteristics of the data, such as non-stationarity, heterogeneity or cross-section dependence, which is crucial for accurately understanding the relevance of each driver to health expenditures.

Keywords health expenditure $\cdot$ panel $\cdot$ determinants $\cdot$ econometric $\cdot$ OECD

\subsection{Introduction}

The enhanced living conditions and the advances in medical science that occurred in the past decades led to significant improvements in health and longevity. However, together with this achievement came several changes that are raising global health and economic concerns about the future demand and delivery of healthcare. One of the most critical matters, which has been calling the attention of health researchers, managers and governments is the rising health expenditures over time and the uncertainty about whether there will be enough resources to deliver the demanded services in the future. A better understanding of the health expenditures determinants - allowing for accurate planning that can help to ensure that health systems can continue to provide quality and timely healthcare services and to contribute to healthy populations sustainably - is of major importance. So far, most of the literature has been dedicated to studying the relationship between income and health expenditures. However, some empirical studies have also focused on other supply- and demand-side explanations for the growth of health care expenditure, such as the aging of the population and the technological progress, which were found to be relevant to the health expenditures evolution (Dreger and Reimers, 2005; Tian et al., 2018; Okunade et al., 2018). Moreover, the problem has been addressed through the use of a wide range of different and 
continually evolving methods. In every case they are presented as the most adequate but do not necessarily lead to the same results and conclusions regarding the effect of individual factors in the health expenditure, even if applied to the same datasets.

This paper comes forth as an attempt to show that despite the undeniable interest of the topic and the growing number of studies devoted to understand and explain the evolution of health expenditures, no consensus has been attained in the literature, neither regarding the factors driving the health expenditures, nor from the point of view of the methodological approaches to be used.

Using a long and recent (1980-2014) panel data on 34 Organization for Economic Cooperation and Development (OECD) countries, we investigate the long-run relationship and the short-run adjustments between health expenditures and the main factors identified in the literature as relevant drivers, both from the supply- (considering technology and human resources) and from the demand-side (including economic, demographic and health-related factors). Moreover, we seek to improve the understanding of the existent body of knowledge by going beyond the prevailing single-model approach, questioning the suitability, exposing the main differences and similarities, and comparing the results of several different models. The models considered in this comparison are the most recommended for the analysis of panels with the characteristics of health expenditures in OECD countries and the ones that have been recently used in the field: the Dynamic Ordinary Least Squares (DOLS), the Fully Modified Ordinary Least Squares (FMOLS), the Auto-regressive Distributed Lag (ARDL) and the Dynamic Common Correlated Effects (DCCE). Moreover, we also aim to provide guidelines for the selection of the most adequate methodological approach for a given setting, depending on some of the characteristics of the data.

The questions we seek to answer in this study, among others, include: 1) accounting for the characteristics of the data, which are the most suitable models for detecting the existence of long-run relationships among health care spending and its determinants?; 2) what are the main differences and similarities between them? Do they lead to similar results and conclusions?; 3) out of the main supply- and demand-side drivers of healthcare expenditures identified in the literature, which are the most significant for OECD countries? And 
what are the shapes of long- and short-run relationships among health care expenditures and these drivers?

The remainder of this paper is organized as follows. Section 2, which is subdivided into two subsections - methodological approaches, and determinants of health expenditures -, reviews the related literature. Section 3 describes the dataset, and Section 4 provides the methodological approach. In Section 5, the empirical results are presented and discussed, and a panel framework selection is proposed. Finally, Section 6 concludes.

\subsection{Background}

Studies aiming to provide a better understanding of the determinants of health expenditure urged from the rising interest in perceiving the main factors causing the rapid increase in health expenditures in many developed countries since the 1960s (WHO, 2015). Since then, a large amount of health expenditures literature has been produced and is still one of the leading research topics in health economics. The contributions arising from the efforts made on explaining health expenditures behavior can generally be grouped in two different types: 1) the ones improving the knowledge on the effect of the key drivers on health expenditures; 2) the ones providing new insights or applications of the methodological approaches available to study the problem. The literature on each of these types was reviewed to construct an overall view of the field and frame the gaps which this study aims to fill.

\subsubsection{Methodological approaches}

The substantial differences in health expenditures across countries, even among the relatively homogeneous industrialized market economies, such as the OECD countries, lead to the interest in approaching this issue through international comparisons of health expenditures (Culyer and Newhouse, 2000). The vast literature on health expenditures can be grouped into three different generations of studies, regarding the core methodology used to approach the problem: cross-sectional regressions, panel data studies, and unit root and cointegration analyses (Atella and Marini, 2006). More recently, the third generation of 
methodological approaches to health expenditures has also been trying to incorporate the concerns on how to deal with dynamic heterogeneous relationships and cross-section dependence.

\subsubsection{First Generation: Cross-section regressions}

The early international comparisons used cross-sectional data to examine the within-country determinants of health expenditures (Getzen and Poullier, 1992). The first studies were based on bivariate analyses aiming to explore the relationship between income and health expenditures (Newhouse, 1987; Parkin et al., 1987). Later, the bivariable cross-section regressions gave place to multivariable analyses, considering other potentially relevant factors to explain health expenditure and introducing new explanatory variables in the health expenditures models, such as the share of the population over 65 years, the number of physicians or the ratio between public and total health expenditure (Gerdtham et al., 1992; Leu, 1986). These later approaches dominated the literature until the early ' 90 s, when they started to be criticized mainly due to the inherent limitations of cross-sectional models, such as the small sample sizes; the study of only contemporaneous relations, which may underestimate the strength of the relationship between health expenditures and its drivers; and the omission of the country- and time-invariant effects, which can generate inconsistent estimates. These critics were addressed by a generation of panel studies (Gerdtham, 1992; Gerdtham et al., 1998) considering more extended time-series for each country and including time- or country-specific effects.

\subsubsection{Second Generation: Panel Data analyses}

Since the early '90s, the literature devoted to the study of the determinants of health expenditure has combinined time-series with cross-section data in panel analyses, in order to overcome some of the issues above mentioned. The use of panel data brings many advantages: grants larger sample size and hence more powerful significance tests; allows for the analysis of dynamic properties in the relationships between health expenditures and its drivers; enables the possibility to relax the assumption of homogeneous relationships 
across units; and makes possible the inclusion of sections- and time-specific effects facilitating the control for the presence of mis-measured or unobserved variables correlated with the explanatory variables (Culyer and Newhouse, 2000).

Nonetheless, some of the difficulties remained, and the first panel approaches to health expenditures were also criticized, mostly for disregarding that variables could be nonstationary, which violates a fundamental assumption of Ordinary Least Squares (OLS) estimation and leads to the identification of spurious relations between health expenditures and its determinants (Phillips, 1986; Engle and Granger, 1987). More recent studies have applied econometric time-series techniques to overcome these methodological issues, considering the possibility of non-stationarity and cointegration between the health expenditures and its drivers (Murthy and Ukpolo, 1994; Hansen and King, 1996; Blomqvist and Carter, 1997).

\subsubsection{Third Generation: Unit roots and cointegration analyses}

Accounting for the possible non-stationarity of the data has been generally recognized as fundamental for achieving unbiased estimates and, therefore, reliable results when studying the relationship between health expenditures and its drivers. Non-stationarity introduces the issue of determining whether there is a long-run equilibrium between health expenditure and its drivers: if time-series are integrated and there is a linear combination of them that is itself stationary, the variables are cointegrated (i.e., there is a long-run relationship between them that can be specified in levels, and short-run dynamics that can be modeled via an error correction process (Moscone and Tosetti, 2010)).

Over time, we observed a shift of the research focus from more theoretical questions such as "Which are the main factors driving health expenditures" or "Is health a luxury good?" to more methodological questions, such as "Is there cointegration between health expenditure and its drivers?" (Atella and Marini, 2006). Since the early 2000s, several studies applying unit root and cointegration tests emerged in the literature of health expenditures (Gerdtham and Löthgren, 2000; Okunade and Karakus, 2001; i Silvestre, 2005). Overall, the literature does not show a clear pattern arising from time-series and panel studies, regarding the 
stationarity and cointegration of health expenditures and its determinants. Results are not unanimous and the main reasons behind the existence of conflicting results on both the stationarity and cointegration have been mainly explained through the dataset considered (countries, time-periods and explanatory variables included) and the approach employed (e.g. panel data or country-by-country analysis, type of tests performed, and exclusion or inclusion of a time trend in the unit root tests).

A large body of empirical work focusing on OECD countries has investigated the stationarity of health expenditures and income, as well as the long-run relationship between them. Despite the vast amount of literature produced, the issue of cointegration is still open, as even among these studies the evidence is often contradictory. While the majority of the authors concluded that health care expenditure and GDP are non-stationary and co-integrated (Gerdtham and Löthgren, 2000; Dreger and Reimers, 2005; Westerlund, 2007; Gerdtham and Löthgren, 2002; Wang, 2011), some rejected the null of non-stationarity for health expenditures and GDP (McCoskey and Selden, 1998; Hartwig, 2008; Lago-Peñas et al., 2013). As both stationarity and cointegration results must affect the choice of the estimation method (and, consequently, the results regarding the relationship between health expenditure and its drivers), these insights changed the direction of the methodological approaches used thenceforth to study health expenditures.

\subsubsection{Dynamic and heterogeneous relationships and cross-section dependence}

Integration and cointegration between health expenditures and its determinants represent fundamental properties when specifying and interpreting health expenditures models. But there are other characteristics of data to be taken into account when choosing an econometric model and respective estimation method. Among them, current primary concerns seem to be on how to deal with dynamic heterogeneous relationships and cross-section dependence across countries, characteristics that are very likely to be present in health expenditures panel data (McCoskey and Selden, 1998; Roberts, 1999). Historical data of OECD health expenditures seems to exhibit a dynamic and heterogeneous nature, as it has varying substantially both over time and across countries. As a share of GDP, health 
expenditures more than doubled since 1970, but this evolution was considerably heterogeneously across OECD countries (McCoskey and Selden, 1998). Additionally, cross-section dependence across health expenditures in OECD countries is also foreseeable, and it has been recognized in the literature (i Silvestre, 2005; Jewell et al., 2003; Chou, 2007). This interdependence arises mainly from two sources. First, through similar responses to common external forces, such as technological advances, health shocks, new diseases, shifts in health policies or sociological structural changes (such as behaviors affecting risk factors or changes in the preferences and expectations of healthcare users) (Andrews, 2005). The other source of interdependence is spatial spillovers, generating correlations among health expenditures in countries that are embedded in similar geographical, economic, or social spaces (Moscone et al., 2007; Baltagi and Moscone, 2010).

It should be noticed that the presence of cross-section dependency constrains the selection of the adequate unit root and cointegration tests. Depending on whether they account for cross-section dependence or not, two generations of tests can be distinguished (Hurlin and Mignon, 2007). The first-generation of panel unit root tests is based on the cross-sectional independence assumption and includes the contributions of Levin and Lin (Levin et al., 2002), Im et al. (Im et al., 2003), Maddala and Wu (Maddala and Wu, 1999), Choi (Choi, 2001) and Hadri (Hadri, 2000). The cross-sectional independency hypothesis is restrictive and unrealistic for the majority of macroeconomic applications (Baltagi, 2008). The presence of cross-sectional correlation of errors in panel data applications in economics is likely to be the rule rather than the exception (Chudik and Pesaran, 2015) and use of first-generation of panel unit root tests to cross-sectionally dependent panels may generate substantial size distortions (O'Connell, 1998). Thus, first-generation panel unit root tests started to be criticized and several new tests allowing for cross-sectional correlations have been proposed. Belonging to the second-generation of panel unit root tests: Bai and $\mathrm{Ng}$ (Bai and Ng, 2004), Phillips and Sul (Phillips and Sul, 2003), Moon and Perron (Moon and Perron, 2004), Choi (Choi, 2006), Moon, Perron and Phillips (Moon et al., 2007), Chang (Chang, 2002) and Pesaran (Pesaran, 2007). Similarly, the cross-section (in)dependence should also be taken into account when selecting the cointegration tests, since there are also 
tests that are based on independence assumption (Kao (Kao, 1999), Pedroni (Pedroni, 1999, 2004), and McCosey and Kao (McCoskey and Kao, 1998)) and others that were developed to deal with cross-section dependence (Westerlund (Westerlund, 2007), and Gengenbach, Urbain, and Westerlund (Gengenbach et al., 2008)).

\subsubsection{Determinants of Health Expenditure}

The trajectory of health expenditures is driven by a set of factors that affect both demand for and supply of healthcare services. Income, population size and structure, and its health status are seen as key determinants of the demand. The most relevant supply-side determinants include technological progress and human resources (EUC, 2018). The main findings on the relation between health expenditures and these drivers are briefly described below.

\subsubsection{Income, ageing and health}

Within the wide range of health expenditures determinants, income was the first to be related to health expenditures (Newhouse, 1977), and it is still considered the most relevant factor in explaining differences in the level and growth of health expenditures (Newhouse, 1992). Newhouse (Newhouse, Rand Corporation. 1974) was the first to show that income is statistically significant on explaining health expenditures, a fact that is nowadays generally accepted after several other authors confirmed the existence of a positive and statistically significant correlation between variations in aggregate income and changes in health expenditures.

The debate on the effect of income is not about its relevance, but regarding the magnitude of this effect. In the past decades, a voluminous literature has been studying the income elasticity of health expenditure to assess whether the healthcare is a luxury good (income elasticity above unity) or a normal good (income elasticity below one), and there is still no consensus on the subject. Nor even for the OECD countries the results are unanimous. While income elasticities above one were usually found in older bivariate cross-sectional or time-series studies, in more recent panel analysis considering non-stationarity and cointegration, and controlling for non-income determinants, the results are more divergent. Most 
of them have found income elasticities equal or below one, suggesting that healthcare is not a luxury good (Gerdtham, 1992; Gerdtham et al., 1998; Blomqvist and Carter, 1997; Dreger and Reimers, 2005; Wang, 2011; Hartwig, 2008; Lago-Peñas et al., 2013; Baltagi and Moscone, 2010; Okunade et al., 2004; Sen, 2005; Mosca, 2007; Chakroun, 2010a; Dormont et al., 2008; Hartwig and Sturm, 2014; Hosoya, 2014; Blazquez-Fernandez et al., 2014; Tian et al., 2018; Barros, 1998; Herwartz and Theilen, 2003), but some authors conclude the opposite (Roberts, 1999; Mehrara M, 2010; Liu et al., 2011; Yu et al., 2015; Okunade et al., 2018).

Population aging is also pointed as a significant determinant of health expenditures, and another of the most studied factors (Przywara et al., 2010), but this subject is also not consensual. While some authors argue that health expenditures tend to rise due to an increase in life expectancy and the consequent decline of the health status (Fogel, 2009), others defend that health expenditures are higher in the period preceding death and that aging, per se, is not that relevant (de la Maisonneuve and Martins, 2013). These two standpoints result in different factors considered in empirical analysis: demographic variables and healthrelated variables (Schulz, 2005). Regarding the effect of demography, indicators such the as share of elders (above 65 or 75 years) have been frequently considered in OECD studies. These variables were found to be relevant by several authors (Gerdtham, 1992; Dreger and Reimers, 2005; Chakroun, 2010b; Lago-Peñas et al., 2013; Okunade et al., 2004; Mosca, 2007; Dormont et al., 2008; Hartwig and Sturm, 2014; Liu et al., 2011; Yu et al., 2015; Okunade et al., 2018), but many other studies have concluded for the irrelevance of the demographic factor (Gerdtham et al., 1998; Roberts, 1999; Baltagi and Moscone, 2010; Sen, 2005; Hosoya, 2014; Blazquez-Fernandez et al., 2014; Barros, 1998; Herwartz and Theilen, 2003). The inclusion of health-related variables is less common in OECD studies, and very few found these indicators to be significant (Dreger and Reimers, 2005; Tian et al., 2018). 


\subsubsection{Technology and human resources}

Among the supply-side factors, technological progress is cited as one of the most significant drivers of health expenditures. Several authors have studied the impact of technological advances on the evolution of the health expenditures by using proxies for changes in health technology (such as surgical procedures performed, life expectancy (Bodenheimer, 2005), pharmaceutical spending (Atella et al., 2012), R\&D expenditures (Okunade and Murthy, 2002) or number of technological patents (Okunade et al., 2018)) or by including a time trend (Blomqvist and Carter, 1997) or a time effect (Matteo, 2005) in the models. Overall, OECD panel studies including a proxy for the technology have confirmed that technological progress is, in fact, a relevant determinant of health expenditures. But there are also exceptions regarding this subject (Gerdtham et al., 1998), and no consensus is attained.

Also from the supply-side, the study of factors such as the number of physicians or the number of beds is explained by the direct dependency between health expenditures and the physical and human resources' levels. The number of physicians is the most considered explanatory variable in this class, mainly for three reasons: healthcare is a labor-intensive industry (Mohammed, 2013; Getzen, 2000); the number of physicians has been the indicator selected to capture the supply-induced-demand effect (Gerdtham and Löthgren, 2000; San and Wang, 1980); and naturally, from a higher access to healthcare usually comes a higher utilization, especially in the presence of unmet needs (San and Wang, 1980). With only one exception (Tian et al., 2018), all the studies examining the effect of this driver in health expenditures for OECD countries found a statistically significant positive relationship between the number of physicians and aggregate health expenditures.

The literature on health expenditures determinants and approaches reveal opportunities for contributions, which may be twofold. First, because the factors driving health expenditures seem to remain only imperfectly understood, as their effect substantially varies depending on the dataset (cross-sections and time-period considered), the variables considered and the methodological approach followed. Second, due to the lack of unanimity and consensus 
regarding the best methodological approach to estimate the relationship between health expenditures and its drivers, which most of the times seem not to be considering some essential characteristics of the data. Table 4.11, in the Appendix, summarizes the macro panel studies of health expenditures determinants for OECD countries, where the diversity on both the methodological approaches and the conclusions regarding the effects of the expenditures drivers is noticeable.

\subsection{Data}

Based on the literature studying the determinants of health expenditures, five of the most relevant drivers were selected to be included in the analysis. Economic, demographic, and health-related factors are recognized as relevant drivers from the demand-side. From the supply side, variables representing technology and resources are also pointed as essential drivers of health expenditures. Thus, data from 34 OECD countries between 1980 to 2014, on both health expenditures and five explanatory variables - each representing one of these drivers - were collected from the OECD statistics. The Gross Domestic Product was chosen for the economic driver, the years of life lost as the proxy to health conditions, the demographic factor is represented by the elderly population, and the number of patents and physicians represent the supply drivers: technology and human resources, respectively.

Both the total health expenditure (THE) and the Gross Domestic Product (GDP) are measured in millions of USD per capita, at constant prices and constant purchasing power parity (OECD base year, 2010). Years of life lost (YLL) are measured in the number of years lost per 100.000 inhabitants between 0 and 69 years, and elderly population (POP65) is represented by the share of the population over 65 years old. The number of patents (PAT), which is used as a proxy for technology, is measured by the total number of patents in co-operation with abroad, and the physicians (PHY) are represented by the number of practicing physicians per 1.000 inhabitants. The descriptive statistics of the variables considered in the analysis are summarized in Table 4.1 (the correlation matrix is presented in the Appendix, Table 4.12). The panel dataset comprises $\mathrm{N}=34$ countries and $\mathrm{T}=35$ years. 
This panel structure should be taken into account for both further data analysis and selection of the adequate panel estimation method, as both $\mathrm{N}$ and $\mathrm{T}$ large numbers.

Table 4.1 - Summary statistics for the variables included in the panel analysis

\begin{tabular}{cccccc}
\hline Variable & Obs. & Mean & Std. Dev. & Min. & Max. \\
\hline THE & 1024 & 2456.50 & 1396.57 & 134.82 & 8396.42 \\
\hline GDP & 1098 & 29638.61 & 12339.33 & 5088.49 & 91280.06 \\
\hline PHY & 1064 & 2.60 & 0.81 & 0.50 & 5.05 \\
\hline POP65 & 1190 & 0.13 & 0.04 & 0.04 & 0.25 \\
\hline YLL & 1107 & 5042.53 & 2376.32 & 2153.70 & 23994.40 \\
\hline PAT & 1190 & 429.75 & 897.01 & 0.00 & 6278.00
\end{tabular}

Notes: THE, total health expenditure per capita; GDP, Gross Domestic

Product per capita; PHY, number of physicians; POP65, share of the population over 65 years old; YLL, years of life lost; PAT, number of cooperation patents.

\subsection{Methods}

The empirical analysis comprises four steps: 1) cross-sectional dependency tests to check for the (in)dependence of each variable across OECD countries; 2) unit root tests to infer on the stationarity of the data; 3 ) cointegration tests to check for the existence of a longrun relationship; and 4) estimation of the relationship between the health expenditures and its determinants using different econometric techniques, and further slope heterogeneity analysis. The methodological approach followed in each of these steps is described below. Variables THE and GDP were previously transformed in logarithms, and both EViews9 and STATA14 software were used to carry out the econometric analysis.

\subsubsection{Cross-section dependence}

Four different cross-section dependence tests are used to check for cross-section dependency between the OECD countries: the Breusch-Pagan LM $(L M)$, the Pesaran Scaled LM $\left(L M_{S}\right)$, the Pesaran CD $(C D)$ and the Bias-Corrected Scaled LM $\left(L M_{B C}\right)$. The LM test, proposed by Breusch and Pagan (1980), is the most well-known cross-section dependence 
test. This test has the advantage of using the square of pairwise correlation coefficients, but may be biased if the number of cross-section units $(\mathrm{N})$ is large or the number of periods (T) is small. For testing the null hypothesis of no cross-equation error correlations the following Lagrange multiplier statistic is used:

$$
L M=T \sum_{i=1}^{N-1} \sum_{j=i+1}^{N} \hat{\rho}_{i j}^{2}
$$

where $\hat{\rho_{i j}}$ are the sample estimates of the pairwise correlations of $q$ (that could be either stationary variables or estimation residuals) between cross-section units $i$ and $j$ :

$$
\hat{\rho_{i j}}=\hat{\rho_{j i}}=\frac{\sum_{t=1}^{T} q_{i t} q_{j t}}{\left(\sum_{t=1}^{T} q_{i t}^{2}\right)^{\frac{1}{2}}\left(\sum_{t=1}^{T} q_{j t}^{2}\right)^{\frac{1}{2}}}
$$

The second diagnostic test for cross-section dependence is the $L M_{S}$ test. This test is based on a standardized version of the original $L M$ statistic, which was proposed by Pesaran (2004) to deal with large N settings:

$$
L M_{S}=\sqrt{\frac{1}{N(N-1)}} \sum_{i=1}^{N-1} \sum_{j=i+1}^{N}\left(T \hat{\rho}_{i j}^{2}-1\right)
$$

As the $L M_{S}$ is still likely to result in size distortions for small T settings, Pesaran (2004) proposed another alternative test $(C D)$, which is based on the average of the pairwise correlation coefficients:

$$
C D=\sqrt{\frac{2 T}{N(N-1)}} \sum_{i=1}^{N-1} \sum_{j=i+1}^{N} \hat{\rho_{i j}}
$$


This $C D$ statistic does not suffer from the potential size distortion, but it uses simple pairwise correlation coefficients rather than their squares, which has the disadvantage of potentially delivering misleading results when cross-correlations are both positive and negative (Moscone and Tosetti, 2010).

The fourth cross-dependency test considered, the $L M_{B C}$, was proposed by Baltagi et al. (2012), and also offers a simple bias correction for the $L M_{S}$ test statistic, without presenting the disadvantaged of the $C D$ statistic aforementioned.

$$
L M_{B C}=\sqrt{\frac{1}{N(N-1)}} \sum_{i=1}^{N-1} \sum_{j=i+1}^{N}\left(T \hat{\rho}_{i j}^{2}-1\right)-\frac{N}{2(T-1)}
$$

Regarding the dataset used in this analysis, where both $\mathrm{T}$ and $\mathrm{N}$ are large, the $C D$ and the $L M_{S}$ are the most suitable cross-section dependence tests.

\subsubsection{Stationarity}

Economic series are frequently non-stationary, which violates a fundamental assumption of the OLS estimation and may lead to the identification of spurious relations between the variables and inconsistent estimates (Engle and Granger, 1987). Thus, we further check the stationarity of the data by performing a set of both first- and second-generation panel unit root tests.

First generation tests performed are the Levin, Lin and Chu (LLC) test, the Im, Pesaran and Shin (IPS) test, and Fisher-type tests using both Augmented Dickey-Fuller (ADF) and Phillips-Perron (PP) statistics (Maddala and Wu, 1999). All of them aim to check the existence of roots equal to the unit in the autoregressive polynomial, as the presence of one unit root indicates the non-stationarity of the data. The LLC assumes that all crosssection units have the same autoregressive parameter and tests the null hypothesis of the existence of common unit root against the alternative of stationarity. The other three tests allow for each unit to have its autoregressive root on testing the non-stationarity hypothesis (existence of at least one cross-section with a unit root in the autoregressive polynomial) 
against the alternative of absence of individual unit root processes.

As mentioned before, the first-generation tests ignore the cross-section dependence in the data. Thus, the CIPS second-generation test (Pesaran, 2007), allowing for heterogeneity in the autoregressive coefficient and the presence of a single unobserved common factor with heterogeneous factor loadings in the data, was also applied. The CIPS test computes the simple average of the t-ratios of $b_{i}$ OLS estimates $\left(\tilde{t}_{i}\right)$ in the following Dickey-Fuller regression of order $p$, augmented with cross-section averages $\left(\bar{z}_{t}\right)$ :

$$
\begin{aligned}
\Delta y_{i t} & =a_{i}+b_{i} y_{i, t-1}+c_{i} t+\sum_{j=1}^{p} d_{i j} \Delta y_{i, t-j}+g_{i} \bar{z}_{t}+e_{i, t} \\
\text { CIPS } & =\frac{1}{N} \sum_{i=1}^{N} \tilde{t}_{i}
\end{aligned}
$$

When series in levels are found to be non-stationary, we apply the method of differencing data and test again for the stationarity of the series in their first differences. We apply as many differences as needed until the data becomes stationary. The number of differences required for making data stationary is their integration order. Insights arising from these tests start pointing for the adequate model to use, as cointegration may only exist between integrated series.

\subsubsection{Cointegration}

To check if there is a long-run relationship between health expenditures and the drivers considered, Westerlund ECM second-generation panel cointegration tests (Westerlund, 2007) are applied. These cointegration tests are known to be robust even when heterogeneity and cross-section dependence is present in the panel (Abdullah et al., 2017). Westerlund proposed four different statistics $\left(G_{\tau}, G_{\alpha}, P_{\tau}\right.$, and $\left.P_{\alpha}\right)$ to test the null of no cointegration by checking if the error-correction term of the following panel Error Correction Model (ECM) is zero: 


$$
\Delta y_{i t}=\delta_{i t}^{\prime} d_{t}+\alpha_{i}\left(y_{i, t-1}-\beta_{i}^{\prime} x_{i, t-1}\right)+\sum_{j=1}^{p_{i}} a_{i j} \Delta y_{i, t-j}+\sum_{j=-q_{t}}^{p_{i}} \gamma_{i j} \Delta x_{i, t-j}+e_{i t},
$$

where $d_{t}$ contains the deterministic components, and $\alpha_{i}$ is the speed of adjustment to the equilibrium relationship $y_{i, t-1}-\beta_{i}^{\prime} x_{i, t-1}$ after a shock. $G_{\tau}$ and $G_{\alpha}$ are group-mean statistic and test the alternative of cointegration in at least one country; $P_{\tau}$ and $P_{\alpha}$ test the null against the alternative that the panel is cointegrated as a whole:

$$
\begin{aligned}
G_{\tau} & =\frac{1}{N} \sum_{i=1}^{N} \frac{\hat{a}_{i}}{S E\left(\hat{a}_{i}\right)} \\
G_{\alpha} & =\frac{1}{N} \sum_{i=1}^{N} \frac{T \hat{a}_{i}}{\hat{a}_{i}(1)} \\
P_{\tau} & =\frac{\hat{a}}{S E(\hat{a})} \\
P_{\alpha} & =T \hat{a}
\end{aligned}
$$

\subsubsection{Long and short-run estimations}

To investigate the long-run relationship between healthcare expenditures and its main drivers, we apply different methodologies, which have been chosen for being recently implemented in the literature and pointed as appropriate to the problem: Dynamic OLS (DOLS), Fully Modified OLS (FMOLS), Autoregressive Distributed Lag (ARDL) and Dynamic Common Correlated Effects (DCCE).

Due to the potential bias of simple OLS estimation, efficient and straightforward methods for estimating a single cointegrating vector in panel settings such as DOLS (Saikkonen, 1992; Stock and Watson, 1993) and FMOLS (Phillips and Hansen, 1990) have been used to study the long-run behavior of health expenditures (Dreger and Reimers, 2005; Abdullah et al., 2017). The main argument supporting these approaches is that the cointegration vector should be common for all the panel units, as fundamental economic principles are 
involved (Dreger and Reimers, 2005). Those techniques have the advantage of controlling for both endogeneity of the regressors and serial correlation.

FMOLS and DOLS approaches are asymptotically equivalent, and their relative merits are determined by comparison in finite samples (Dreger and Reimers, 2005). While in the FMOLS procedure nonparametric techniques are used to transform the residuals from the cointegration regression and make corrections for serial correlation, DOLS is a fully parametric approach, that estimates lagged first-differenced terms and offers a computationally convenient alternative to the FMOLS estimator (Pedroni, 2001a). Following Abdullah et al. (Abdullah et al., 2017), both FMOLS and DOLS approaches are used, and for each three estimators are considered: Pooled (P), Pooled Weighted (PW), and Grouped Mean (GM). Pooled estimation performs standard FMOLS/DOLS on the pooled sample, after removing the deterministic components from both the dependent and independent variables, allowing the short-run dynamics to be cross-section specific (Kao and Chiang, 2001; Phillips and Moon, 1999); Pooled Weighted estimation accounts for long-run heterogeneity by using specific cross-section estimates prior to applying the pooled estimation (Kao and Chiang, 2001; Pedroni, 2001b; Mark and Sul, 2003; Mark and Sul); and Grouped Mean estimation averages the individual cross-section estimates (Pedroni, 2001a,b). The ARDL cointegration modeling approach has also recently become popular in panel analyses of health expenditures (Herwartz and Theilen, 2003; Okunade et al., 2018; Murthy and Okunade, 2016; Yerdelen, 2011). In this study, we use a panel ARDL(p,q,q,...q) model that can generally be represented as follows:

$$
y_{i t}=\alpha_{i}+\sum_{j=1}^{p} \lambda_{i, j} y_{i, t-j}+\sum_{j=0}^{q} \delta_{i j}^{\prime} X_{i, t-j}+e_{i t},
$$

where $y$ is the dependent variable, $X$ is the vector of explanatory variables, $\alpha_{i}$ represent the country fixed-effects; the coefficients of lagged dependent variables $\left(\lambda_{i, j}\right)$ are scalars, $\delta_{i j}$ are coefficient vectors for the explanatory variables, and $e_{i, t}$ represents the error term.

The ARDL model is estimated considering Pooled (P), Mean Group (MG) and Pooled 
Mean Group (PMG) estimators. While the Pooled estimator assumes that coefficients are common for all the cross-sections, the MG estimator (Pesaran and Smith, 1995) presents the coefficients mean of the estimations for the $\mathrm{N}$ country-specific regressions. The PMG estimator (Pesaran et al., 1999) is a combination of the previous two, which includes for both pooling and average: the long-run coefficients are constrained to be identical across countries (long-run homogeneity is assumed), but it allows the short-run adjustments to differ from country to country.

Despite the popularity of ARDL models, they have the drawback of not allowing for crosssection dependence, which may lead to inconsistent estimates (Chudik et al., 2016). This issue can be addressed through the use of cross-sectionally augmented ARDL (CS-ARDL) models without lagged dependent variables, such as the Common Correlated Effects (CCE) model. This approach presents four significant advantages: i) it does not require the number of factors to be known; ii) it allows the common factors and the idiosyncratic component to be serially correlated; iii) it yields consistent estimators regardless of the factors being stationary or not; and iv) it performs well even in small samples (Moscone and Tosetti, 2010; Baltagi and Moscone, 2010; Pesaran, 2006). In this work, we apply the Dynamic Common Correlated Effects (DCCE) estimator, an extension of the CCE approach that was developed by Chudik and Pesaran (Chudik et al., 2016) to allow for heterogeneous panel data models with lagged dependent variable and weakly exogenous regressors. The DCCE model considered is given by the following equation:

$$
y_{i t}=\alpha_{i}+\lambda_{i} y_{i, t-1}+\beta_{i} X_{i, t}+\sum_{l=0}^{p_{t}} \delta_{i, l} z_{t-l}^{-}+e_{i t},
$$

where $\bar{z}_{t}$ are the cross-section means for dependent and independent variables, $p_{t}=\sqrt{T}$ refers to the number of cross-section averages for each variable, $\delta_{i, l}$ are the loadings, $y$ is the dependent variable, $X$ is the vector of explanatory variables, $\alpha_{i}$ represent the country fixed effects; $\lambda_{i}$ and $\beta_{i}$ are the coefficients for lagged dependent variable and for the explanatory variables, respectively, and $e_{i, t}$ represent the error term. 
Similarly to the ARDL approach, three different estimators are also considered for the DCCE model: the Pooled estimator (DCCE-P), the Mean Group estimator (DCCE-MG), and the Pooled Mean Group estimator (DCCE-PMG). For the convenience of the analysis, both equations (4.13) and (4.14) were further re-parameterized and transformed into Error Correction Models.

\subsection{Results and discussion}

This section is devoted to the presentation, comparison, and discussion of the empirical results, both regarding the study of the main characteristics of the data and from the application of the several different methodological approaches to study the long- and short-run relationship between health expenditures and the considered drivers. Furthermore, due to the sensitivity of the results regarding the approach applied, in the last subsection we propose a framework to help on the adequate selection of the panel approach regarding the main characteristics of the data.

\subsubsection{Cross-section dependence, stationarity, and cointegration}

We first start by checking the cross-section dependence of the data. Table 4.2 reports the cross-country dependence tests for the variables in the first differences, regressed on a country-specific intercept. The average correlation coefficients $(\bar{\rho})$ are also presented in the last column. The four tests performed are unanimous on rejecting the null of cross-sectional independence at the 5\% significant level, indicating the presence of cross-sectional dependence between pairs of countries for all the variables. This results confirm the ones previously obtained for OECD countries (Baltagi and Moscone, 2010).

The presence of cross-section dependence should be taken into account in the analysis of additional data properties, such as stationarity and cointegration, as well as in the selection of methods to estimate the relationship between healthcare expenditures and its drivers, as failure to do so may lead to misleading inference (Andrews, 2005).

Table 4.3 reports the results of the first-generation panel unit root tests: LLC, IPS, ADF, 
Table 4.2 - Cross-section dependence tests

\begin{tabular}{cccccc}
\hline Variable & $\begin{array}{c}\text { Breusch- } \\
\text { Pagan LM }\end{array}$ & $\begin{array}{c}\text { Pesaran } \\
\text { scaled LM }\end{array}$ & $\begin{array}{c}\text { Bias-corrected } \\
\text { scaled LM }\end{array}$ & $\begin{array}{c}\text { Pesaran } \\
\text { CD }\end{array}$ & $\bar{\rho}$ \\
\hline$\Delta$ THE & $898.12^{* * *}$ & $10.06 * * *$ & $9.55^{* * *}$ & $12.14 * * *$ & 0.157 \\
$\Delta$ GDP & $4027.81^{* * *}$ & $103.50^{* * *}$ & $102.98^{* * *}$ & $55.42^{* * *}$ & 0.541 \\
$\Delta$ POP65 & $6230.56 * * *$ & $169.26 * * *$ & $168.74 * * *$ & $61.36 * * *$ & 0.363 \\
$\Delta$ PAT & $1732.16^{* * *}$ & $34.96 * * *$ & $34.45^{* * *}$ & $19.27 * * *$ & 0.189 \\
$\Delta$ PHY & $5123.24 * * *$ & $136.20 * * *$ & $134.27 * * *$ & $18.58 * * *$ & 0.092 \\
$\Delta \mathrm{LL}$ & $651.58^{* * *}$ & $2.70^{* * *}$ & $2.19 * *$ & $6.40 * * *$ & 0.082
\end{tabular}

Notes: Null hypothesis for all cross-section dependence tests: no cross-section dependence;

Degrees of Freedom $(\mathrm{DF})=561 ; *, * *$ and $* * * *$ indicates statistical significance at 10\%, 5\% and $1 \%$, respectively.

and PP. Unit root tests for the variables in levels suggest the non-stationarity of the data. When the same tests are applied to the variables in their first-differences, results reject the null of panel unit root, indicating the stationarity of the first-differenced variables and suggesting that all the considered variables are integrated of order one: I(1).

Table 4.3 - Panel unit root tests (levels and first-differences)

\begin{tabular}{|c|c|c|c|c|c|c|c|c|c|c|c|c|}
\hline \multirow{2}{*}{ Test } & \multicolumn{6}{|c|}{ Levels } & \multicolumn{6}{|c|}{ First-differences } \\
\hline & THE & GDP & PHY & POP65 & LL & PAT & $\triangle \mathrm{THE}$ & $\Delta \mathrm{GDP}$ & $\Delta \mathrm{PHY}$ & $\Delta \mathrm{POP} 65$ & $\Delta \mathrm{LL}$ & $\Delta \mathrm{PAT}$ \\
\hline LLC & 0.82 & 1.65 & 35.81 & 5.51 & 2.58 & -0.06 & $-9.52^{* * *}$ & $-10.53^{* * *}$ & $-18.68^{* * * *}$ & $-4.89^{* * *}$ & $-9.60^{* * *}$ & $-10.55^{* * *}$ \\
\hline IPS & 2.32 & 3.03 & 0.27 & 9.97 & 10.53 & 6.38 & $-10.56 * * *$ & $-11.61^{* * *}$ & $-19.99^{* * *}$ & $-3.39 * * *$ & $-16.22^{* * * *}$ & $-17.17 * * *$ \\
\hline $\mathrm{ADF}$ & 54.74 & 36.25 & 83.30* & 33.68 & 12.12 & 18.71 & $257.16^{* * * *}$ & $2269.29 * * *$ & $472.50 * * *$ & $154.32^{* * * *}$ & $381.58 * * *$ & $423.33^{* * * *}$ \\
\hline PP & 38.38 & 24.30 & 62.41 & 3.41 & 44.36 & 33.47 & $452.72 * * *$ & $367.37 * * *$ & $506.64 * * *$ & 27.66 & $722.49 * * *$ & $799.30^{* * * *}$ \\
\hline
\end{tabular}

Given the cross-country dependence detected, second-generation tests are more adequate to infer on the stationarity of the series. Table 4.4 shows the CIPS statistics for the variables in levels and in their first-differences, for lag orders $p=0,1,2$. Results show that even when accounting for cross-section dependence, most of the variables are non-stationary and became stationary when unit root tests are applied to their first-differences, being the only exception the demographic variable POP65. Thus, the results obtained with second-generation panel unit root tests do not contradict the ones obtained by applying first-generation tests. Although comparisons as such for other countries or considering different time-period may provide different insights, our results using different generations of stationarity tests are not able to explain the conflicting conclusions presented by studies using less modern method- 
ologies to check stationarity (McCoskey and Selden, 1998; Hartwig, 2008; Lago-Peñas et al., 2013).

Table 4.4 - CIPS panel unit root tests (levels and first-differences)

\begin{tabular}{|c|c|c|c|c|c|c|c|c|c|c|c|c|}
\hline \multirow{2}{*}{ Lags } & \multicolumn{6}{|c|}{ Levels } & \multicolumn{6}{|c|}{ First-differences } \\
\hline & THE & GDP & PHY & POP65 & LL & PAT & $\Delta \mathrm{THE}$ & $\Delta \mathrm{GDP}$ & $\Delta \mathrm{PHY}$ & $\Delta \mathrm{POP} 65$ & $\Delta \mathrm{LL}$ & $\triangle \mathrm{PAT}$ \\
\hline $\mathrm{p}=0$ & 5.62 & 5.36 & 1.77 & 12.25 & 0.06 & $-6.64 * * *$ & $-13.94 * * *$ & $-10.25^{* * * *}$ & $-14.38^{* * * *}$ & 2.72 & $-17.94^{* * * *}$ & $-20.56 * * *$ \\
\hline $\mathrm{p}=1$ & 5.05 & 2.61 & 1.25 & $-1.31 *$ & 0.36 & -1.03 & $-7.95 * * *$ & $-3.59 * * *$ & $-5.86^{* * * *}$ & 2.22 & $-9.00^{* * * *}$ & $-12.28 * * *$ \\
\hline $\mathrm{p}=2$ & 4.36 & 3.73 & 0.99 & 2.51 & 0.62 & -0.69 & $-3.71^{* * * *}$ & $-3.32^{* * * *}$ & $-2.73^{* * * *}$ & 1.75 & $-1.88 * *$ & $-7.96 * * *$ \\
\hline
\end{tabular}

Results from the implementation of the Westerlund ECM tests for panel cointegration are presented in Table 4.5. This approach, robust for heterogeneity and cross-sectional dependence, shows that the null hypothesis of no cointegration may be rejected at the $5 \%$ significance level for both the panel statistics $\left(P_{\tau}\right.$ and $\left.P \alpha\right)$ and for one of the group statistics $(G \alpha)$. Overall, as only one of the group statistic $\left(G_{\tau}\right)$ fails to reject the null of no cointegration, the results show evidence supporting the existence of a long-run relationship among health expenditures and the drivers considered. This result supports the conclusions of most of the studies of cointegration in OECD countries and will further be checked through the analysis of the ECT of the estimated models.

Table 4.5 - Westerlund ECM panel cointegration tests

\begin{tabular}{ccccc}
\hline Statistic & \multicolumn{4}{c}{ Westerlund cointegration tests } \\
\hline & Value & Z-Value & P-value & Robust P-value \\
$G_{\tau}$ & -2.308 & -0.582 & 0.280 & 0.120 \\
$G \alpha$ & -10.495 & 0.862 & 0.806 & $0.000^{* * *}$ \\
$P_{\tau}$ & -16.679 & -5.357 & 0.000 & $0.030^{* *}$ \\
$P \alpha$ & -12.245 & -2.853 & 0.002 & $0.039^{* *}$ \\
\hline
\end{tabular}

Notes: Null hypothesis: no cointegration; Dependent variable: THE;

Lags (0 2); Leads (0 2); Width =3; Regression estimation with bootstrapping $100 ; *, * *$ and $* * * *$ indicates statistical significance at $10 \%, 5 \%$ and $1 \%$, respectively.

Overall, the analysis of the data main characteristics is according to what was expected, based on the theoretical background and on empirical insights from previous studies. Results show that health expenditures and the economic, demographic, health-related, technology and human resources variables exhibit cross-country dependence, are non-stationary 
and integrated of order one, and that there is a stable long-run relationship between the health expenditures and these drivers. Our results are in line with most of the previous research on health expenditures, independently of the applied methods, data sample and variables considered, but do not corroborate the conclusion achieved by a few authors, who have found no cointegration relationship between the health expenditures and its drivers or do not even conclude for the non-stationarity of the series (see Table 4.11 in the appendix).

\subsubsection{Long and short-run estimation}

As the data pointed to the existence of cointegration between health expenditures and the selected drivers, we proceed with the estimation of the long-run relationship among the variables.

We start by estimating both FMOLS and DOLS models, each one considering Pooled, Pooled Weighted, and Grouped Mean estimators. Results, which are presented in Table 4.6, show that the only variable that is found to be not significant to health expenditures variations is the variable used as proxy for the technology (PAT), which contradicts the results obtained by other authors for the OECD countries (Blomqvist and Carter, 1997; Hartwig, 2008; Hartwig and Sturm, 2014) . The other four variables (GDP, POP65, PHY and LL) are found to be relevant drivers of health expenditures, as they all are statistically significant at the 5\% level. Also, their coefficients have the expected sign, according to the theoretical background reviewed: GDP, POP65 and PHY positively affect the health expenditures, as opposed to LL, which have a negative impact.

Table 4.6 - Panel DOLS and FMOLS

\begin{tabular}{ccccccc}
\hline \multirow{2}{*}{ Variable } & \multicolumn{3}{c}{ DOLS } & & \multicolumn{3}{c}{ FMOLS } \\
\cline { 2 - 7 } & Pooled & Weighted & Grouped & Pooled & Weighted & Grouped \\
\hline GDP & $0.973^{* * *}$ & $0.923^{* * *}$ & $0.649 * * *$ & $1.157^{* * *}$ & $1.112 * * *$ & $0.684 * * *$ \\
POP65 & $2.163 * *$ & $2.188^{* * *}$ & $0.848^{* * *}$ & $1.186^{* * *}$ & $1.547 * * *$ & 0.463 \\
PAT & 0.000 & 0.000 & 0.000 & 0.000 & -0.092 & 0.000 \\
PHY & $0.076 * * *$ & $0.057 * * *$ & $0.489 * * *$ & $0.081 * * *$ & $0.065 * * *$ & $0.181 * * *$ \\
LL & $-0.348^{* * *}$ & $-0.383^{* * *}$ & $-0.932^{* * *}$ & $-0.215^{* * * *}$ & $-0.262^{* * *}$ & $-0.424 * * *$ \\
\hline
\end{tabular}

Notes: Dependent variable: THE. Long-run variance (Bartlett kernel, Newey-West fixed bandwidth) used for coefficient covariances. Cointegrating equation deterministic: C. *,** and *** indicates statistical significance at $10 \%, 5 \%$ and $1 \%$, respectively. 
Both for FMOLS and DOLS, the estimator does not seem to substantially influence the inference regarding the impact of these determinants on health expenditures, since the conclusion would only be different for the variable POP65 with the Grouped FMOLS estimation. However, the value of the coefficients differs among the approach and across the estimation method. Regarding the income elasticities, DOLS presents lower coefficients than FMOLS, and elasticities tend to be higher when pooled estimators are used and lower for grouped estimators. From these results, it is not evident if the income elasticity in OECD countries is below or above one. While DOLS and the grouped FMOLS estimations seem to reveal that healthcare is a normal good, with elasticity coefficients varying between 0.97 and 0.65 , the FMOLS pooled and polled weight estimations, by exhibiting coefficients of 1.15 and 1.11 , respectively, suggest that healthcare is a luxury good. However, betweengroup (mean) estimators are known to preferable to the within-group (pooled) estimators (Pedroni, 1999), and when heterogeneity is taken into account, both DOLS and FMOLS suggest that income elasticity is around below unit (approximately 0.65 ). Our second approach to the study of the long-run relationship between healthcare expenditures and its drivers is based on a panel ARDL model. The results of the Polled, Mean Group and Polled Mean Group estimations of this model are presented in Table 4.7.

The results obtained with the different estimation methods are substantially different, both for the long- and for the short-run. Regarding the long-run, they all confirm GDP as a significant driver and both PAT and LL as non-significant variables. Also, the income elasticities are all greater than one, contradicting the results obtained with the grouped FMOLS and DOLS, but in line with previous results using ARDL models (Roberts, 1999; Okunade et al., 2018). In the short-run, the three estimations match on showing that PHY and LL do not affect the adjustment to the long-run equilibrium relationship.

Apart from these similarities, several different conclusions come up from the results of the different estimations. As so, Hausman tests were performed to compare the consistency and efficiency of these estimators. From the results, presented in Table 4.13 in the appendix, we conclude that the PMG estimator is superior to both Pooled and MG. These results confirm the superiority of the between-group estimators, are in concordance with previous litera- 
Table 4.7 - Panel ARDL (Pooled, MG and PMG)

\begin{tabular}{cccc}
\hline \multicolumn{4}{c}{$\begin{array}{c}\text { Pooled } \\
\text { Long Run }\end{array}$} \\
\hline GDP & $1.3842 * * *$ & $1.1235^{* * *}$ & $1.2349 * * *$ \\
POP65 & $1.2146 *$ & 107.383 & $1.9102 * *$ \\
PAT & 0.00002 & -0.0012 & $8.53 \mathrm{E}-06$ \\
PHY & $0.0577 *$ & -0.3144 & $0.0532 * * *$ \\
LL & 0.0215 & -13.082 & -0.0367 \\
\hline \multicolumn{4}{c}{ Short Run } \\
\hline ECT & $-0.1687 * * *$ & -0.2880 & $-0.2146 * *$ \\
D(THE(-1)) & $0.2118 * * *$ & -0.1305 & $0.0957 * *$ \\
D(GDP) & $0.0990^{*}$ & $-0.4424 * *$ & -0.0623 \\
D(PHY) & -0.0038 & 0.1257 & -0.0063 \\
D(POP65) & 0.7703 & 319.630 & -48.818 \\
D(PAT) & $-0.00003 * *$ & -0.0007 & $-0.0001 * *$ \\
D(LL) & 0.0024 & -0.2665 & -0.0159 \\
C & $-1.1716 * * *$ & -108.775 & $-1.0743 * * *$ \\
\hline Log-likelihood & 452.722 & 367.374 & 1996.08 \\
\hline
\end{tabular}

Notes: Dependent variable: D(THE); for the Pooled estimation, Dynamic Fixed Effects (DFE) are considered; standard errors are corrected for possible heteroscedasticity in the cross-sectional variances; Lag length for each country selected based on the Akaike information criterion; *,** and **** indicates statistical significance at $10 \%, 5 \%$, and $1 \%$, respectively.

ture, and provide insights about the slope homogeneity. Since the estimators considering non-homogeneous slopes are the ones performing better, we conclude that heterogeneity exists for OECD countries and that it should be considered in the selection of adequate models. According to the Hausman tests performed, the best model is the ARDL-PMG. As so, further analysis is made based on its estimation results.

The long-run relationships show that GDP, POP65, and PHY have a positive and statistically significant impact on health expenditures, with income elasticity being greater than one (1.23). Contrarily, PAT and LL are found to be not significant to explain health expenditures. These results are somehow similar with the ones provided by DOLS and FMOLS estimations, only being different regarding the significance of the LL variable, and in the magnitude of the effects.

Regarding the short-run estimation results, the negative and statistically significant error correction term confirms the existence of a long-run relationship among the variables con- 
sidered. This coefficient $(-0.21)$ shows that about $20 \%$ of the disequilibrium is corrected each year, and that the variable contributing the most to the adjustment is the healthcare expenditures itself (responsible for $10 \%$ of the annual correction). The variable PAT also has a significant adjustment coefficient, but all the others (GDP, POP65, LL and PHY) seem irrelevant to the adjustment process of health expenditures in the short-run, which follows previous results for OECD and might indicate that these variables are weak exogenous (Okunade et al., 2018). The country-specific short-run coefficients for the PMG estimation are provided in the appendix (Table 4.14).

Finally, our third approach to the study of the relationship between healthcare expenditures is based on a Dynamic Common Correlated Effects model. Due to the cross-section dependence previously found (Table 4.2), from all the applied methodologies this one should be the most reliable as it accounts for essential characteristics of the data. Results for Pooled, MG and PMG estimators are presented in Table 4.8.

Similarly to the ARDL model, the results differ considerably between the three estimators, both for the long- and for the short-run. Also in line with the ARDL model, coefficients for GDP and PHY are positive and statistically significant, and both PAT and LL are found to be insignificant.

The main difference between the results arising from ARDL and DCCE is in the effect of the variable POP65, which was statistically significant and turns out to be insignificant when accounting for cross-section dependence. Although these results seem inconsistent, they confirm the results of earlier studies on OECD health expenditures, which have found the variable to be significant by using ARDL models (Okunade et al., 2018) and nonsignificant through the use of CCE models (Baltagi and Moscone, 2010).

Regarding the income elasticities, results from DCCE confirm what was previously verified through the other approaches: that within-group estimators seem to provide larger elasticities than between-group estimators, by not accounting for cross-country heterogeneity. Therefore, the results suggest that income elasticity is below but closer to one, and that health expenditure is not a luxury good, which is broadly consistent with recent studies for OECD countries (Hosoya, 2014; Blazquez-Fernandez et al., 2014; Tian et al., 2018). 
Table 4.8 - Panel DCCE (Pooled, MG and PMG)

\begin{tabular}{|c|c|c|c|}
\hline & DCCE-Poolec & DCCE-MG & DCCE-PMG \\
\hline \multicolumn{4}{|c|}{ Long Run } \\
\hline GDP & $1.0246 * * *$ & $0.8539 * * *$ & $0.9672 * * *$ \\
\hline POP65 & 4.2262 & -17.1569 & 2.3686 \\
\hline PAT & -0.0001 & -0.0002 & -0.0001 \\
\hline PHY & $0.1112 * *$ & 0.1160 & $0.1059 * *$ \\
\hline LL & -0.0501 & -0.4147 & -0.0714 \\
\hline \multicolumn{4}{|c|}{ Short Run } \\
\hline ECT & $-0.4593 * * *$ & $-0,9126 * * *$ & $-0.4903 * * *$ \\
\hline $\mathrm{D}(\mathrm{THE}(-1))$ & $0.1028 * * *$ & $0.2463 * * *$ & $0.1550 * * *$ \\
\hline $\mathrm{D}(\mathrm{GDP})$ & -0.2075 & 0.0010 & -0.1689 \\
\hline D(PHY) & -0.0333 & -0.0985 & -0.0024 \\
\hline D(POP65) & -1.3911 & 0.6691 & -4.9365 \\
\hline $\mathrm{D}(\mathrm{PAT})$ & -0.0000 & -0.0001 & -0.0001 \\
\hline $\mathrm{D}(\mathrm{LL})$ & 0.0330 & 0.0169 & 0.0629 \\
\hline $\mathrm{C}$ & -3.9771 & $11.0923 * *$ & -0.6157 \\
\hline CD statistic & $4.52 * * *$ & $1.05 * *$ & $2.64 * * *$ \\
\hline
\end{tabular}

Regarding the short-run estimates, the negative and statistically significant error correction term supports the existence of a long-run relationship among the variables considered. This coefficient in the DCCE-PMG estimation shows a faster speed of adjustment than the one estimated using the ARDL-PMG, of about 50\% correction per year, being the lagged variable THE the main responsible for the adjustment to the long-run equilibrium after a shock. The country-specific short-run coefficients for the DCCE-PMG estimation are provided in the appendix (Table 4.15). Hausman tests were also performed to conclude about the consistency and efficiency of the three estimators. The results, presented in Table 4.13 in the appendix, show that, also for the DCCE model, the PMG estimator is preferred to both Pooled and MG, and confirm the superiority of the between-group estimators and the heterogeneity in OECD countries.

The synthesis of the results that were obtained with the different models and estimators, provided in Table 4.9, clearly shows that different methods lead to different conclusions regarding the effect of the considered drivers in the evolution of health expenditures.

This lack of unanimity, added to the lack of consensus in the literature (which is evident 
Table 4.9 - Summary of the results

\begin{tabular}{cccccccccccccc}
\multirow{2}{*}{ Results } & \multicolumn{3}{c}{ DOLS } & \multicolumn{4}{c}{ FMOLS } & \multicolumn{1}{c}{ ARDL } & \multicolumn{2}{c}{ DCCE } \\
\cline { 2 - 15 } & P & PW & GM & P & PW & GM & P & MG & PMG & P & MG & PMG \\
\hline Income elasticity & $>1$ & $>1$ & $<1$ & $<1$ & $<1$ & $<1$ & $>1$ & $>1$ & $>1$ & $>1$ & $<1$ & $<\mathbf{1}$ \\
Ageing & + & + & 0 & + & + & + & 0 & 0 & + & 0 & 0 & $\mathbf{0}$ \\
Technology & 0 & 0 & 0 & 0 & 0 & 0 & 0 & 0 & 0 & 0 & 0 & $\mathbf{0}$ \\
Human Resources & + & + & + & + & + & + & 0 & 0 & + & + & + & + \\
Health problems & - & - & - & - & - & - & 0 & 0 & 0 & 0 & 0 & $\mathbf{0}$ \\
\hline
\end{tabular}

Notes: $>1$ and $<1$ indicates income elasticity above and below one, respectively;

+ / - represent statistically significant positive / negative relationship, and 0 stands for statistically insignificant relationship.

in Table 4.10, comparing the results of DCCE-PMG approach with the previous results reported in the literature), calls the attention for the need of having a structured framework to help on the selection of the most appropriate methodology to approach the subject.

Table 4.10 - Comparison with previous literature

\begin{tabular}{|c|c|c|}
\hline Driver & Studies with results according to DCCE-PMG & Studies with results contrary to DCCE-PMG \\
\hline Income & $\begin{array}{c}\text { Blomqvist and Carter (1997), Gerdtham et al. (1998), } \\
\text { Barros (1998), Herwartz and Theilen (2003), } \\
\text { Okunade et al. (2004), Sen (2005), Mosca (2007), } \\
\text { Hartwig (2008), Chakroun (2010), } \\
\text { Baltagi and Moscone (2010), Wang (2011), } \\
\text { Lago-Peñas et al.(2013), Hartwig and Sturm (2014), } \\
\text { Hosoya (2014), Blasquez-Fernandez et al. (2014), } \\
\text { Tian et at. (2018) }\end{array}$ & $\begin{array}{c}\text { Gerdtham (1992), Roberts (1999), } \\
\text { Dreger and Reimers (2005), Dormont et al. (2010), } \\
\text { Mehara et al. (2010), Liu et al. (2011), } \\
\text { Yu at al. (2011), Okunade et al. (2018) }\end{array}$ \\
\hline Ageing & $\begin{array}{c}\text { Gerdtham et al. (1998), Barros (1998), } \\
\text { Roberts (1999), Herwartz and Theilen (2003), } \\
\text { Sen (2005), Baltagi and Moscone (2010), } \\
\text { Hosoya (2014), Blasquez-Fernandez et al. (2014) }\end{array}$ & $\begin{array}{c}\text { Gerdtham (1992), Okunade et al. (2004), } \\
\text { Dreger and Reimers (2005), Mosca (2007), } \\
\text { Chakroun (2010), Dormont et al. (2010), } \\
\text { Liu et al. (2011), Yu at al. (2011), } \\
\text { Lago-Peñas et al.(2013), Hartwig and Sturm (2014), } \\
\text { Okunade et al. (2018), Tian et at. (2018) }\end{array}$ \\
\hline Technology & Gerdtham et al. (1998), Herwartz and Theilen (2003) & $\begin{array}{l}\text { Blomqvist and Carter (1997), Hartwig (2008), } \\
\text { Blasquez-Fernandez et al. (2014), Hosoya (2014), } \\
\text { Hartwig and Sturm (2014), Okunade et al. (2018) }\end{array}$ \\
\hline $\begin{array}{c}\text { Human } \\
\text { Resources }\end{array}$ & $\begin{array}{c}\text { Gerdtham et al. (1998), Okunade et al. (2004), } \\
\text { Sen (2005), Mosca (2007), Yu at al. (2011), } \\
\text { Hartwig and Sturm (2014) }\end{array}$ & Tian et at. (2018) \\
\hline Health problems & Sen (2005) & Dreger and Reimers (2005), Tian et at. (2018) \\
\hline
\end{tabular}

\subsubsection{Panel Framework Selection}

As the range of considerations and methodologies for panel analyses is vast, and given sensibility of the results to the selected approach, we propose a framework to guide the 
selection of panel models and estimators. This framework, presented in Figure 4.1, aims to help in selecting the most appropriate methodology, avoiding that some fundamental characteristics of the data are disregarded and, consequently, that the inference regarding the relevance of the health expenditures drivers is biased or incorrect. The framework can be used for cointegrated panels with both $\mathrm{T}$ and $\mathrm{N}$ large, which encompasses most of the panels used in macroeconomic studies.

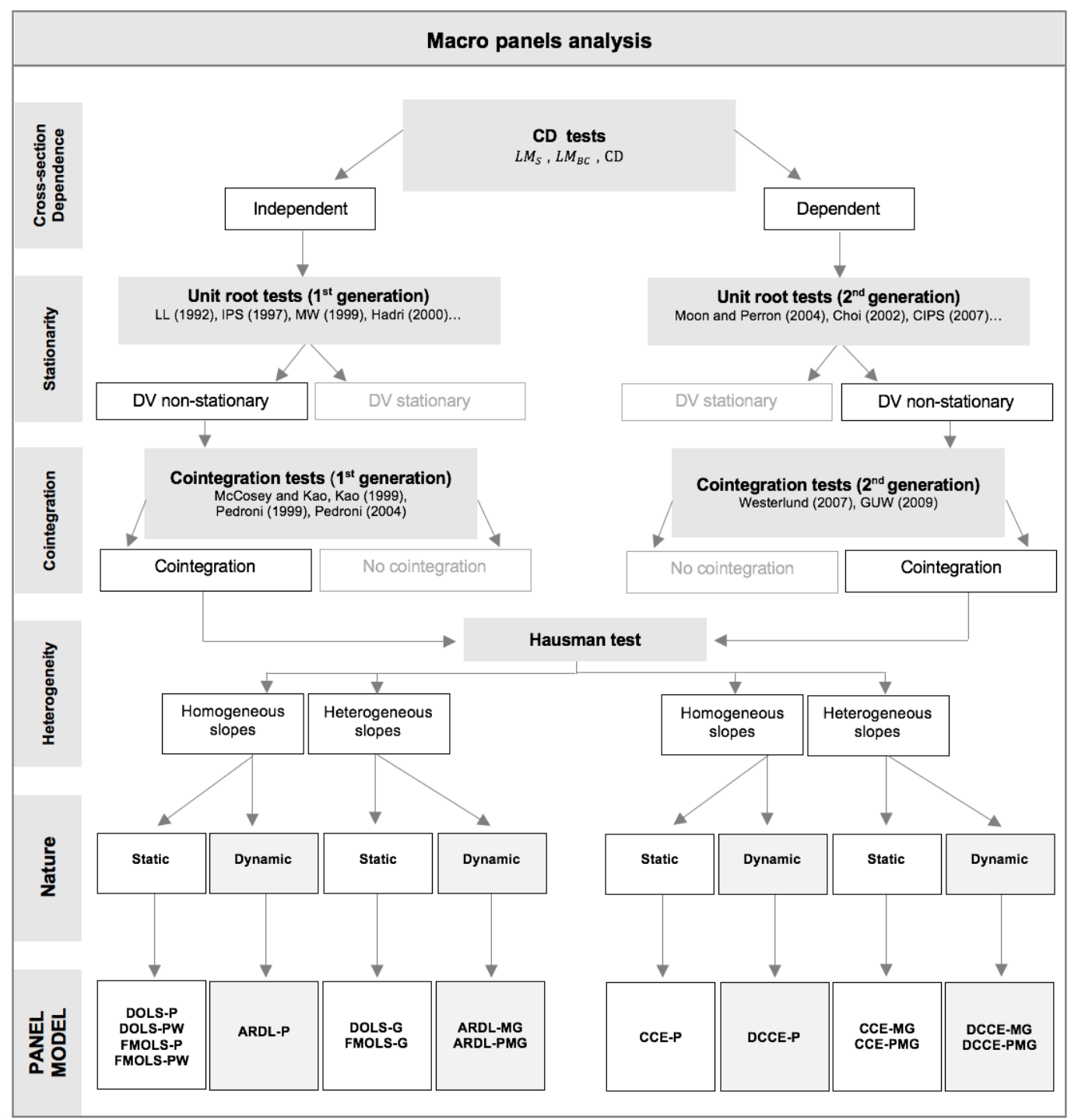

Figure 4.1 - Framework for selecting the model for cointegrated macro panels 
We suggest starting with the analysis of cross-section dependence. The cross-section dependence tests used should be the ones that are adapted to deal with large $\mathrm{N}$ settings: $L M_{S}$, $L M_{B C}$, or CD. The results of the cross-section dependence tests will dictate the rest of the approach: if there is evidence of dependency, second-generation of panel unit root tests and cointegration tests must be performed. If the cross-sections are found to be independent, first-generation tests are adequate to infer on both the stationarity and on the existence of a long-run relationship among the variables.

Cointegration tests are only performed if variables are non-stationary. If the stationarity hypothesis is not rejected, different methodologies should be considered, such as Fixed Effects (FE) or Random Effects (RE) panel models. Additionally, if variables are nonstationary but no evidence of cointegration among them is found, alternative models including transformed stationary variables (such as the variables in their first differences) should be considered.

For panels found to be cointegrated, which are the focus of the proposed framework, two types of models can be applied, independently of exhibiting or not cross-section dependence: the ones constraining the coefficients to be the same for all the cross-section units and others allowing for different slopes across cross-sections. The selection between these two types may be based on theoretical arguments or previous empirical analysis, but the most recommended is either to assume heterogeneity or estimate both types, and further compare the consistency and efficiency of the estimators through the Hausman test. Finally, the selection of the adequate model is only dependent on whether the model should or not be a dynamic model, which depends on the subject that the model is intended to study. Given the dynamic nature of most macroeconomic variables, dynamic models in this field are likely to be more appropriate than static models. Summarily, for cointegrated panels without cross-section dependence, the recommended models are: DOLS-P, DOLSPW, FMOLS-P and FMOLS-PW (for static nature and homogeneous slopes); ARDL-P (for dynamic nature and homogeneous slopes); DOLS-G and FMOLS (for static nature and heterogeneous slopes); and ARDL-MG and ARDL-PMG (for dynamic nature and heterogeneous slopes). For cointegrated panels with cross-section dependence, we suggest 
the following models: CCE-P (for static nature and homogeneous slopes); DCCE-P (for dynamic nature and homogeneous slopes); CCE-MG and CCE-PMG (for static nature and heterogeneous slopes); and DCCE-MG and DCCE-PMG (for dynamic nature and heterogeneous slopes).

\subsection{Conclusions}

In this paper, we synthesize the methodological advances which, in the last decades, have been guiding the macro studies of health expenditures from simple cross-country or timeseries analysis to most advanced panel studies. Regarding the previous literature on health expenditures, contradictions on the factors driving health expenditures were also emphasized. These contradictory results (such as the ones concerning the effect of the share of population over 65 years or the magnitude of the income elasticity of health expenditures) were hypothesized to be not only the result of the dataset considered (as conflicting results are found even for the same or similar datasets), but also due to the characteristics of the data that are accounted for and to the subsequent model that is applied to the study of the relationship between healthcare and its potential determinants. Using recent panel data on 34 OECD countries during 35 years (1980-2014), we studied the main characteristics of the data: stationarity, cointegration, homogeneity, and cross-section dependence. Moreover, we compare different models (DOLS, FMOLS, ARDL, and DCCE) and estimation methods (Pooled, MG, and PMG) used in recent works studying the relationship between health expenditures and its drivers. Also, the drivers considered were the ones identified in the literature as the most relevant drivers of health expenditures, both from the demand- (economic, demographic and health-related factors) and supply-side (technology and human resources). Results show that variables are non-stationary and cointegrated, thus confirming the existence of a long-run relationship between health expenditures and the considered drivers. Furthermore, there is evidence of both heterogeneity and cross-section dependence for OECD countries. The comparison of the results arriving from different methodological approaches shows that the conclusions on the relevance of each driver are highly influenced 
by the methods applied. The estimation of the relationship between the health expenditures and its determinants, using different econometric techniques, show that: 1) the selection of both the model and the estimation method may significantly influence the results and subsequent inference regarding the effect of the drivers in health expenditures; 2) FMOLS and DOLS approaches identified more statistically significant factors than ARDL (namely, the health-related driver considered); 3) ARDL estimations provide larger (>1) income elasticities than the rest of the approaches, as well as the pooled estimators; 4) the existence of a long-relationship is confirmed by the sign and magnitude of all the error correction terms; 5) the variable contributing the most to the return to the long-run equilibrium is the health expenditures itself; 6) there is slope heterogeneity for OECD countries that should be considered in the selection of the most adequate approach; 7) some variables that previously seemed relevant turn out to be not statistically significant by correctly accounting for the cross-section dependence in the data (such as the case of the population over 65 years old); 8) the number of physicians positively affect the level of health expenditures in the long-run; and 9) there is evidence for income elasticities below (but close) to the unit. Overall, approaches not accounting for neither heterogeneity or cross-section dependence show that almost all the considered drivers are relevant, whether the income and number of physicians are the only statistically significant factors when heterogeneity and dependence across countries are taken into account. Studying the characteristics of the data is essential. Results arising from the analysis of stationarity, cointegration, heterogeneity and cross-section dependence should be taken into account so that the models and estimation methods selected are appropriate and, consequently, the inference is reliable. As so, a framework selection for macro panels is proposed, to help on the selection of the adequate approach according to the main characteristics of the data.

Overall, this work contributes to the research field by showing that the selection of the methodological approach is crucial for a better understanding of the health expenditures, by presenting insights regarding the factors driving the health expenditures, and by providing guidelines to help on the selection of the most appropriate approach. Notwithstanding, interesting insights may arise from future empirical studies applying the proposed frame- 
work for selection of the methodological approach for different contexts or data sets (e.g., for groups of developing countries), considering different variables to represent each driver (such as the inclusion of a time trend in the models, instead of using a specific variable representing the technological progress), or even including other drivers than those that were considered in this study. Moreover, further work on the development and enlargement of the framework hereby provided to include different situations and models (e.g., appropriate panel models when $\mathrm{N}$ or $\mathrm{T}$ are small) may also be helpful, not only for health economics research but also for other fields that are facing challenges on the selection of the appropriate methodological approach due to the lack of consensus in the literature.

\section{Bibliography}

S. M. Abdullah, S. Siddiqua, and R. Huque. Is health care a necessary or luxury product for asian countries? an answer using panel approach. Health Economics Review, 7(1):4, Jan 2017. ISSN 2191-1991.

D. W. Andrews. Cross-section regression with common shocks. Econometrica, 73(5): 1551-1585, 2005.

V. Atella and G. Marini. Is health care expenditure really a luxury good? re-assessment and new evidence based on oecd data. Re-Assessment and New Evidence Based on OECD Data (November 2006), 2006.

V. Atella, J. Bhattacharya, and L. Carbonari. Pharmaceutical price controls and minimum efficacy regulation: Evidence from the united states and italy. Health Services Research, 47(1pt1):293-308, 2012.

J. Bai and S. Ng. A panic attack on unit roots and cointegration. Econometrica, 72(4): 1127-1177, 2004. ISSN 00129682, 14680262.

B. Baltagi. Econometric analysis of panel data. John Wiley \& Sons, 2008. 
B. H. Baltagi and F. Moscone. Health care expenditure and income in the oecd reconsidered: Evidence from panel data. Economic Modelling, 27(4):804 - 811, 2010. ISSN 0264-9993. Special Issue on Health Econometrics.

B. H. Baltagi, Q. Feng, and C. Kao. A lagrange multiplier test for cross-sectional dependence in a fixed effects panel data model. Journal of Econometrics, 170(1):164 - 177, 2012. ISSN 0304-4076.

P. P. Barros. The black box of health care expenditure growth determinants. Health Economics, 7(6):533-544, 1998.

C. Blazquez-Fernandez, D. Cantarero, and P. Perez. Disentangling the heterogeneous income elasticity and dynamics of health expenditure. Applied Economics, 46(16):18391854, 2014.

A. Blomqvist and R. Carter. Is health care really a luxury? Journal of Health Economics, 16(2):207 - 229, 1997. ISSN 0167-6296.

T. Bodenheimer. High and Rising Health Care Costs. Part 2: Technologic Innovation. Annals of Internal Medicine, 142(11):932-937, 06 2005. ISSN 0003-4819.

T. S. Breusch and A. R. Pagan. The lagrange multiplier test and its applications to model specification in econometrics. The Review of Economic Studies, 47(1):239-253, 1980. ISSN 00346527, 1467937X.

M. Chakroun. Health care expenditure and gdp: An international panel smooth transition approach. International Journal of Economics, 4(1):189-200, 2010a.

M. Chakroun. Health care expenditure and gdp: An international panel smooth transition approach. International Journal of Economics, 4:189-200, 2010b.

Y. Chang. Nonlinear iv unit root tests in panels with cross-sectional dependency. Journal of econometrics, 110(2):261-292, 2002. 
I. Choi. Unit root tests for panel data. Journal of international money and Finance, 20(2): 249-272, 2001.

I. Choi. Combination unit root tests for cross-sectionally correlated panels. Econometric Theory and Practice: Frontiers of Analysis and Applied Research: Essays in Honor of Peter CB Phillips. Cambridge University Press, Chapt, 11:311-333, 2006.

W. L. Chou. Explaining china's regional health expenditures using lm-type unit root tests. Journal of Health Economics, 26(4):682-698, 2007.

A. Chudik and H. Pesaran. Large panel data models with cross-sectional dependence. In The Oxford Handbook of Panel Data. 2015.

A. Chudik, K. Mohaddes, M. H. Pesaran, and M. Raissi. Long-Run Effects in Large Heterogeneous Panel Data Models with Cross-Sectionally Correlated Errors, chapter 4, pages 85-135. 2016.

A. J. Culyer and J. P. Newhouse. Handbook of health economics. Elsevier, 2000.

C. de la Maisonneuve and J. O. Martins. Public spending on health and long-term care. (6), 2013.

B. Dormont, J. Oliveira Martins, F. Pelgrin, and M. Suhrcke. Health expenditures, longevity and growth. Florian and Suhrcke, Marc, Health Expenditures, Longevity and Growth, 2008.

C. Dreger and H.-E. Reimers. Health care expenditures in oecd countries: a panel unit root and cointegration analysis. 2005.

R. F. Engle and C. W. Granger. Co-integration and error correction: representation, estimation, and testing. Econometrica: journal of the Econometric Society, pages 251-276, 1987.

EUC. The 2018 ageing report: Economic and budgetary projections for the eu member states (2016-2070). European Commission., 2018. 
R. W. Fogel. Forecasting the cost of u.s. health care in 2040. Journal of Policy Modeling, 31(4):482 - 488, 2009. ISSN 0161-8938.

C. Gengenbach, J. Urbain, and J. Westerlund. Panel error correction testing with global stochastic trends. 2008.

U.-G. Gerdtham. Pooling international health care expenditure data. Health Economics, 1 (4):217-231, 1992.

U.-G. Gerdtham and M. Löthgren. On stationarity and cointegration of international health expenditure and gdp. Journal of Health Economics, 19(4):461-475, 2000.

U.-G. Gerdtham and M. Löthgren. New panel results on cointegration of international health expenditure and gdp. Applied Economics, 34(13):1679-1686, 2002.

U.-G. Gerdtham, J. Sogaard, F. Andersson, and B. Jonsson. An econometric analysis of health care expenditure: A cross-section study of the oecd countries. Journal of Health Economics, 11(1):63-84, 1992.

U.-G. Gerdtham, B. Jönsson, M. MacFarlan, and H. Oxley. The determinants of health expenditure in the oecd countries: a pooled data analysis. In Health, the medical profession, and regulation, pages 113-134. Springer, 1998.

T. E. Getzen. Forecasting health expenditures: Short, medium and long (long) term. Journal of Health Care Finance, 26(3):56-72, 2000.

T. E. Getzen and J.-P. Poullier. International health spending forecasts: concepts and evaluation. Social Science $\mathcal{E}$ Medicine, 34(9):1057-1068, 1992.

K. Hadri. Testing for stationarity in heterogeneous panel data. The Econometrics Journal, 3(2):148-161, 2000.

P. Hansen and A. King. The determinants of health care expenditure: A cointegration approach. Journal of Health Economics, 15(1):127 - 137, 1996. ISSN 0167-6296. 
J. Hartwig. What drives health care expenditure?-baumol's model of 'unbalanced growth' revisited. Journal of Health Economics, 27(3):603 - 623, 2008.

J. Hartwig and J.-E. Sturm. Robust determinants of health care expenditure growth. Applied Economics, 46(36):4455-4474, 2014.

H. Herwartz and B. Theilen. The determinants of health care expenditure: testing pooling restrictions in small samples. Health Economics, 12(2):113-124, 2003.

K. Hosoya. Determinants of health expenditures: Stylized facts and a new signal. Modern Economy, page 1171-1180, 2014.

C. Hurlin and V. Mignon. Second generation panel unit root tests. Working papers, HAL, 2007.

J. L. C. i Silvestre. Health care expenditure and gdp: Are they broken stationary? Journal of Health Economics, 24(5):839 - 854, 2005. ISSN 0167-6296.

K. S. Im, M. H. Pesaran, and Y. Shin. Testing for unit roots in heterogeneous panels. Journal of econometrics, 115(1):53-74, 2003.

T. Jewell, J. Lee, M. Tieslau, and M. C. Strazicich. Stationarity of health expenditures and gdp: evidence from panel unit root tests with heterogeneous structural breaks. Journal of Health Economics, 22(2):313-323, 2003.

C. Kao. Spurious regression and residual-based tests for cointegration in panel data. Journal of econometrics, 90(1):1-44, 1999.

C. Kao and M.-H. Chiang. On the estimation and inference of a cointegrated regression in panel data, pages 179-222. 2001.

S. Lago-Peñas, D. Cantarero-Prieto, and C. Blázquez-Fernández. On the relationship between gdp and health care expenditure: A new look. Economic Modelling, 32:124 129, 2013. ISSN 0264-9993. 
R. E. Leu. The public-private mix and international health care costs, culyer, a.j., jonsson, b.; basil blackwell oxford, england. Public and Private Health Services., 1986.

A. Levin, C.-F. Lin, and C.-S. J. Chu. Unit root tests in panel data: asymptotic and finitesample properties. Journal of econometrics, 108(1):1-24, 2002.

D. Liu, R. Li, and Z. Wang. Testing for structural breaks in panel varying coefficient models: with an application to oecd health expenditure. Empirical Economics, 40(1): 95-118, Feb 2011. ISSN 1435-8921.

G. S. Maddala and S. Wu. A comparative study of unit root tests with panel data and a new simple test. Oxford Bulletin of Economics and Statistics, 61(S1):631-652, 1999.

N. C. Mark and D. Sul. A computationally simple cointegration vector estimator for panel data.

N. C. Mark and D. Sul. Cointegration vector estimation by panel dols and long-run money demand. Oxford Bulletin of Economics and Statistics, 65(5):655-680, 2003.

L. D. Matteo. The macro determinants of health expenditure in the united states and canada: assessing the impact of income, age distribution and time. Health Policy, 71(1):23 - 42, 2005. ISSN 0168-8510.

S. McCoskey and C. Kao. A residual-based test of the null of cointegration in panel data. Econometric Reviews, 17(1):57-84, 1998.

S. K. McCoskey and T. M. Selden. Health care expenditures and gdp: panel data unit root test results. Journal of health economics, 17(3):369-376, 1998.

A. H. Mehrara M, Musai M. The relationship between health expenditure and gdp in oecd countries using pstr. Eur J Econ Financ Adm Sci., 2010.

B. Mohammed. Determinants for demand for health care services in mekelle city. Ethiop Heal Reforms, 22:102-10, 2013. 
H. R. Moon and B. Perron. Testing for a unit root in panels with dynamic factors. Journal of Econometrics, 122(1):81 - 126, 2004. ISSN 0304-4076.

H. R. Moon, B. Perron, and P. C. Phillips. Incidental trends and the power of panel unit root tests. Journal of Econometrics, 141(2):416-459, 2007.

I. Mosca. Decentralization as a determinant of health care expenditure: empirical analysis for oecd countries. Applied Economics Letters, 14(7):511-515, 2007.

F. Moscone and E. Tosetti. Health expenditure and income in the united states. Health economics, 19(12):1385-1403, 2010.

F. Moscone, M. Knapp, and E. Tosetti. Mental health expenditure in england: a spatial panel approach. Journal of Health Economics, 26(4):842-864, 2007.

N. V. Murthy and V. Ukpolo. Aggregate health care expenditure in the united states: evidence from cointegration tests. Applied Economics, 26(8):797-802, 1994.

V. N. Murthy and A. A. Okunade. Determinants of u.s. health expenditure: Evidence from autoregressive distributed lag (ardl) approach to cointegration. Economic Modelling, 59: 67 - 73, 2016. ISSN 0264-9993.

J. P. Newhouse. Medical-care expenditure: a cross-national survey. The Journal of Human Resources, 12(1):115-125, 1977.

J. P. Newhouse. Cross national differences in health spending what do they mean? Journal of Health Economics, 6(2):159-162, 1987.

J. P. Newhouse. Medical care costs: How much welfare loss? Journal of Economic Perspectives, 6(3):3-21, September 1992.

J. P. Newhouse. Forecasting demand for medical care for the purpose of planning health services. Rand Corporation. 1974.

P. G. O'Connell. The overvaluation of purchasing power parity. Journal of international economics, 44(1):1-19, 1998. 
A. A. Okunade and M. C. Karakus. Unit root and cointegration tests: timeseries versus panel estimates for international health expenditure models. Applied Economics, 33(9): 1131-1137, 2001.

A. A. Okunade and V. N. R. Murthy. Technology as a 'major driver' of health care costs: a cointegration analysis of the newhouse conjecture. Journal of Health Economics, 21(1): 147-159, 2002.

A. A. Okunade, M. C. Karakus, and C. Okeke. Determinants of health expenditure growth of the oecd countries: jackknife resampling plan estimates. Health Care Management Science, 7(3):173-183, 2004.

A. A. Okunade, X. You, and K. Koleyni. Cross-country Medical Expenditure Modeling Using OECD Panel Data and ARDL Approach: Investigating GDP, Technology, and Aging Effects, chapter 14, pages 327-358. 2018.

D. Parkin, A. McGuire, and B. Yule. Aggregate health care expenditures and national income: Is health care a luxury good? Journal of Health Economics, 6(2):109-127, 1987.

P. Pedroni. Critical values for cointegration tests in heterogeneous panels with multiple regressors. Oxford Bulletin of Economics and statistics, 61(S1):653-670, 1999.

P. Pedroni. Purchasing power parity tests in cointegrated panels. The Review of Economics and Statistics, 83(4):727-731, 2001a.

P. Pedroni. Fully modified OLS for heterogeneous cointegrated panels, pages 93-130. $2001 b$.

P. Pedroni. Panel cointegration: Asymptotic and finite sample properties of pooled time series tests with an application to the ppp hypothesis. Department of Economics Working Papers 2004-15, Department of Economics, Williams College, 2004. 
M. H. Pesaran. 'General Diagnostic Tests for Cross Section Dependence in Panels'. Cambridge Working Papers in Economics 0435, Faculty of Economics, University of Cambridge, June 2004.

M. H. Pesaran. Estimation and inference in large heterogeneous panels with a multifactor error structure. Econometrica, 74(4):967-1012, 2006. ISSN 00129682, 14680262.

M. H. Pesaran. A simple panel unit root test in the presence of cross-section dependence. Journal of Applied Econometrics, 22(2):265-312, 2007.

M. H. Pesaran and R. Smith. Estimating long-run relationships from dynamic heterogeneous panels. Journal of Econometrics, 68(1):79 - 113, 1995. ISSN 0304-4076.

M. H. Pesaran, Y. Shin, and R. P. Smith. Pooled mean group estimation of dynamic heterogeneous panels. Journal of the American Statistical Association, 94(446):621-634, 1999. ISSN 01621459.

P. C. Phillips and D. Sul. Dynamic panel estimation and homogeneity testing under cross section dependence. The Econometrics Journal, 6(1):217-259, 2003.

P. C. B. Phillips. Understanding spurious regressions in econometrics. Journal of econometrics, 33(3):311-340, 1986.

P. C. B. Phillips and B. E. Hansen. Statistical inference in instrumental variables regression with i(1) processes. The Review of Economic Studies, 57(1):99-125, 1990. ISSN $00346527,1467937 X$

P. C. B. Phillips and H. R. Moon. Linear regression limit theory for nonstationary panel data. Econometrica, 67(5):1057-1111, 1999. ISSN 00129682, 14680262.

B. Przywara, E. C. D.-G. for Economic, and F. Affairs. Projecting Future Health Care Expenditure at European Level: Drivers, Methodology and Main Results. European economy: Economic papers. European Commission, Directorate-General for Economic and Financial Affairs, 2010. ISBN 9789279149030. 
J. Roberts. Sensitivity of elasticity estimates for oecd health care spending: analysis of a dynamic heterogeneous data field. Health Economics, 8(5):459-472, 1999.

P. Saikkonen. Estimation and testing of cointegrated systems by an autoregressive approximation. Econometric Theory, 8(1):1-27, 1992. ISSN 02664666, 14694360.

E. San and P. Wang. The effects of an ageing population and other factors on aggregate health care expenditure in singapore. 1980.

E. Schulz. The influence of supply and demand factors on aggregate health care expenditure with a specific focus on age composition. ENEPRI Research Reports, 16(45), 2005.

A. Sen. Is health care a luxury? new evidence from oecd data. International Journal of Health Care Finance and Economics, 5(2):147-164, 2005.

J. H. Stock and M. W. Watson. A simple estimator of cointegrating vectors in higher order integrated systems. Econometrica, 61(4):783-820, 1993. ISSN 00129682, 14680262.

F. Tian, J. Gao, and K. Yang. A quantile regression approach to panel data analysis of health-care expenditure in organisation for economic co-operation and development countries. Health Economics, 27(12):1921-1944, 2018.

K.-M. Wang. Health care expenditure and economic growth: Quantile panel-type analysis. Economic Modelling, 28(4):1536-1549, 2011.

J. Westerlund. Testing for error correction in panel data*. Oxford Bulletin of Economics and Statistics, 69(6):709-748, 2007.

WHO. World report on ageing and health. World Health Organization., pages 1-260, 2015.

F. Yerdelen. The relationships between the human capital investment and economic growth: A panel error correction model. Journal of Economic and Social Research, 13:77-90, 012011. 
T. H.-K. Yu, D. H.-M. Wang, and L.-Y. Chang. Examining the heterogeneous effect of healthcare expenditure determinants. International Journal of Behavioural and Healthcare Research, 2(205), 2015.

\section{Appendix 4.A Supplementary material}




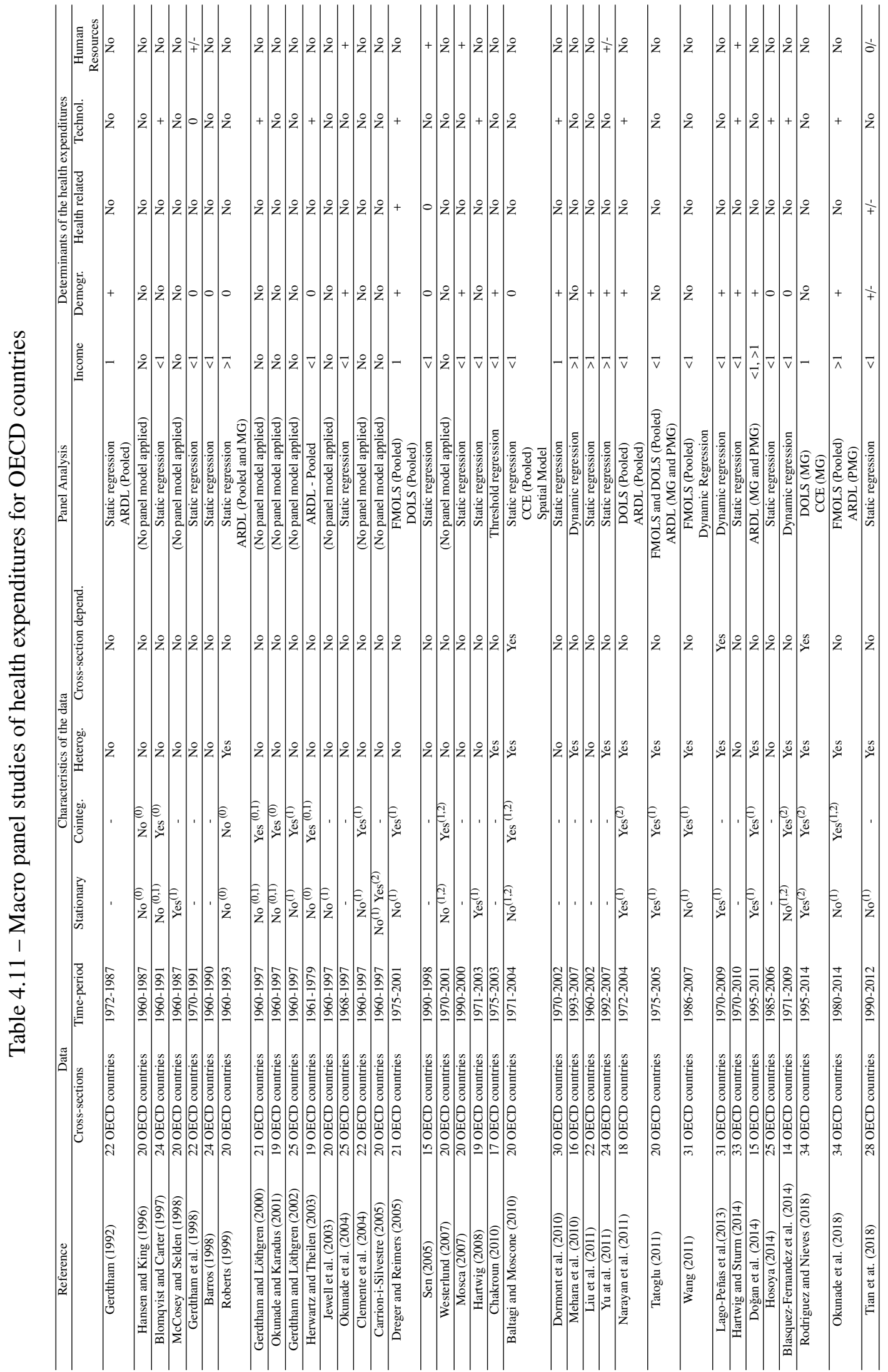


Table 4.12 - Correlation matrix

\begin{tabular}{ccccccc}
\hline & THE & GDP & POP65 & PAT & PHY & YLL \\
\hline THE & 1.00 & & & & & \\
\hline GDP & 0.93 & 1.00 & & & & \\
\hline POP65 & 0.82 & 0.81 & 1.00 & & & \\
\hline PAT & 0.46 & 0.43 & 0.51 & 1.00 & & \\
\hline PHY & 0.75 & 0.77 & 0.73 & 0.52 & 1.00 & \\
\hline LL & 0.82 & 0.77 & 0.68 & 0.43 & 0.79 & 1.00
\end{tabular}

Table 4.13 - Hausman tests

\begin{tabular}{ccccccc}
\hline & ARDL & & DCCE \\
\hline & MG/P & PMG/P & MG/PMG & MG/P & PMG/P & MG/PMG \\
\hline Hausman Stat. & $217.12^{* * *}$ & $20.65^{* *}$ & 11.50 & $31.36^{* * *}$ & $10.07^{* *}$ & 5.60 \\
\hline
\end{tabular}


Table 4.14 - Country-specific short-run effects (ARDL-PMG)

\begin{tabular}{|c|c|c|c|c|c|c|c|c|}
\hline & Coint. Eq. & $\mathrm{D}(\mathrm{THE}(-1))$ & $\mathrm{D}$ (GDP) & $\mathrm{D}(\mathrm{LL})$ & D(POP65) & $\mathrm{D}$ (PHY) & $\mathrm{D}$ (PAT) & Cons \\
\hline \multirow[t]{2}{*}{ Australia } & $-0,0592$ & 0,0898 & 0,1618 & $-0,1331$ & $-1,7153$ & $-0,0299$ & 0,0001 & $-0,2792$ \\
\hline & $-0,0705$ & $-0,1814$ & $-0,1434$ & $-0,1219$ & $-3,3878$ & $-0,0435$ & $-0,0001$ & $-0,3652$ \\
\hline \multirow[t]{2}{*}{ Austria } & $-0,0934$ & $0,1836^{* * * *}$ & $0,8145^{* *}$ & $-0,0164$ & 1,2499 & 0,1294 & $-0,0001$ & $-0,4781$ \\
\hline & $-0,0608$ & $-0,0374$ & $-0,4503$ & $-0,3036$ & $-3,58$ & $-0,1895$ & $-0,0001$ & $-0,321$ \\
\hline \multirow[t]{2}{*}{ Belgium } & $-0,1276^{* * *}$ & $-0,0111$ & $-0,4683 *$ & $-0,1837$ & 0,8652 & $-0,026$ & 0,0001 & $-0,6269^{* * *}$ \\
\hline & $-0,0441$ & $-0,0172$ & $-0,2613$ & $-0,1931$ & $-2,3766$ & $-0,0168$ & $-0,0001$ & $-0,2389$ \\
\hline \multirow[t]{2}{*}{ Canada } & $-0,2213^{* * * *}$ & 0,014 & $-0,4293^{* * *}$ & $-0,171$ & $-7,5246$ & $0,2330^{*}$ & 0.0000 & $-1,0609^{* * * *}$ \\
\hline & $-0,0528$ & $-0,018$ & $-0,1283$ & $-0,1628$ & $-4,7853$ & $-0,1359$ & $(0.0000)$ & $-0,301$ \\
\hline \multirow[t]{2}{*}{ Czech Republic } & $-0,3761^{* * *}$ & 0,1902 & $-0,3194$ & $-0,5392$ & 1,7256 & 0,2288 & $-0,0004$ & $-1,9876^{* * * *}$ \\
\hline & $-0,1404$ & $-0,1703$ & $-0,4074$ & $-0,5357$ & $-8,3804$ & $-0,153$ & $-0,0005$ & $-0,8047$ \\
\hline \multirow[t]{2}{*}{ Denmark } & $-0,1987 * * * *$ & 0,0198 & $-0,5200^{* * *}$ & $0,4878^{* * * *}$ & 0,1958 & 0,1227 & $-0,0001$ & $-0,9786^{* * *}$ \\
\hline & $-0,0743$ & $-0,1483$ & $-0,2131$ & $-0,1495$ & $-2,7611$ & $-0,0751$ & $-0,0001$ & $-0,4166$ \\
\hline \multirow[t]{2}{*}{ Estonia } & $-0,2298^{* * *}$ & $0,3081^{* *}$ & $-0,0577$ & $-0,0136$ & $8,1042 *$ & $0,2300^{* *}$ & $-0,0006^{* *}$ & $-1,2435^{* * * *}$ \\
\hline & $-0,0874$ & $-0,1449$ & $-0,1182$ & $-0,0904$ & $-4,7026$ & $-0,0995$ & $-0,0003$ & $-0,4641$ \\
\hline \multirow[t]{2}{*}{ Finland } & $-0,2491^{* * * *}$ & $0,3394 * * *$ & $-0,2283$ & 0,1604 & $-0,1134$ & $-0,0986$ & $-0,0001$ & $-1,2515^{* * *}$ \\
\hline & $-0,0579$ & $-0,1287$ & $-0,1727$ & $-0,1972$ & $-3,1345$ & $-0,0981$ & $-0,0001$ & $-0,348$ \\
\hline \multirow[t]{2}{*}{ France } & $-0,3955^{* * * *}$ & $-0,106$ & $-0,1938$ & $-0,2333$ & 7,2619 & $-0,4753$ & 0 & $-1,9386^{* * * *}$ \\
\hline & $-0,1359$ & $-0,1751$ & $-0,3483$ & $-0,3198$ & $-5,6851$ & $-0,4218$ & 0 & $-0,7021$ \\
\hline \multirow[t]{2}{*}{ Germany } & 0,0386 & $-0,2562$ & 0,2349 & 0,2903 & $-2,5748$ & $-0,1584$ & 0 & 0,2456 \\
\hline & $-0,1267$ & $-0,2148$ & $-0,2829$ & $-0,277$ & $-2,8878$ & $-0,1644$ & 0 & $-0,6417$ \\
\hline \multirow[t]{2}{*}{ Greece } & $-0,3723^{* * * *}$ & 0,2498 & $0,7544 *$ & $-0,5017$ & $-26,7122$ & $-0,3271$ & $-0,0003$ & $-1,8119^{* *}$ \\
\hline & $-0,1414$ & $-0,1742$ & $-0,452$ & $-0,6257$ & $-19,5791$ & $-0,2338$ & $-0,001$ & $-0,796$ \\
\hline \multirow[t]{2}{*}{ Hungary } & $-0,4464 * *$ & $-0,0324$ & $0,8325^{* *}$ & 0,3577 & $-30,7044 * *$ & 0,0012 & 0,0001 & $-2,2142^{* * *}$ \\
\hline & $-0,1909$ & $-0,1908$ & $-0,4135$ & $-0,3982$ & $-14,4584$ & $-0,0469$ & $-0,0004$ & $-1,0723$ \\
\hline Iceland & $-0,3464^{* * *}$ & $0,3164 * * *$ & 0,2778 & $-0,0378$ & $-10,6890^{*}$ & 0,0138 & 0,0005 & $-1,7273^{* * *}$ \\
\hline & $-0,0964$ & $-0,1101$ & $-0,193$ & $-0,0545$ & $-6,4783$ & $-0,1064$ & $-0,0011$ & $-0,5373$ \\
\hline Ireland & $-0,2233^{* * *}$ & 0,2582 & $-0,3736^{*}$ & 0,2127 & 7,3499 & 0,0624 & $-0,0002$ & $-1,0979^{* * *}$ \\
\hline & $-0,0593$ & $-0,1668$ & $-0,1985$ & $-0,1403$ & $-5,8237$ & $-0,0451$ & $-0,0002$ & $-0,3177$ \\
\hline Israel & $-0,5383^{* * *}$ & 0,0343 & $-0,0236$ & 0,2711 & $-16,1352^{* * *}$ & 0,01 & 0,0001 & $-2,7306^{* * * *}$ \\
\hline & $-0,1756$ & $-0,1783$ & $-0,3219$ & $-0,1839$ & $-8,2337$ & $-0,0367$ & $-0,0001$ & $-1,0464$ \\
\hline Italy & $-0,2229^{* *}$ & 0,1427 & 0,146 & 0,0448 & 0,8088 & $-0,0688$ & 0,0001 & $-1,1591^{* *}$ \\
\hline & $-0,1107$ & $-0,1842$ & $-0,3124$ & $-0,2579$ & $-6,0356$ & $-0,0422$ & $-0,0001$ & $-0,5793$ \\
\hline Japan & 0,0519 & $-0,0137$ & $-0,1666$ & $0,3319^{* *}$ & 1,315 & 0,2288 & 0,0001 & 0,2994 \\
\hline & $-0,0583$ & $-0,0302$ & $-0,2323$ & $-0,1679$ & $-3,6467$ & $-0,6544$ & $-0,0001$ & $-0,3168$ \\
\hline Korea & $-0,2708^{* * *}$ & 0,0237 & $0,4752^{*}$ & 0,0302 & $18,2139^{*}$ & 0,3725 & $-0,0001$ & $-1,4888^{* *}$ \\
\hline & $-0,1075$ & $-0,1632$ & $-0,2723$ & $-0,3684$ & $-10,4531$ & $-0,2862$ & $-0,0003$ & $-0,6185$ \\
\hline Luxembourg & $-0,4186^{* * * *}$ & 0,2964 & $-0,7570^{* *}$ & 0,038 & $28,4010^{*}$ & $-0,0962$ & $-0,0007$ & $-2,2516^{* * * *}$ \\
\hline & $-0,1282$ & $-0,1984$ & $-0,3206$ & $-0,1549$ & $-16,8743$ & $-0,1069$ & $-0,0005$ & $-0,7687$ \\
\hline Mexico & 0,2844 & $-0,3057$ & $-0,0867$ & $-0,7702^{*}$ & $-177,3293^{* * * *}$ & $-0,3611$ & 0,0002 & 1,6358 \\
\hline & $-0,2245$ & $-0,2571$ & $-0,3876$ & $-0,4335$ & $-61,4289$ & $-0,2318$ & $-0,0007$ & $-1,1877$ \\
\hline Netherlands & $-0,1904^{* * *}$ & $-0,0398$ & $-0,3146$ & 0,0746 & 2,1828 & 0,099 & 0,0001 & $-0,9478^{* *}$ \\
\hline & $-0,0822$ & $-0,0357$ & $-0,2521$ & $-0,2329$ & $-5,0747$ & $-0,2463$ & $-0,0001$ & $-0,4451$ \\
\hline New Zealand & $-0,0002$ & $-0,0021$ & $-0,1256$ & $-0,2173$ & $-9,5922$ & 0,0901 & $-0,0001$ & 0,0329 \\
\hline & $-0,0529$ & $-0,0251$ & $-0,2797$ & $-0,2644$ & $-8,6628$ & $-0,1204$ & $-0,0005$ & $-0,2754$ \\
\hline Norway & $-0,0556$ & 0,0451 & 0,4318 & 0,2603 & $-1,7312$ & $-0,1498^{* * *}$ & 0,0001 & $-0,2538$ \\
\hline & $-0,0594$ & $-0,1698$ & $-0,4821$ & $-0,2909$ & $-4,7802$ & $-0,0734$ & $-0,0003$ & $-0,3221$ \\
\hline Poland & $-0,6131^{* * * *}$ & $-0,0004$ & $-1,2856^{* * *}$ & $-0,1733$ & $-23,4830^{* * * *}$ & 0,0845 & $-0,0006^{*}$ & $-3,0471^{* * *}$ \\
\hline & $-0,133$ & $-0,1653$ & $-0,3706$ & $-0,2623$ & $-5,3672$ & $-0,0817$ & $-0,0004$ & $-0,8022$ \\
\hline Portugal & $-0,0228$ & $-0,0333$ & $0,9223^{* * * *}$ & $0,6243^{*}$ & $-8,8061$ & $-0,2824$ & $-0,0003$ & $-0,0384$ \\
\hline & $-0,0747$ & $-0,0593$ & $-0,3346$ & $-0,3484$ & $-10,1288$ & $-0,2679$ & $-0,0009$ & $-0,3945$ \\
\hline Slovak Republic & $-0,3802$ & 0,5601 & $-0,1506$ & $-1,0702$ & $-7,8049$ & 0,2596 & $-0,0011$ & $-1,9578$ \\
\hline & $-0,313$ & $-0,4861$ & $-0,9327$ & $-0,8842$ & $-28,339$ & $-0,1991$ & $-0,0017$ & $-1,7025$ \\
\hline Slovenia & $-0,1147$ & $-0,2753$ & 0,0001 & $-0,0478$ & $59,4211^{* *}$ & $-0,6288^{* * * *}$ & $-0,0008^{* * *}$ & $-0,6724$ \\
\hline & $-0,0944$ & $-0,3112$ & $-0,1986$ & $-0,1258$ & $-29,3544$ & $-0,2399$ & $-0,0003$ & $-0,499$ \\
\hline Spain & $-0,2464 * *$ & 0,0404 & $-0,1342$ & 0,2398 & 1,4 & $-0,0184$ & $-0,0002$ & $-1,2511 * *$ \\
\hline & $-0,1091$ & $-0,0292$ & $-0,4512$ & $-0,2499$ & $-4,6852$ & $-0,0224$ & $-0,0002$ & $-0,6055$ \\
\hline Sweden & $-0,3416^{* * * *}$ & 0,1638 & $-0,5411$ & 0,0339 & $14,1170^{* * *}$ & 0,1494 & $0,0004 *$ & $-1,7777^{* * * *}$ \\
\hline & $-0,1213$ & $-0,1654$ & $-0,4051$ & $-0,3044$ & $-6,5276$ & $-0,1924$ & $-0,0002$ & $-0,6922$ \\
\hline Switzerland & $-0,0571$ & 0,027 & $-0,1883$ & $-0,0076$ & $-8,4148$ & 0,1032 & 0,0001 & $-0,2336$ \\
\hline & $-0,0604$ & $-0,0347$ & $-0,1625$ & $-0,1996$ & $-5,8142$ & $-0,0865$ & $-0,0001$ & $-0,2851$ \\
\hline United Kingdom & $-0,1872^{* * *}$ & 0,0356 & $-0,2228$ & 0,1613 & 15,2834 * & 0,2112 & $-0,0001$ & $-0,9709^{* *}$ \\
\hline & $-0,0872$ & $-0,166$ & $-0,3903$ & $-0,4788$ & $-8,7033$ & $-0,2118$ & $-0,0001$ & $-0,4904$ \\
\hline United States & $-0,2444 * * *$ & $\overline{0,7988^{* * * * *}}$ & $-0,4572^{* * * *}$ & $-0,0113$ & $9,2183^{* *}$ & $-0,1109^{* * *}$ & 0 & $-1,1148^{* * * *}$ \\
\hline & $-0,0586$ & $-0,1695$ & $-0,1363$ & $-0,1182$ & $-3,7321$ & $-0,0535$ & 0 & $-0,3443$ \\
\hline
\end{tabular}


Table 4.15 - Country-specific short-run effects (DCCE-PMG)

\begin{tabular}{|c|c|c|c|c|c|c|c|c|}
\hline & Coint. Eq. & $\mathrm{D}(\mathrm{THE}(-1))$ & $\mathrm{D}$ (GDP) & $\mathrm{D}(\mathrm{LL})$ & $\mathrm{D}$ (POP65) & $\mathrm{D}$ (PHY) & $\mathrm{D}$ (PAT) & Cons \\
\hline \multirow[t]{2}{*}{ Australia } & $-0,0592$ & 0,0898 & 0,1618 & $-0,1331$ & $-1,7153$ & $-0,0299$ & 0,0001 & $-0,2792$ \\
\hline & $-0,0705$ & $-0,1814$ & $-0,1434$ & $-0,1219$ & $-3,3878$ & $-0,0435$ & $-0,0001$ & $-0,3652$ \\
\hline \multirow[t]{2}{*}{ Austria } & $-0,0934$ & 0,1836 *** & $0,8145^{\text {*** }}$ & $-0,0164$ & 1,2499 & 0,1294 & $-0,0001$ & $-0,4781$ \\
\hline & $-0,0608$ & $-0,0374$ & $-0,4503$ & $-0,3036$ & $-3,58$ & $-0,1895$ & $-0,0001$ & $-0,321$ \\
\hline \multirow[t]{2}{*}{ Belgium } & $-0,1276^{* * * *}$ & $-0,0111$ & $-0,4683^{*}$ & $-0,1837$ & 0,8652 & $-0,026$ & 0,0001 & $-0,6269 * * *$ \\
\hline & $-0,0441$ & $-0,0172$ & $-0,2613$ & $-0,1931$ & $-2,3766$ & $-0,0168$ & $-0,0001$ & $-0,2389$ \\
\hline \multirow[t]{2}{*}{ Canada } & $-0,2213^{* * *}$ & 0,014 & $-0,4293^{* * *}$ & $-0,171$ & $-7,5246$ & $0,2330^{*}$ & 0.0000 & $-1,0609^{* * *}$ \\
\hline & $-0,0528$ & $-0,018$ & $-0,1283$ & $-0,1628$ & $-4,7853$ & $-0,1359$ & $(0.0000)$ & $-0,301$ \\
\hline \multirow[t]{2}{*}{ Czech Republic } & $-0,3761^{* * * *}$ & 0,1902 & $-0,3194$ & $-0,5392$ & 1,7256 & 0,2288 & $-0,0004$ & $-1,9876^{* * * *}$ \\
\hline & $-0,1404$ & $-0,1703$ & $-0,4074$ & $-0,5357$ & $-8,3804$ & $-0,153$ & $-0,0005$ & $-0,8047$ \\
\hline \multirow[t]{2}{*}{ Denmark } & $-0,1987^{* * * *}$ & 0,0198 & $-0,5200 * *$ & $0,4878^{* * * *}$ & 0,1958 & 0,1227 & $-0,0001$ & $-0,9786^{* * *}$ \\
\hline & $-0,0743$ & $-0,1483$ & $-0,2131$ & $-0,1495$ & $-2,7611$ & $-0,0751$ & $-0,0001$ & $-0,4166$ \\
\hline \multirow[t]{2}{*}{ Estonia } & $-0,2298^{* * *}$ & $0,3081 * *$ & $-0,0577$ & $-0,0136$ & $8,1042^{*}$ & $0,2300^{* * *}$ & $-0,0006^{* *}$ & $-1,2435 * * *$ \\
\hline & $-0,0874$ & $-0,1449$ & $-0,1182$ & $-0,0904$ & $-4,7026$ & $-0,0995$ & $-0,0003$ & $-0,4641$ \\
\hline \multirow[t]{2}{*}{ Finland } & $-0,2491^{* * *}$ & $0,3394 * * *$ & $-0,2283$ & 0,1604 & $-0,1134$ & $-0,0986$ & $-0,0001$ & $-1,2515^{* * *}$ \\
\hline & $-0,0579$ & $-0,1287$ & $-0,1727$ & $-0,1972$ & $-3,1345$ & $-0,0981$ & $-0,0001$ & $-0,348$ \\
\hline \multirow[t]{2}{*}{ France } & $-0,3955^{* * * *}$ & $-0,106$ & $-0,1938$ & $-0,2333$ & 7,2619 & $-0,4753$ & 0 & $-1,9386^{* * * *}$ \\
\hline & $-0,1359$ & $-0,1751$ & $-0,3483$ & $-0,3198$ & $-5,6851$ & $-0,4218$ & 0 & $-0,7021$ \\
\hline \multirow[t]{2}{*}{ Germany } & 0,0386 & $-0,2562$ & 0,2349 & 0,2903 & $-2,5748$ & $-0,1584$ & 0 & 0,2456 \\
\hline & $-0,1267$ & $-0,2148$ & $-0,2829$ & $-0,277$ & $-2,8878$ & $-0,1644$ & 0 & $-0,6417$ \\
\hline \multirow[t]{2}{*}{ Greece } & $-0,3723^{* * * *}$ & 0,2498 & $0,7544 *$ & $-0,5017$ & $-26,7122$ & $-0,3271$ & $-0,0003$ & $-1,8119^{* * *}$ \\
\hline & $-0,1414$ & $-0,1742$ & $-0,452$ & $-0,6257$ & $-19,5791$ & $-0,2338$ & $-0,001$ & $-0,796$ \\
\hline \multirow[t]{2}{*}{ Hungary } & $-0,4464 * *$ & $-0,0324$ & $0,8325^{* * *}$ & 0,3577 & $-30,7044 * *$ & 0,0012 & 0,0001 & $-2,2142^{* *}$ \\
\hline & $-0,1909$ & $-0,1908$ & $-0,4135$ & $-0,3982$ & $-14,4584$ & $-0,0469$ & $-0,0004$ & $-1,0723$ \\
\hline Iceland & $-0,3464 * * *$ & $0,3164 * * *$ & 0,2778 & $-0,0378$ & $-10,6890^{*}$ & 0,0138 & 0,0005 & $-1,7273^{* * *}$ \\
\hline & $-0,0964$ & $-0,1101$ & $-0,193$ & $-0,0545$ & $-6,4783$ & $-0,1064$ & $-0,0011$ & $-0,5373$ \\
\hline Ireland & $-0,2233^{* * * *}$ & 0,2582 & $-0,3736^{*}$ & 0,2127 & 7,3499 & 0,0624 & $-0,0002$ & $-1,0979$ **** \\
\hline & $-0,0593$ & $-0,1668$ & $-0,1985$ & $-0,1403$ & $-5,8237$ & $-0,0451$ & $-0,0002$ & $-0,3177$ \\
\hline Israel & $-0,5383^{* * * *}$ & 0,0343 & $-0,0236$ & 0,2711 & $-16,1352^{* * *}$ & 0,01 & 0,0001 & $-2,7306^{* * * *}$ \\
\hline & $-0,1756$ & $-0,1783$ & $-0,3219$ & $-0,1839$ & $-8,2337$ & $-0,0367$ & $-0,0001$ & $-1,0464$ \\
\hline Italy & $-0,2229 * *$ & 0,1427 & 0,146 & 0,0448 & 0,8088 & $-0,0688$ & 0,0001 & $-1,1591^{* *}$ \\
\hline & $-0,1107$ & $-0,1842$ & $-0,3124$ & $-0,2579$ & $\begin{array}{l}-6,0356 \\
\end{array}$ & $-0,0422$ & $-0,0001$ & $-0,5793$ \\
\hline Japan & 0,0519 & $-0,0137$ & $-0,1666$ & $0,3319^{* *}$ & 1,315 & 0,2288 & 0,0001 & 0,2994 \\
\hline & $-0,0583$ & $-0,0302$ & $-0,2323$ & $-0,1679$ & $-3,6467$ & $-0,6544$ & $-0,0001$ & $-0,3168$ \\
\hline Korea & $-0,2708^{* * *}$ & 0,0237 & $0,4752 *$ & 0,0302 & $18,2139^{*}$ & 0,3725 & $-0,0001$ & $-1,4888^{* * *}$ \\
\hline & $-0,1075$ & $-0,1632$ & $-0,2723$ & $-0,3684$ & $-10,4531$ & $-0,2862$ & $-0,0003$ & $-0,6185$ \\
\hline Luxembourg & $-0,4186^{* * * *}$ & 0,2964 & $-0,7570 * *$ & 0,038 & $28,4010^{*}$ & $-0,0962$ & $-0,0007$ & $-2,2516^{* * *}$ \\
\hline & $-0,1282$ & $-0,1984$ & $-0,3206$ & $-0,1549$ & $-16,8743$ & $-0,1069$ & $-0,0005$ & $-0,7687$ \\
\hline Mexico & 0,2844 & $-0,3057$ & $-0,0867$ & $-0,7702^{*}$ & $-177,3293 * * *$ & $-0,3611$ & 0,0002 & 1,6358 \\
\hline & $-0,2245$ & $-0,2571$ & $-0,3876$ & $-0,4335$ & $-61,4289$ & $-0,2318$ & $-0,0007$ & $-1,1877$ \\
\hline Netherlands & $-0,1904 * *$ & $-0,0398$ & $-0,3146$ & 0,0746 & 2,1828 & 0,099 & 0,0001 & $-0,9478^{* *}$ \\
\hline & $-0,0822$ & $-0,0357$ & $-0,2521$ & $-0,2329$ & $-5,0747$ & $-0,2463$ & $-0,0001$ & $-0,4451$ \\
\hline New Zealand & $-0,0002$ & $-0,0021$ & $-0,1256$ & $-0,2173$ & $-9,5922$ & 0,0901 & $-0,0001$ & 0,0329 \\
\hline & $-0,0529$ & $-0,0251$ & $-0,2797$ & $-0,2644$ & $-8,6628$ & $-0,1204$ & $-0,0005$ & $-0,2754$ \\
\hline Norway & $-0,0556$ & 0,0451 & 0,4318 & 0,2603 & $-1,7312$ & $-0,1498^{* * *}$ & 0,0001 & $-0,2538$ \\
\hline & $-0,0594$ & $-0,1698$ & $-0,4821$ & $-0,2909$ & $-4,7802$ & $-0,0734$ & $-0,0003$ & $-0,3221$ \\
\hline Poland & $-0,6131^{* * * *}$ & $-0,0004$ & $-1,2856^{* * * *}$ & $-0,1733$ & $-23,4830^{* * * *}$ & 0,0845 & $-0,0006^{*}$ & $-3,0471^{* * * *}$ \\
\hline & $-0,133$ & $-0,1653$ & $-0,3706$ & $-0,2623$ & $-5,3672$ & $-0,0817$ & $-0,0004$ & $-0,8022$ \\
\hline Portugal & $-0,0228$ & $-0,0333$ & $0,9223^{* * * *}$ & $0,6243^{*}$ & $-8,8061$ & $-0,2824$ & $-0,0003$ & $-0,0384$ \\
\hline & $-0,0747$ & $-0,0593$ & $-0,3346$ & $-0,3484$ & $-10,1288$ & $-0,2679$ & $-0,0009$ & $-0,3945$ \\
\hline Slovak Republic & $-0,3802$ & 0,5601 & $-0,1506$ & $-1,0702$ & $-7,8049$ & 0,2596 & $-0,0011$ & $-1,9578$ \\
\hline & $-0,313$ & $-0,4861$ & $-0,9327$ & $-0,8842$ & $-28,339$ & $-0,1991$ & $-0,0017$ & $-1,7025$ \\
\hline Slovenia & $-0,1147$ & $-0,2753$ & 0,0001 & $-0,0478$ & $59,4211^{* *}$ & $-0,6288^{* * * *}$ & $-0,0008^{* *}$ & $-0,6724$ \\
\hline & $-0,0944$ & $-0,3112$ & $-0,1986$ & $-0,1258$ & $-29,3544$ & $-0,2399$ & $-0,0003$ & $-0,499$ \\
\hline Spain & $-0,2464 * * *$ & 0,0404 & $-0,1342$ & 0,2398 & 1,4 & $-0,0184$ & $-0,0002$ & $-1,2511^{* *}$ \\
\hline & $-0,1091$ & $-0,0292$ & $-0,4512$ & $-0,2499$ & $-4,6852$ & $-0,0224$ & $-0,0002$ & $-0,6055$ \\
\hline Sweden & $-0,3416^{* * * *}$ & 0,1638 & $-0,5411$ & 0,0339 & $14,1170^{\text {*** }}$ & 0,1494 & $0,0004 *$ & $-1,7777 * * *$ \\
\hline & $-0,1213$ & $-0,1654$ & $-0,4051$ & $-0,3044$ & $-6,5276$ & $-0,1924$ & $-0,0002$ & $-0,6922$ \\
\hline Switzerland & $-0,0571$ & 0,027 & $-0,1883$ & $-0,0076$ & $-8,4148$ & 0,1032 & 0,0001 & $-0,2336$ \\
\hline & $-0,0604$ & $-0,0347$ & $-0,1625$ & $-0,1996$ & $-5,8142$ & $-0,0865$ & $-0,0001$ & $-0,2851$ \\
\hline United Kingdom & $-0,1872 * *$ & 0,0356 & $-0,2228$ & 0,1613 & $15,2834^{*}$ & 0,2112 & $-0,0001$ & $-0,9709^{* *}$ \\
\hline & $-0,0872$ & $-0,166$ & $-0,3903$ & $-0,4788$ & $-8,7033$ & $-0,2118$ & $-0,0001$ & $-0,4904$ \\
\hline United States & $-0,2444^{* * *}$ & $0,7988^{* * * *}$ & $-0,4572^{* * *}$ & $-0,0113$ & $9,2183^{* *}$ & $-0,1109^{* *}$ & 0 & $-1,1148^{* * *}$ \\
\hline & $-0,0586$ & $-0,1695$ & $-0,1363$ & $-0,1182$ & $-3,7321$ & $-0,0535$ & 0 & $-0,3443$ \\
\hline
\end{tabular}





\title{
Nursing specialization
}

\section{The impact of specialized nursing care in Portugal: an economic evaluation and a policy analysis}

\author{
Sofia Cruz-Gomes* · Mário Amorim-Lopes* · Bernardo Almada-Lobo*
}

Submitted to International Journal of Nursing Studies, 2019

\begin{abstract}
An ageing population with chronic diseases and multiple morbidities along with technological developments and organisational changes led to the growing complexity of healthcare delivery, in medicine and also in nursing. Specialisation emerged as a response to these challenges, and significant evidence points towards positive effects for all stakeholders, including patients, practitioners, and health organisations. However, specialised resources tend to be more expensive, resulting in additional costs that may hinder the further expansion of these new roles. In this work, we provide a policy framework to assist policymakers and health planners in enacting the changes needed to incorporate Clinical Nurse Specialists in their health systems. First, we present the case for having nurse specialists by reporting the empirical evidence and performing an international benchmark. Next, we discuss the barriers, enablers, and regulation, and we propose a professional and academic curriculum for training nursing specialists. Finally, we estimate the evolution of the nursing workforce, as well as the economic and budgetary impact. We illustrate the application of this framework in a real setting.
\end{abstract}

\footnotetext{
*INESC TEC, Faculdade de Engenharia, Universidade do Porto, Rua Dr. Roberto Frias, 4200-465, Porto, Portugal
} 
Keywords $\cdot$ nursing specialization $\cdot$ clinical nurse specialists $\cdot$ economic impact $\cdot$ HHR policy

\subsection{Introduction}

Within the possible ways to deal with the rising volume and complexity of the demand for healthcare that are discussed in the literature, workforce specialization has been calling the attention of researchers, managers, and practitioners. Nursing specialization has been pointed out as a complementary mode of delivering care that can help to ensure the quality, access, and sustainability of healthcare delivery, and its relevance on chronic diseases management and care for older people with multiple morbidities has been highlighted (Bodenheimer et al., 2005).

According to the International Council of Nurses, an Advanced Practice Nurse (APN) is $a$ Registered Nurse who has acquired the expert knowledge base, complex decision-making skills and clinical competencies for expanded practice, the characteristics of which are shaped by the context and/or country in which s/he is credentialed to practice (ICN, 2008). More generally, the term is used to refer to all nurses who perform differentiated activities in the context of clinical practice. Advanced practice is about the title, the scope of the practice, and the underlying training. At the international level, advanced practice nursing practice encompasses two professional profiles: Nurse practitioners (NPs) and Clinical nurse specialists (CNSs). In the first case, the job goes beyond the traditional domain of nursing and nurses also perform functions that are typically associated with general practitioners (such as diagnosing, making prescriptions, and referring patients). In the second case, the nurse is specialized in a particular clinical area, acquiring the skills and know-how to deliver high-quality nursing care to patients and promote performance in nursing teams (Schober, 2016). However, there is no uniformity in the application of these terms and there is a wide variation between countries. This paper is focused on CNSs, who 
are also commonly designated as Nurse Specialists (NS). Hereafter, we will use NS and CNS interchangeably.

The development of nursing specialization has become a global trend in the last few decades (ICN, 2002). In the current context (represented in Figure 5.1), of well-marked technological evolution, relevant organizational changes, and demographic evolution leading to an ageing population, the rationale supporting the specialization of the nurse workforce is reinforced. The technological developments turned healthcare delivery more technical and complex, requiring more specific knowledge. Along with that, current organizational challenges (such as rising healthcare expenditures, lack of HHR, or unmet care needs) and an ageing population with chronic diseases and multiple morbidities, call for a change promoting a higher quality of and access to healthcare services (Sheer and Wong, 2008a; Fagerström, 2012; CNA, 2008). Thus, a redefinition of HHR management policies - in terms of intervention roles, qualifications, number, and distribution - enhancing productivity and meeting these societal challenges, may be required to ensure that timely and quality healthcare services are delivered in a sustainable way (Kabene et al., 2006).

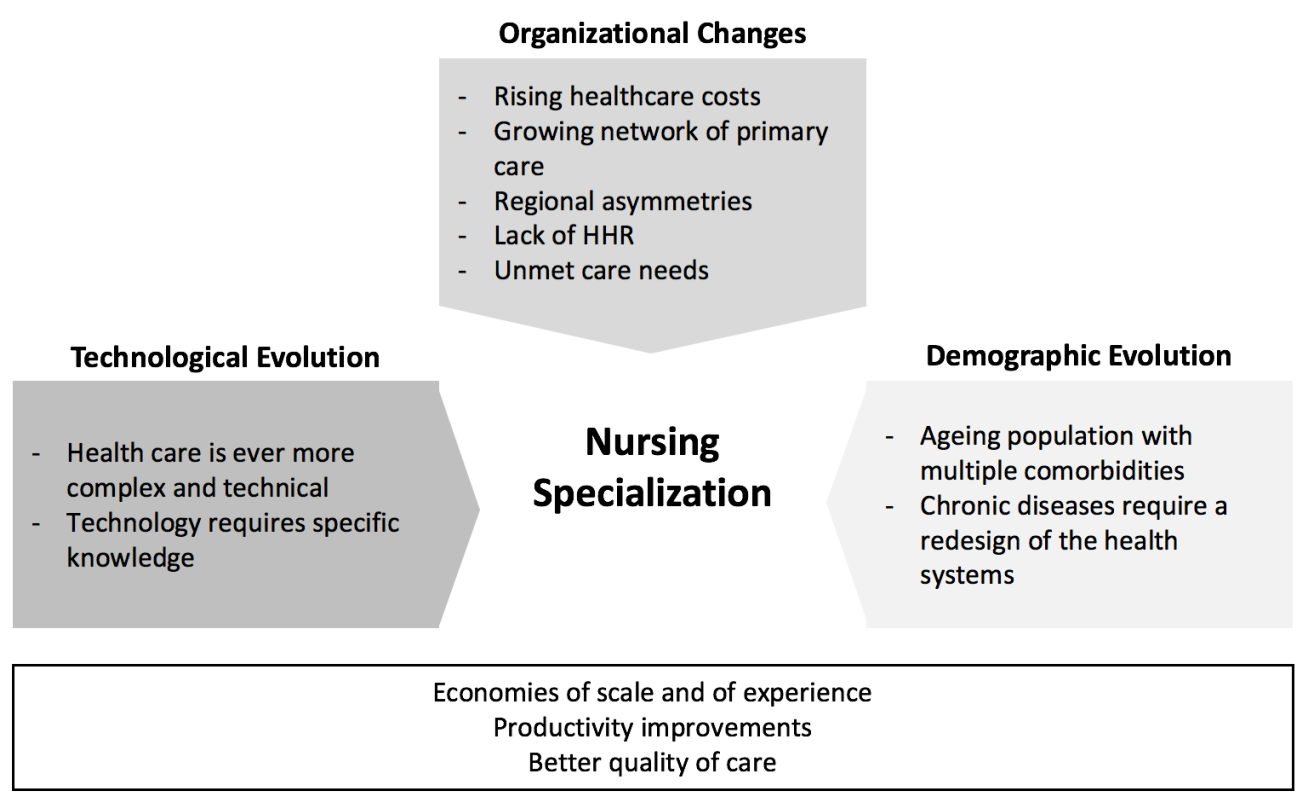

Figure 5.1 - Rationale for the nursing specialization 
The specialization of human resources in health emerges as a response to the societal challenges that lie ahead. Investing in human capital, through the specialization of providers, is a pressing need, fostering economies of scale and knowledge and improving both the productivity of HHR and the quality of healthcare (Rosen, 1983). This response essentially seeks to strengthen the specialized knowledge of human resources. As such, it is an investment in human capital, which has been repeatedly shown to be fundamental for economic growth, social well-being, and above all, for achieving healthier populations.

According to an OECD (Organization for Economic Cooperation and Development) study, the increasing access to healthcare, the quality of care, and the changing needs of the patients - due to the growing incidence of chronic diseases in an aging population - are three of the main reasons justifying the focus on nursing specialization (Sheer and Wong, 2008a). The lack of doctors, the need to contain expenses, reduce waiting times, and serve the underprivileged are also pointed out as factors justifying the redefinition of the nurses' role. Finally, increasing the attractiveness of the profession and improving the career perspective are also factors identified as relevant, as these factors may increase significantly the work satisfaction and the retention rates of professionals (Wiskow et al., 2010).

The most relevant results of studies evaluating specialized nursing practice show its positive effect on the quality of health services provided and the improved access to health care. The empirical evidence on the subject also seems unanimous regarding the importance of the care provided by these professionals in monitoring, educating, advising and promoting good practice. Moreover, specialized nursing care is relevant to chronic disease management and improving health outcomes. Despite the efforts made on better understanding the main effects of having a specialized nursing workforce, studies assessing, presenting and discussing the implementation and governance of nursing specialization are still scarce.

This paper comes forth as an attempt to inform policymakers and health planners that may be considering the implementation of these nursing roles, by answering three main questions: 1) Where did nursing specialization have been already implemented?; 2) Why should specialized nursing roles be implemented?; and 3) How to roll-out nursing specialization in a specific country?. As so, it aims to synthesize the international trends and benchmarks, 
informing about the countries where nursing specialization was already implemented. It also intends to compile the empirical evidence on the main effects of having a specialized workforce. Moreover, it aims to provide a policy framework for the creation and governance of such role, by providing insights regarding i) the main barriers and enablers that may hinder or facilitate the implementation of the role; ii) the regulation guiding the main aspects of both the implementation and governance of the measure; iii) the estimation and plan for the workforce that should be specialized and hired as a specialist; iv) the education and training processes that are required to perform the role of nurse specialist; v) the payment policies to reward a workforce with differentiated training and functions; and vi) the budgetary impact of both the specialization process and the maintenance of a specialized workforce in the health system, to ensure the sustainability of the measure. The analysis covering each of these topics also allowed to support the discussion and negotiation of the implementation of this role in Portugal, in collaboration with the Portuguese Nursing Council.

The remainder of this paper is organized as follows. Section 2 presents an international comparison of the experience and trends of specialization in countries where specialized nursing roles were implemented. Section 3 resumes the empirical evidence on the effects of nursing specialization, and Section 4 is devoted to the proposal of a policy framework for rolling-out this role, also providing the analysis and results for the real-context application. Finally, Section 5 concludes and summarizes the main policy insights.

\subsection{Where? The international experience}

Policies that promote HHR specialization and the performance of specialized and differentiated functions are a growing trend. Several countries have been seeking to improve healthcare delivery by reviewing the roles of health professionals and promoting an expansion of the role of the nursing professionals in response to the several societal challenges that health systems are currently facing (Sheer and Wong, 2008b).

Countries such as Australia, Canada, Finland, the Netherlands, Ireland, New Zealand, and 
the United Kingdom have recruited nurses with specialized training for some decades, especially at the primary healthcare level. Canada and the USA established the role of nurse specialist in the $60 \mathrm{~s}$, initially intending to provide primary healthcare in rural areas, which typically have a very low density of physicians. The UK introduced this role in the 70 s, with the aim of increasing access to healthcare. Finland also has a long history of cooperation between physicians and nurses with specialized training in multidisciplinary teams, especially at the level of healthcare centers. In the case of Belgium, France, Japan, Poland, or the Czech Republic, the implementation of these roles is still recent (Delamaire and Lafortune, 2010).

The scope of practice of the specialized nurse workforce varies from country to country. In countries where the specialized role is established, the position is well-defined, and the range of care services that can be performed may be vast and include activities commonly performed by physicians, such as drugs prescriptions, diagnosis, and evaluation of health and treatment decisions (Savrin, 2009). In countries such as Germany, Austria, Croatia, Cyprus, France, Iceland, Israel, Lithuania, Norway, Spain, Sweden or Switzerland, where the implementation of specialized training programs is recent, their practice is still limited. Some of these countries had already implemented specialized training in several clinical areas, which is recognized by the regulatory body by awarding the title of Specialist (Pulcini et al., 2010a). In this context, it is argued that differentiated competencies increase the performance of these professionals. However, and despite the potential gains obtained from this improved know-how, some countries do not fit them into the formal structure of the organization. In countries such as Belgium, Denmark, Estonia, Hungary, Italy, Latvia, Luxembourg, Malta, Poland, and the Czech Republic, the role is not still fully embodied in the organizational structure of health institutions, or the mechanism that confers the degree is not yet defined (Delamaire and Lafortune, 2010).

The international comparison of the role regulation and the main requirements to become a CNS/NS in countries where this role is recognized is summarized in Table 5.1. Due to different contextual characteristics of the countries where the role is already recognized and integrated into the health system, both the type of regulation, and the education and training 
requirements (education level, clinical practice, and certification) vary across countries, and in some cases, there are even some variations within countries (Heale and Buckley, 2015b).

Table 5.1 - International comparison of CNS regulation and requirements

\begin{tabular}{cccccc}
\hline Country & Role Designation & Regulation & Education level required & Clinical practice & Certification \\
\hline Australia & CNS & National and Decentralised & Master's level & Yes & Yes \\
Austria & NS & National & Master's level & Yes & Yes \\
Canada & CNS & Not regulated & Master's level & Yes & Yes \\
Czech Republic & NS & Not regulated & Master's level & Yes & Yes \\
Denmark & NS & National and Decentralised & Post-graduate diploma & Yes & Yes \\
Finland & CNS & Not regulated & Post-graduate diploma or Master's level* & Yes & Yes \\
France & NS & National & Master's level & Yes & Yes \\
Greece & CNS & National & Graduate Diploma & No & No \\
Ireland & CNS & Not regulated & Post-graduate diploma & Yes & Yes \\
Italy & NS & National & Master's level & Yes & Yes \\
Malaysia & CNS & Not regulated & Graduate Diploma & No & Yes \\
Netherlands & CNS & Not regulated & Master's level & No & Yes \\
Poland & CNS & National and Decentralised & Master or Doctorate* & No & Yes \\
Switzerland & CNS & Not regulated & Master's level & Yes & Yes \\
Thailand & NS & National & Master's level & Yes & No \\
United Kingdom & CNS & Not regulated & Graduate Diploma or Master's level * & Yes & Yes \\
U.S.A. & CNS & Decentralised & Master's level & Yes & Yes \\
\hline
\end{tabular}

\subsection{Why? The empirical evidence}

The international literature on the effects of nursing specialization has been emerging in recent years, especially in countries where specialization has been in place for some time, such as the U.S.A., Canada, United Kingdom, and Australia, for which several studies analyzing the effect of specialization on the different types of healthcare provided have been published.

There are already a few systematic literature reviews trying to compile the main effects of specialization that are reported in the literature. These reviews provide a good overview of the effects of nursing specialization, showing that results are promising and hence reinforcing the rationale supporting the specialization of the nurse workforce. However, in the context of this work, where the main focus is on the implementation of the clinical nurse specialist role, the existent reviews present some limitations. Most of them do not differentiate between different types of APNs (NPs and CNSs) (Donald et al.; Tsiachristas and de Bont, 2015) or are specifically focused on NPs (Martínez-González et al., 2014a; Newhouse and Heindel, 2011). Additionally, some are outdated (Fulton and Baldwin, 2004) or strictly focused on a specific type of care (such as primary care), on a specific type of ef- 
fects (such as health outcomes or economic effects), or only dedicated to a specific type of CNSs (certified nurses, for example) (Martínez-González et al., 2014b; Whitehead, 2019). As so, we conduct our own literature review. This review is exclusively focused on the effects of having CNSs delivering care and covers a wide time-horizon of studies and several different types of healthcare contexts and services. Additionally, it aims to structure the results by those who are the main stakeholders affected by the specialization of the nurse workforce, namely Patients and population (in 5.3.2), Workers and labour market (5.3.3), and Organizations providing healthcare services (5.3.4). In the following subsection, the design of the literature review is presented in more detail.

\subsubsection{Literature review design}

For the review of the empirical literature on the effects of nursing specialization, several scientific articles published in the last 25 years were considered. The articles reviewed are from the following online databases: PubMed, CINAHL Complete, MEDLINE Complete, Nursing \& Allied Health Collection: Comprehensive, Cochrane Central Register of Controlled Trials, Cochrane Database of Systematic Reviews, Cochrane Methodology Register, Library, Information Science \& Technology Abstracts and MedicLatina. Initially, two searches were performed: one for the PubMed database and one for the remaining databases via the EBSCO platform. In both researches a set of search terms related to nursing specialization and different combinations of these terms was used (see Figure 5.2). The first 50 articles resulting from each of these surveys - sorted by relevance - were considered for analysis, after the duplicates have been excluded. By reading the titles and abstracts of the remaining articles we excluded the ones that i) did not fall within the scope of the study although they included the search terms used; ii) reported no qualitative or quantitative results; iii) were focused on very specific health problems, not allowing for a broader view of the effects of specialization; or iv) were focused on comparisons not relevant to the study (such as comparisons between specialist nurses and physicians).

As a complement to the empirical evidence provided by the selected articles, additional searches were performed in aggregate databases using the same search terms or by search- 
ing specifically for articles referenced by the initial articles, notably in some review articles found. The application of these criteria resulted in 32 articles considered relevant for analysis, which have been analyzed in detail (see Table 5.5 in the Appendix). In order to provide a comprehensive and reliable view of the effects of specialization, all studies were included, regardless of the results obtained, even if the results seem to contradict one another.

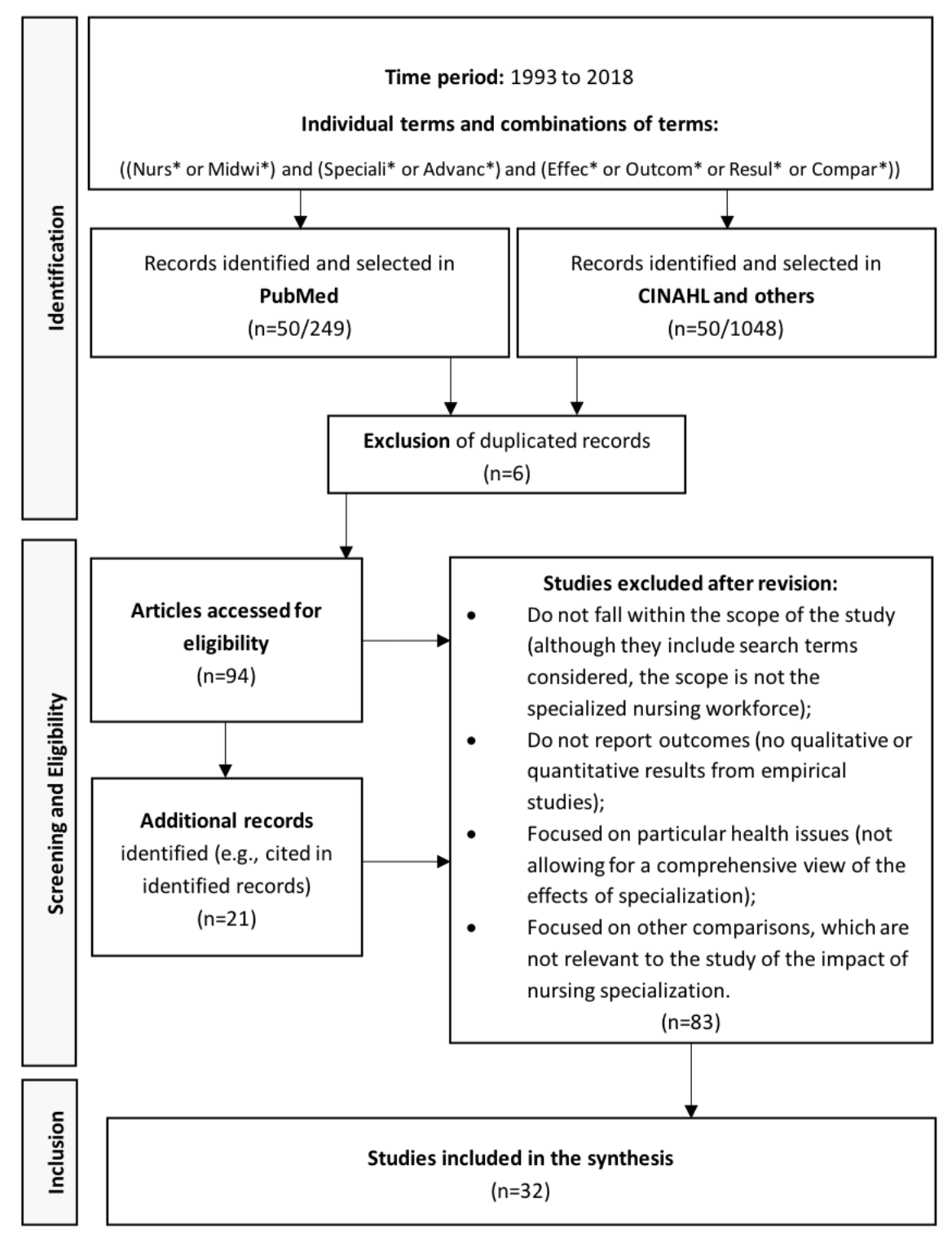

Figure 5.2 - Study selection process 
The main effects of nursing specialization empirically tested are access to healthcare, customer satisfaction, effects on health and well-being indicators, quality of services provided, costs associated with the specialization, and commitment and satisfaction of nursing professionals. These effects can be generally grouped in three categories, based on those who are the main stakeholders of the specialization results: 1) Patients and population; 2) Workers and labour market; and 3) Institutions providing healthcare services. The three categories are interlinked: health workers and institutions providing healthcare are patientcentred and health-oriented. As so, their main focus is on the success of the first category of effects, related to the patients. In addition, there is also a dependency between the objectives of healthcare institutions and those of their workers, as they should be aligned to ensure the quality of the healthcare services provided.

\subsubsection{Patients and population}

Empirical studies analysing the impact of nursing specialization on patients are related to the main objectives of these intervenients: health, well-being and quality of life. Among the indicators studied in the literature, mortality, health complications and patients' satisfaction with healthcare are the most frequently analysed.

Regarding the effects of specialization on mortality, several studies were able to demonstrate that nursing specialization has a positive impact on mortality, helping to reduce the mortality rates (Brooten et al., 2001; Kendall-Gallagher and Blegen, 2009; KendallGallagher et al., 2011; Boltz et al., 2013). Empirical evidence also shows that in hospital units with in-service nurse specialists, patients received nursing care more frequently and had better health results (Wheeler, 1999, 2000).

In primary care, empirical evidence shows that the introduction of nurse specialists increases the services related with health promotion and detection, and treatment of diseases. Additionally, studies also show that specialists are significantly more effective, both in the prevention and in the detection and treatment, when compared to the non-specialist nurses (Martin-Misener et al., 2009; Mousquès et al., 2010; Hart et al., 2006).

Regarding the quality of life, the studies do not all point in the same direction: while some 
conclude that patients' quality of life does not differ significantly with the introduction of nurse specialists (Frank-Stromborg et al., 2002), others conclude that elderly and terminally ill patients report less symptoms, greater vitality and better physical and mental functioning due to the geriatric and palliative care provided by nurse specialists (Aiken et al., 2010). Empirical studies also demonstrate that specialization contributes to improve healthcare delivery through a better direct patient care - more timely, personalized and comprehensive care - and, indirectly, through disease education, counselling, help in self-management of diseases and promotion of good practices (NCPDNM, 2005). This improvement in the care received led, according to the literature, to a higher patient satisfaction regarding the healthcare services received, which they consider to be more appropriate and more useful (Martin-Misener et al., 2009; Litaker et al., 2003). International empirical evidence also highlights the relevance of nurse specialists in the management of chronic diseases and the in the clinical outcomes of these patients. Studies on the effects of nursing specialization on the management of chronic diseases, such as diabetes or hypercholesterolemia, show that patients followed by nurse specialists are more likely to remain or become well-controlled (Litaker et al., 2003).

\subsubsection{Workers and labour market}

Empirical studies addressing the impact of nursing specialization on workers and on the characteristics of the labour market are mainly based on the opinion of health professionals regarding the specialization and its impact on their professional activity, satisfaction with the developed work and personal fulfilment. Among the indicators studied in the literature, the capacity of performing the necessary work, the recognition and the personal satisfaction are the most studied.

Nurse specialists tend to agree on statements about the value of specialization related to feelings of fulfilment, personal satisfaction and recognition of specialized skills. They admit to have more technical capacity and clinical competence due to specialization and indicate a greater professional growth, better standards of practice, higher confidence and reinforced professional commitment, responsibility and credibility among other health pro- 
fessionals (Gaberson et al., 2003). The empirical evidence suggests that the relationship between the specialization of nurses and their perception of capacity, competence and aptitude for the work performed is positive and statistically significant (Krapohl et al., 2010) and that nurse specialists tend to have greater knowledge about diseases and their treatments: results show that nurse specialists have more knowledge and have fewer incidents and complications (Kendall-Gallagher and Blegen, 2009; Litaker et al., 2003; Gaberson et al., 2003; Cary, 2001; Krapohl et al., 2010). Empirical evidence also shows that specialization leads to financial rewards and improves career prospects (Cary, 2001) and that nurse specialists are more likely to participate in continuing education actions than nonspecialists (Coleman et al., 2009). Patients attended by nurse specialists report higher satisfaction, which is largely due to the quality of communication and to enthusiasm, commitment, and professionalism of these professionals (Cox et al., 2017; Litaker et al., 2003). Specialization also increases collaboration with other health professionals: studies show that nurse specialists report higher levels of effective collaboration with physicians and other health professionals, which result in more positive attitudes of the nursing teams (Martin-Misener et al., 2009; Cox et al., 2017). Nurse specialists have higher participation in decision-making and increased recognition of expertise by other health professionals (Wade, 2009).

Regarding employee retention, empirical studies show that in hospitals with higher rates of specialists, nurses are less likely to report dissatisfaction, high levels of stress or intention to leave their current position (Niebuhr and Biel, 2007; Kelly et al., 2012). Additionally, evidence points that the support to the specialization by the organizations is effective to promote the professionals' satisfaction, which translates in fewer days of lost work and better retention of health professionals (Wade, 2009; Niebuhr and Biel, 2007; Kelly et al., 2012).

\subsubsection{Organizations providing healthcare services}

The impact of nursing specialization on healthcare institutions is usually addressed considering one of the two main objectives of these organizations: i) ensure access and quality; 
and ii) ensure the efficiency and continuity of healthcare provision. Thus, among the indicators used, hospitalization time and costs associated with the provision of healthcare services are the most frequently analysed indicators.

Regarding the hospitalization time, several studies showed that nursing specialization has a positive impact on length of stay (Brooten et al., 2001; Nelson et al., 2007). Some empirical studies reported a positive effect of nursing specialization on the access to healthcare (Martin-Misener et al., 2009; NCPDNM, 2005) and showed that higher ratios of nurse specialists are associated with fewer complications, hospital infections and adverse effects (Kendall-Gallagher and Blegen, 2009; Cary, 2001; Boyle et al., 2014; Newhouse et al., 2005; Hanneman et al., 1993).

Nurse specialists, as well as their managers, tend to have a high level of agreement with statements of value of the specialized practice, both considering that a specialized nursing workforce improves the access and the quality of the care provided (Gaberson et al., 2003; Niebuhr and Biel, 2007).

Overall, studies suggest that healthcare organizations should seek for specialized nurses and inform both the patients and the public about the specialization of their workforce. Furthermore, they should support the nursing specialization by implementing strategies to overcome major barriers to specialization and provide appropriate incentives and rewards (Wheeler, 1999, 2000).

\subsection{How? Rolling out the role of Nurse Specialist}

This section proposes a general framework for implementation and governance of CNS role. Furthermore, it instantiates the framework for the Portuguese case, which served as a basis for the negotiations and implementation of the CNS role in Portugal.

The need of having a specialized nurse workforce is easily justified by the rationale supporting the existence of this new nursing role in a context of rising volume and complexity of healthcare services needed, and by the empirical evidence showing different positive effects of specialization for patients, workers, and health organizations. However, the de- 
cision of rolling out the CNS role in a specific country should account for several other factors, which should be previously considered and analyzed to ensure that the implementation is politically feasible and sustainable.

Thus, a framework for rolling out the role of nurse specialists is schematically represented in Figure 5.3. This framework aims to guide analysis, actions and policies through six elements that are fundamental to a successful implementation and governance of this specialized nurse role: i) Barriers and enablers; ii) Workforce planning; iii) Education and training requirements; iv) Payment policies; v) Regulation and governance; and vi) Economic Impact.

First, the identification of the main barriers and enablers is critical to a successful implementation, removing obstacles and complications. For that purpose, it is necessary to ensure that the required policy measures are effectively and timely taken both to overcome the main challenges, fading the oppositions and obstacles that may block or hinder the implementation, and to take advantage of the key factors that may lead the several stakeholders to agree with the measure and to collaborate in its execution.

Regarding HHR policies, three main policy decisions must be considered. The first is related to the planning for the nurse specialists needed in the health system. The estimation and plan for the workforce that should be specialized (educated and trained), and posteriorly hired to the NHS as a specialist should be performed. The second is related to the definition of the educational path and practical training that must be required to perform specialized nursing roles, which must be fulfilled to obtaining the title of nursing specialist. Finally, the last HHR policy concerns to payment policies, where the financial rewarding of a workforce with differentiated training and functions should be delineated. Other payments that may eventually arise from hiring and integration policies of this specialized nursing workforce should also be analyzed.

Throughout HHR policies, the international experience from countries that already go through implementation processes of specialized roles as such should be considered to help guiding the main HHR policies proposals, measures, and decisions. Moreover, in order to ensure clear and transparent implementation and governance processes, it is necessary to 


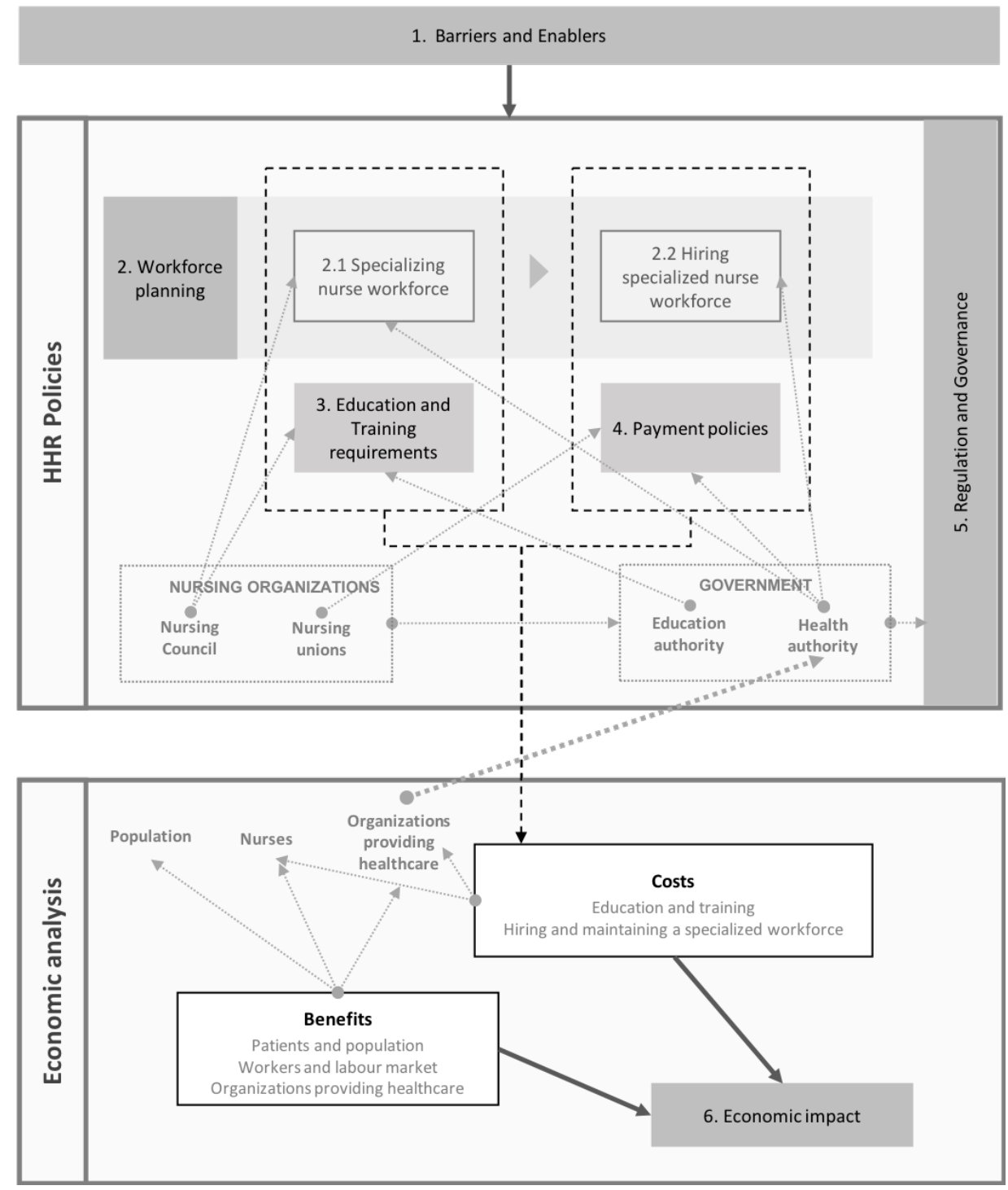

Figure 5.3 - Framework for implementation and governance

assure that they are based on a robust regulatory body that guides the main criteria, rights, duties, and requirements (such as the role, its functions and position in the nursing career, the education and training required, the specialty recognition and hiring process, or the associated remuneration).

Finally, the last element identified as essential in rolling out the role of nurse specialist is related to its economic impact. Financially, it is crucial to ensure that the implementation and maintenance of the measure are sustainable for public accounts. Thus, the costs 
arising from both the education and training processes and from hiring and maintaining a specialized workforce must be estimated. On the one hand, these costs depend on both the number of nurses to be specialized and on the education and training process defined. On the other hand, specialization costs will also be linked to the number of specialized nursed to be hired and maintained in the health system, and to the payment policies agreed. The expected benefits of having a specialized nursing workforce, which can be foreseen by analyzing the empirical evidence of the effects of specialization in other countries, should also be quantified. An economic analysis crossing the main costs and benefits should be further performed so that the net economic impact and the subsequent financial effort required in public accounts is known, and to infer whether this effort is reasonable and sustainable to the public budget. The entities identified as relevant institutional actors for the different policy decisions are also represented in the proposed framework and linked to the framework components for which they should contribute or intervene. The Nursing Council, for example, should provide insights regarding the need for nurse specialists for the calculation of the number of nurses to specialize (component 2.1). Moreover, it should also play an essential role in the definition of the education and training requirements to become a nurse specialist (component 3) and, together with other nursing associations (such as nursing unions), to also contribute for the regulation regarding the several aspects of nurse specialization (component 5).

The six framework components ( 1 to 6 in Fig.5.3) will be detailed in the following subsections (5.4.1 to 5.4.6). For each of them, the performed analysis for the Portuguese context is also presented. For sake of clarity, we provide in the remainder of this section, the ground of the Portuguese setting.

In Portugal, there were six Nursing specialties currently recognized by law, namely: Community care, Perioperative care, Rehabilitation, Pediatric care, Maternal care, and Mental health. Recently, the process of recognition by the Nursing Council of new areas of specialization in Nursing has been completed for the following four specialties: Palliative care, Critical care, Chronic care, and Family health.

Despite the statutory existence of these specialties, the clinical and academic training that 
provides the degree of specialist, and the presence of a specialized workforce estimated at $26 \%$ of all registered nurses, the Portuguese health system, and in particular the National Health Service (NHS), had not an organizational formal structure for the full recognition and use of this differentiated practice implemented.

In the last years, the Portuguese Nursing Council has been demanding the formal recognition and integration into the organizational structure, and also in the career plans of nurses. This goal was recently accomplished, in 2019, through the introduction of changes in the nursing career, as well as in the requirements for the admission to the different career classes. The new regulation recognizes the competencies held by nurse specialists, updating and modernizing the role and adapting it to the current reality, aiming to contribute to the improvement of the quality of care. In addition to the skills of a Registered Nurse $(\mathrm{RN})$, a nurse specialist should have specific competences in the area of expertise, namely: i) to identify the health needs of the individual, family, group or community; ii) to provide specialized and complex nursing care; and iii) to be responsible for the nursing part in the multidisciplinary teams (DL71/2019, 2019).

\subsubsection{Barriers and enablers}

The implementation of a role such as the nursing specialist is primarily dependent on empowering the main enablers and on tearing down the most significant barriers. Several factors may enable and support the implementation and full use of a specialized nurse workforce. Similarly to the proposed aggregation of the empirical evidence, these factors are mainly related to patients, health workers, and organizations. The need for health gains and improvement of patients' satisfaction are the essential enablers from the patient's side. For nurses, the professional accomplishment and notoriety, the self-confidence and increased knowledge, the need for continued efforts to increase awareness and attractiveness of nursing work, and the opportunity of career progression are the main drivers enabling this implementation (Halcomb and Daly, 2008). Finally, organizational enablers are mostly related with the existence of political or organizational vision/plan for the development of the role, and with the access to appropriate education and training. All of the mentioned 
enablers represent factors favoring and smoothing the roll-out of nursing specialization (McKenna et al., 2015).

However, the implementation of nursing specialties may also face some challenges. The most relevant barriers to overcome are the inter-professional opposition (i.e., objection to the development of the nursing roles by other health professionals) and the outdated regulation, which encompasses a diminished role for nurses, and the lack of a legal framework to support new functions (Maier, 2015). Additional difficulties may also arise from other barriers, such as inertia in the profession and resistance to change, from the lack of understanding the need for the role, or from the insufficient availability of education and training places to provide the necessary skills (Niezen and Mathijssen, 2014; Delamaire and Lafortune, 2010).

In Portugal, the primary enabler of the implementation of specialized nursing roles was the recognition of some reasons motivating the development of such functions: changing patients' needs, search for higher quality and continuity of care, and aim for nurse carrier progression. As so, the emphasis on promoting evidence-based practice has been enhanced, and the demand for nursing specialization by the nursing associations increased. On the other hand, the main barrier seems to be related to the lack of regulation clarifying the recognition of the role, its scope of practice, and guiding the processes of education, training, and hiring. Additionally, economic conditions may also play an important role as this measure may put some pressure on the state budget for health. Both the specialization process and the maintenance of a specialized workforce entails public costs, mostly due to the unions' attempt to increase the wage for specialists. The professional opposition from medical associations would also be a crucial challenge for the eventual implementation of NPs roles, but it is irrelevant for CNSs (Temido and Dussault, 2015).

\subsubsection{Workforce planning}

The main challenge regarding the HHR policies lies in planning a health care workforce that fits the needs of the population, which implies a health care workforce that has the 
appropriate competencies especially in the area of chronic illness care (De Geest et al., 2008). Additionally, the skill mix that contributes to both adequate clinical and economical outcomes needs to be defined, and the requirements for the future planned (Buchan and Calman, 2004). Thus, forecasts for the evolution of nursing professionals need to be generated. These forecasts will help to determine the residency vacancies that should be opened and the number of nurse specialists that should be hired to meet the desired skill-mix.

The predictions for the Portuguese nursing workforce were generated using an agent simulation model that implements the life cycle of a nurse, from the time he enters the university until he retires. This model is an adaptation of another previously developed to simulate the evolution of the physicians' path (Amorim-Lopes et al., 2015). Several frictions have been considered, such as emigration, probability of dropping out of university and death. As a starting point it was assumed that there were 15,092 students enrolled in the degree in Nursing; 43,279 nurses working in the NHS (9,954 specialists and the remaining 33,325 providing general care); 3,200 nurses working in private health care facilities or as independent professionals, and 647 retirees. Of the 20,686 enrolled in the Nursing Council whose status is unknown, it was assumed that they were practicing in the private sector, although a significant part may have emigrated. However, the uncertainty about these numbers does not affect the projections for the evolution of the nurses specialist. Also, since this analysis is only focused on evaluating the public costs, residency programs that may occur in the private sector may also be disregarded.

Considering the limits of the formative capacity, the access to the residency is conditioned by a total of 3000 places. If evenly distributed by the ten specialties, 300 places per specialty are available. This value is not binding, it only limits the number of nurses who can join the residency each year, and the total number of residents ends up varying each year. The residency vacancies were further adjusted to achieve the objectives defined by the Nursing Council for the ratios of nurse specialists for the next 5,10 and 15 years, both for the primary and for the secondary care. These ratios, which are presented in Table 5.2 have been calculated to meet the Safe Nurse Staffing levels (OE, 2014). 
Table 5.2 - Targets for the ratio of Specialist Nurses in the NHS.

\begin{tabular}{ccc}
\hline & Primary care & Secondary Care \\
\hline 5 years & $60 \%$ & $35 \%$ \\
\hline 10 years & $80 \%$ & $40 \%$ \\
\hline 15 years & $90 \%$ & $50 \%$ \\
\hline
\end{tabular}

Note. The needs for the long-term care were not considered in the analysis, since in Portugal this type of care is fundamentally provided by the social and the private sectors, and its impact on the public health sector is insignificant.

It will be expected that it will take some time for the newly created nursing specialties (Palliative care, Perioperative care, Critical care, Chronic care, and Family practice) to be able to have residency for training specialists, especially taking into account the access criteria. However, there is a steady increase since 2018 (Figure 5.4). Moreover, it was assumed that nurses choose the specialty to be performed arbitrarily, so that, in equilibrium, the distribution by specialty will be uniformly distributed.

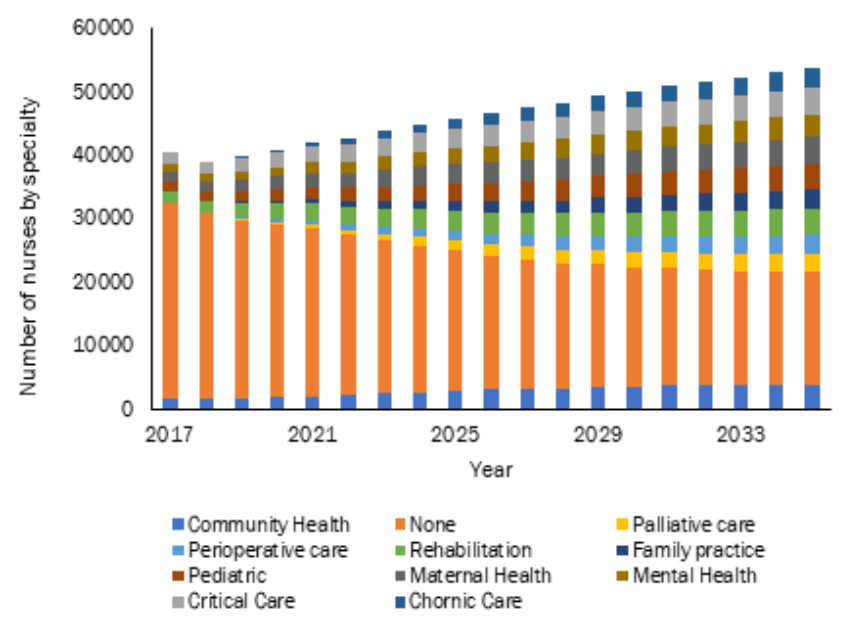

Figure 5.4 - Estimated evolution of the number of specialists

Regarding the number of NHS places for nurse specialists to be opened each year, and given the uncertainty around this number, three different scenarios have been considered: 1000, 1500, and 2000 positions per year. These scenarios aim to address the uncertainty and to allow for the analysis of the financial results' sensibility to this parameter.

Figure 5.5 shows the expected evolution of the number of nurses with and without a specialty in the NHS, assuming that the current numerus clausus for nursing in the universities 
is maintained, and the policy of hiring nurse specialists for the NHS is set at 2,000/year. As a result, the workforce foreseen in the NHS continues to increase, maintaining the upward evolution trend in the number of nurses in Portugal, and its composition changes: the percentage of specialist nurses increases considerably, and there is a less than a proportional reduction in the proportion of general nurses. At the end of the period in analysis, nurse specialists represent more around $65 \%$ of the total nurse workforce.

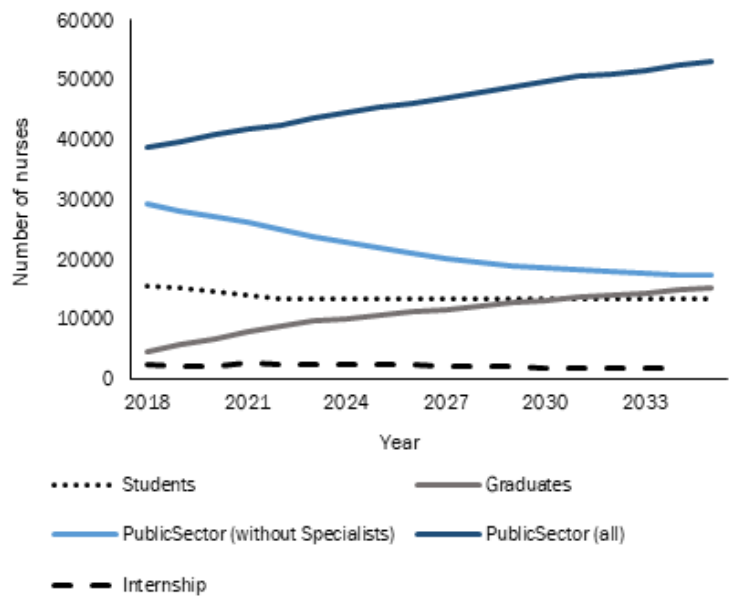

Figure 5.5 - Forecast of the evolution of the Nursing workforce in the next 15 years.

\subsubsection{Education and training}

In most countries, nursing specialists have an equivalent to an MSc degree, as is the case of Australia, U.K., Canada or U.S.A.. Less frequently, the education required to become a CNS is only a bachelor's degree (e.g., in Belgium, Greece, and Malaysia) or a bachelor's degree and a post-graduation (which is the case in the Denmark, for example) (Heale and Buckley, 2015a). Independently of the educational degree that is required, the Universities or other educational providers usually have the freedom to define the curricula associated to the academic training. In addition to the educational requirements, specialized clinical practice is also needed. This requirement can be put into practice through the imposition of minimum time of work experience in the specialization field, a more formal specialty 
residency, or through a combination of both. The specialty residency is a common way to implement this need for practice and is essential for allowing for an hands-on practice period as pre-requisite to become a specialist (Goode et al., 2009). These residency programs are usually defined by Nursing councils and health authorities. Moreover, it may also be necessary, in countries such as the U.S.A., to take a certification exam to become a specialist.

In Portugal, it is proposed that the nurses with one of the currently existing specialties and more than two years of professional practice are awarded the professional title of specialist nurse specialist by the Nursing Council, through a process of recognition, validation, and certification. For the new specialists, the Portuguese Nursing Council proposal for the educational path includes a bachelor's degree (required to become a RN) and a postgraduation. Regarding the experience requirements, a least of 800 hours of clinical experience is needed to access the residency, which is to be in the format of a program of 9 (or 15, for Maternal Health) months of supervised clinical practice. The proposed education and training process is represented in Figure 5.6.

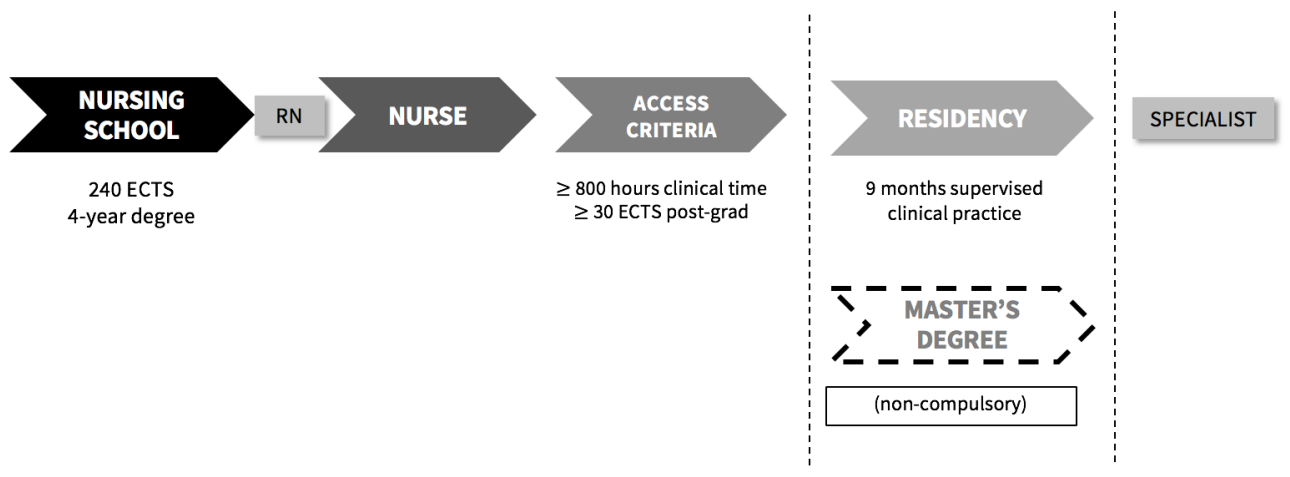

Figure 5.6 - Training and education process 


\subsubsection{Payment policies}

To make full use of the skills of the specialized workforce, specific work positions for nurse specialists need to be opened, and nurse specialists to be hired. The career progression after the education and training process is usually not automatic and hiring should be made on a need or merit base.

Commonly, payment policies derive from the integration of a specialized workforce in the health system, as the wage for nurse specialist positions is usually higher than the average wage of RNs, recognizing the efforts invested in training and rewarding their added patient care responsibilities and outcomes (Dicenso and Bryant-Lukosius, 2010). Eventually, nurses supervising the specialty residents may also be financially compensated for that function.

Moreover, at the organizational level, financial (dis)incentives may also play an important role. Incentives for primary care centers and hospitals to host nurse residents and to hire CNSs, or the application of financial penalties for those that do not employ nurse specialists may help the nurse specialists to work at their full potential and scope of practice (McComiskey et al., 2018).

In Portugal, the payment of a salary differential was the only financial compensation proposed in the negotiations regarding the implementation of this role, as well as a career development plan. The institution of this compensatory amount for specialist has recently been analyzed and approved by the Portuguese Ministry of Health. The initial proposal of the Nursing Union was an increase of $600 €$ regarding RNs' wages, who were earning an average base remuneration of $1232 € /$ month. After the negotiations with the Ministry of Health, the amount of the monthly wage differential has been set in $150 €$, which represents difference higher than $10 \%$ between specialists and non-specialist' wages. 


\subsubsection{Regulation and governance}

In many countries there is a lack of basic nursing regulation, rules or regulatory mechanisms, and expanded nursing roles are even less defined in regulation (Bryant, 2005). However, their development has been requiring legislative and regulatory changes in most countries, mainly to remove some barriers to the implementation of these specialized roles (Delamaire and Lafortune, 2010).

There are a number of different types of nursing regulation. Two main types of regulation are state-based and profession-based (ICN, 2009). Also, regarding the regulation guiding the titles or the scope of practice of nurse specialists, three different types of governance approaches may be identified: i) national-level regulation, such as is the case of Austria, France and Greece; ii) decentralized or devolved regulation, as in Australia, Denmark and U.S.A ; and iii) no regulation or at discretion of providers and settings, as it is the case of Czech Republic, Finland and Switzerland (Maier, 2015).

The regulatory national-level body can both act as driver for nurse role advancement and ensure smaller variations in specialized training and practice (Pulcini et al., 2010b). Decentralized regulation with several levels of regulation, in a number of jurisdictions within a country is also common (Heale and Buckley, 2015a). Finally, in the third type, a separate regulation (i.e., different from that of the registered nurse) is not required, and other mechanisms for recognizing can be implemented, such as clinical and educational requirements (DiCenso and Bryant-Lukosius, 2010).

Given the centralized nature of the Portuguese NHS, a national-level regulation is needed. However, a mixed approach is proposed. In Portugal, the responsibility for defining the scope of the professions lies with the professional public associations. As so, the regulation model should include some delegation to the Nursing Council, the nursing regulatory body, regarding the regulation and the supervision of access and exercise of the profession. Private healthcare providers are responsible for integrating these healthcare professionals according to their needs, and the government stays accountable for rolling out the imple- 
mentation at their pace, according to the needs and budgetary conditions.

\subsubsection{Economic impact}

The empirical studies evaluating the effects of having a specialized nursing workforce show positive effects of nurse specialization on both the quality of the care provided and in access to healthcare, two crucial pillars of any health system.

However, costs also arise from the training and maintenance of a specialized nursing workforce, and this investment should be quantified and analyzed to assure compliance with budgetary.Therefore, an in-depth cost-benefit analysis is essential to estimate the budgetary impact of nursing specialization and to assist a more rational and well-informed decision of whether the role should be implemented and how.

There are a number of assumptions and forecasts built into the process of cost-benefit analysis, such as the forecasts for the evolution of the nursing workforce. In the course of the economic analysis, several assumptions have to be made, as well as some parameters have to be considered for the calculation of the different costs and benefits involved. Whenever possible, real data and expectations may be considered.

\section{Costs}

In the quantification of the costs associated with the nursing specialization, both the costs that flow directly from the specialization process and the indirect and opportunity costs that will have to be borne during and after the specialization of these health workers should be considered.

In cases where the curricular training is not the responsibility of the nurses, training costs should also be accounted for. Otherwise, the only costs arising from the specialization process that are relevant to the public accounts are the ones related with the residency. On the other hand, the most relevant cost that must be supported afterwards result from the existence of a more qualified workforce and the subsequent payment of the salary differentials to nurse specialists, and eventual financial incentives that may arise from hiring a more specialized workforce. 
The following three main costs were considered for the cost-benefit analysis performed for Portugal:

1. Cost of nurse unavailability $(\mathbf{C N})$. It is an opportunity cost, resulting from the absence of the nurse from his job.

$$
C N=P M * W_{n} * r * A_{r},
$$

where $P M$ is the number of paid months during the residency, $W_{n}$ is the monthly base salary of a non-specialist nurse, $r$ is the number of residents, and $A_{r}$ is the $\%$ of time allocation of the nurse to the residency program.

2. Cost of supervision (CS). It is an opportunity cost, resulting from the absence of the supervisor from his job.

$$
C S=P M * W_{n s} * r * A_{s},
$$

where $W_{n s}$ is the monthly base salary of a nurse specialist, and $A_{s}$ is the $\%$ of time allocation of the clinical supervisor to the residency program of each resident.

3. Cost with the wage increase (CW). It was assumed that a specialist nurse is in a differentiated remuneration category, compatible with his position and responsibility, and therefore we considered the following cost:

$$
C W=P M y *\left[W_{n s}-W_{n}\right] * n s,
$$

where $P M_{y}$ is the number of paid months during a year, $\left[W_{n s}-W_{n}\right]$ is the wage differential for nurse specialists, and $n s$ is the number of nurse specialists in the NHS.

To calculate the costs that are estimated to result from the nursing specialization, several parameters were considered, which are presented in Table 5.3. 
Table 5.3 - Parameters and assumptions assumed in the calculation of costs.

\begin{tabular}{lc}
\hline Base salary of non-specialist nurse (average) & $1,232 €$ \\
Salary differential for nurse specialists & $150 €$ \\
Allocation of clinical supervisor to the residency & $10 \%$ \\
Duration of the residency in MH (15 months) & 17,5 salaries \\
Duration of the residency in the remaining specialties (9 months) & 10,5 salaries \\
Allocation of nurses to the residency & $100 \% *$ \\
\hline * baseline scenario for the allocation of the nurse to the residency. Two additional scenarios were considered in the analysis: $30 \%$ and $50 \%$.
\end{tabular}

The average base remuneration of a non-specialist nurse $(1,232 €)$ was reported by the Central Administration of the Health System (ACSS). The salary differential considered $(150 €)$ reflects the recent decision of the Ministry of Health to institute a compensatory package for specialist nurses, although not yet in effect (and without prejudice to a change in the process of nursing career negotiation, with impact on a future remuneration table). The remaining values were based on the recommendations of the Nursing Council, and include the average duration of the residency (where one year represents 14 monthly salaries) and the time allocation of the nurse and of the respective clinical supervisor to the residency.

All residencies with the exception of the Maternal Health (MH) have a duration of approximately 9 months. In the case of Maternal Health this period lasts for 15 months. Additionally, we assume that $10 \%$ of the time of the clinical supervisor - a nurse specialist in the corresponding salary range - will be dedicated to each resident. Regarding the allocation of nurses' time to the residency, several scenarios have been considered $(30 \%, 50 \%$ and $100 \%$ ), thus attempting to address some of the uncertainties.

Figure 5.7 illustrates the projection of annual costs with the residency considering the number of residents and nurse specialists obtained in the previous subsection, assuming the baseline scenario where the resident is working full-time (allocation=100\%), and it is necessary to assume the costs of another full-time nurse to replace him (1 Full Time Equivalent (FTE) with base salary), and considering a $10 \%$ allocation of the supervisor (0,1 FTE Specialist, with salary added). Given the variability in the number of nurses in the residency program, the costs fluctuate over time, but not significantly. On average, the yearly cost of the residency is estimated at 38.4 million Euros, for around 2200 residents per year. 


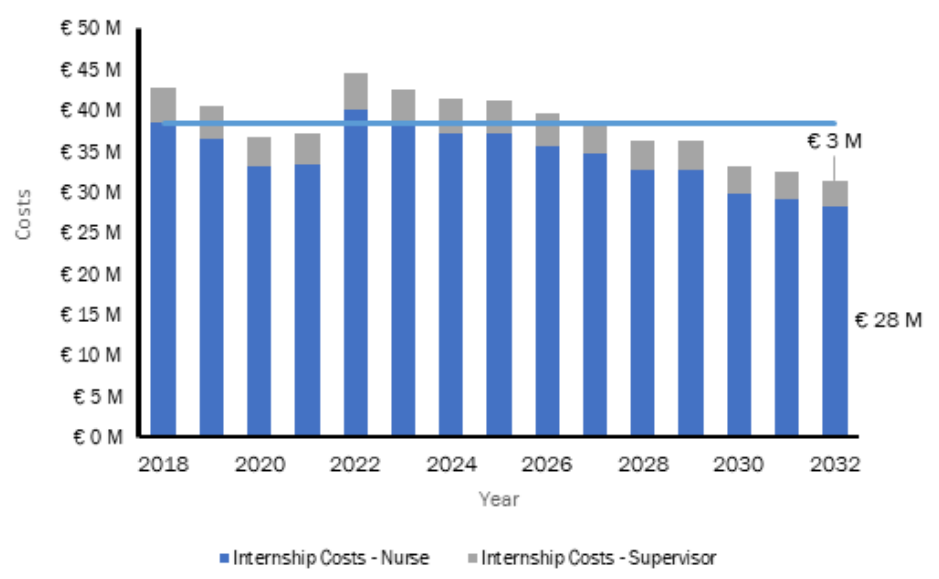

Figure 5.7 - Costs with the residency program

The costs arising from the increase in salary due to salary differential for nurse specialists are costs that depend directly on the number of nurse specialists positions to be made available each year in the NHS. Figure 5.8 shows the evolution of wage costs as positions are made available, and the total cost at the end of the planning horizon for the three scenarios considered. Thus, at the end of the planning horizon, the increase in expenditures on salaries is $63.00,47.25$, and 31.50 million Euros for 2000, 1500 and 1000 positions/year, respectively. These values correspond to $30,000,22,500$ and 15,000 nurses hired as specialists by the NHS at the end of the planning horizon (2032).

\section{Benefits}

Despite the significant number of papers pointing to significant gains from specialized training, the calculation of benefits is complex. The difficulty in measuring and quantifying the most relevant benefits arising from having a specialized workforce is increased: many of the variables positively affected by specialization - such as health status, access, quality of services provided or user satisfaction - are not directly or easily measurable in monetary terms. Thus, a large part of the literature has chosen to report the monetary gains resulting from a lower use of some healthcare services, in order to maintain the objectivity and rigor of the analysis (Martin-Misener et al., 2009; Tier and Hall, 2015; Cox et al., 2017). 


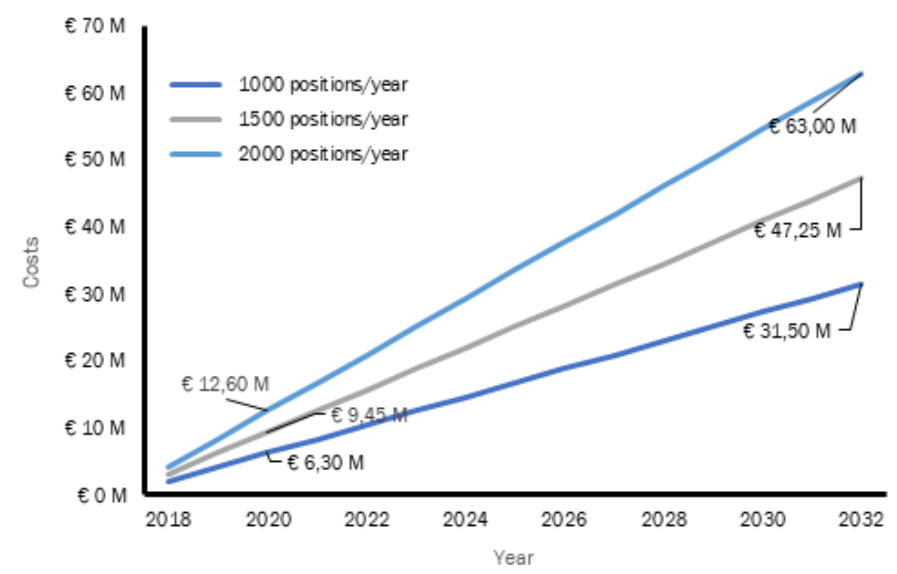

Figure 5.8 - Estimated cost with differentiated nurse specialist remuneration

However, many of the benefits associated with specialization will not be included in the analysis and the value of benefits will be therefore undervalued. In addition, the analysis of the benefits may also not be capable of translating the different effects of specialization that may have strong positive effects on the health of the population, and consequently on the reduction of public health expenditure in the medium- and long-term.

To estimate the benefits of nurse specialization for the case of Portugal, we have chosen to consider only the monetary gains resulting from the decrease in hospitalizations, as it is an indicator frequently mentioned in the literature, and because both its volume $(819,476$ admissions in 2016) and its cost (around 1.87 billion Euros) are significant.

Based on the values reported by the empirical studies regarding the reduction of admissions due to the specialization of nurses (Mathew et al., 1994; Brooten et al., 2001; Ahrens et al., 2003; Nelson et al., 2007; Ulch and Schmidt, 2013; Whitty et al., 2017), three different scenarios were considered for the reduction of the annual number of hospitalizations: $3 \%$, $5 \%$, and $10 \%$. The consideration of different scenarios is because the savings reported depend on the percentage of nurse specialists, the country and the nurses' intervention area. Hence, it is assumed that the estimated benefits for Portugal will also be dependent on the number of specialist nurses to be hired annually, and on the ability of organizations 
to make full use of their skills, avoiding mismatches with current needs. Additionally, it should be noted that the benefits are not exhausted here, and that the considered values are somehow conservative when compared to the ones reported in the literature for the reduction in the number of hospitalizations and in their duration, which can reach more than 20\% (Ulch and Schmidt, 2013) and 30\% (Ahrens et al., 2003), respectively.

To represent the cost of each hospitalization, the contractual base price per episode for 2017 was considered, which despite not representing the exact real cost of an inpatient, is an approximate value of its average price for cases of medium complexity. As a proxy of the annual number of hospitalizations, the number of discharges in 2016 was used. The parameters used to calculate the monetary benefits are shown in Table 5.4.

Table 5.4 - Parameters and assumptions assumed for benefits calculation

\begin{tabular}{lc}
\hline Base rate for hospitalization episode & $2285 €$ \\
\hline Annual number of discharges & 819476 \\
\hline * baseline scenario for the Reduction in the number of hospitalization episodes. Two additional scenarios were considered in the analysis: $3 \%$ and $10 \%$.
\end{tabular}

Considering a $3 \%$ reduction in the number of hospitalization episodes, the total benefits are of around 56 million Euros. In the scenario that assumes a saving of $10 \%$ of hospitalizations, the benefits reach 187 million Euros in 2022 (the year when the full effect of the measure is accomplished). Figure 5.9 shows the annual evolution of estimated benefits assuming the baseline scenario (reduction of 5\%), where the total savings are of around 93 million Euros.

As can be seen, the effect is only complete by 2022 , since a gradual impact of the benefits has been assumed (i.e., its impact is not immediate, but unfolds over five years). This gradual introduction of the benefits in the analysis is because benefits of specialization should be observed as specialist nurses are hired and integrated into the NHS, and as organizations make full use of the specialized functions of these professionals. 


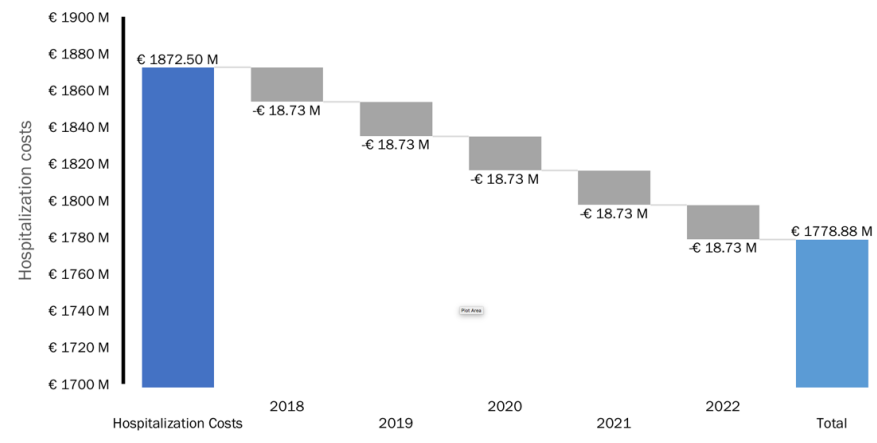

Figure 5.9 - Decomposition of savings in hospitalization costs, assuming gains of 5\%.

\section{Estimated economic impact}

Once the benefits of nurse specialization are calculated, as well as the associated costs, the subtraction of the costs from the benefits yields a concrete result that can be used to infer on the sustainability of the measure and help on a more informed decision.

When we cross the calculated costs and benefits, it is possible to obtain the expected net effect of the implementation of the nurse specialization in Portugal. As expected, the first two years represent a burden on the government's budget, since the expected benefits take time to take effect. But this trend is reversed later (in 2020, considering the scenario with 1500 new positions per year), and the benefits outweigh the associated costs as Figure 5.10 shows.

The sensitivity of the cost-benefit outcome will be fundamentally dependent on two policy instruments: the number of residency places and the number of positions for nurse specialists in the NHS. However, even in the scenario where the number of positions is 2000 / year, the net result remains positive at the end of the time horizon considered. Costs and benefits calculated for all the different scenarios considered in the analysis of the budgetary impact of implementing nursing specialization are presented in the Appendix (Table 5.6). 


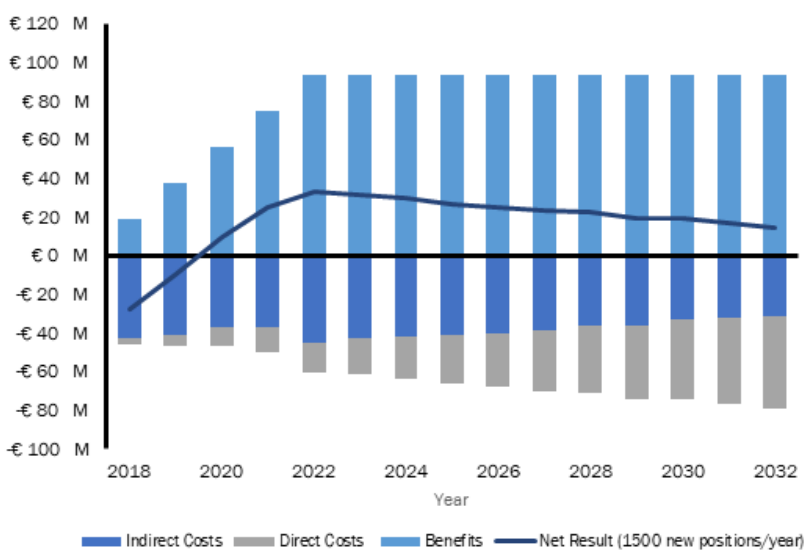

Figure 5.10 - Budgetary impact of the specialty residency

\subsection{Conclusions}

Health systems are currently facing pressures both in the levels of care and in the resources needed. Therefore, it is imperative to find ways of dealing with the current challenges and providing adequate and sustainable care to a population with changing needs. Within the possible ways to deal with the rising demand and complexity of healthcare, the nursing specialization is presented as an alternative mode of delivering care, which has been claimed to help ensuring the quality, access, and sustainability of healthcare delivery.

Most of the empirical evidence shows that the specialization of nurses improves the quality of healthcare provided, improves access, enhances health promotion, and helps on chronic illness management. However, the analysis of the international experience shows that both the characteristics and processes of the implementation and governance of this specialized nursing roles considerably differ from country to country.

Despite rolling out a policy measure as such is very dependent of the specific context, there are several common points that should to be considered, analysed and estimated by countries considering to implement these roles. As so, we provide a policy framework for the implementation and governance of such role, providing insights about barriers and enablers, workforce planning, education and training processes, payment policies, regulation, and economic impact of the measure. 
The identification of the main challenges and opportunities is critical to a successful implementation. As so, it is crucial to start by work on recognizing and overcoming the main obstacles and oppositions to the implementation, also taking advantage of the factors that may facilitate its execution. A successful implementation will also depend on several HHR policy decisions. It is crucial to accurately estimate and plan the workforce that should be specialized and hired to meet the population' needs. Moreover, a clear definition of the required educational path and practical training is essential, as well as the delineation and implementation of policies concerning the rewarding of a workforce with differentiated training and functions. Additionally, a clear and transparent implementation and governance will also require a robust regulatory body, guiding the main criteria, rights, duties, and requirements. Finally, it is crucial to ensure that the implementation and maintenance of the measure are sustainable for public accounts. Thus, the costs arising from training and maintaining a specialized workforce must be estimated, as well as the expected benefits of having nurse specialists proving care. An economic analysis crossing the main costs and benefits will inform on the net economic impact of the measure and the subsequent financial effort and sustainability to the public budget.

This framework was used in Portugal, helping to inform policy-makers. The results of the analysis, which supported the discussion and negotiation of the implementation process of this role in Portugal are also provided. Moreover, forecasts for the evolution of nursing professionals, implementing the life cycle of a nurse, were generated. This prediction served as a basis for the evaluation of the budgetary impact that is estimated through a cost-benefit analysis. The cost-benefit analysis shows that the estimated benefits considered, which are supported by the empirical evidence, exceed the costs of nurse specialization. These results depend on the number of residency places, as well as on the number of positions for nurses specialists to be opened in the NHS, but even in the scenario where the number of positions is higher, the net result remains positive. Additionally, it should be noted that although all the identified costs are incorporated in the analysis, many benefits were excluded due to quantification difficulties. Therefore, the potential gain is probably much higher than the one presented. Moreover, the numerical results provided are country-specific, and accord- 
ing to the particular context, expectations and data. Notwithstanding, insights provided may be useful to inform other countries that may be considering the implementation of these roles about what can be their expected costs and benefits. Overall, we conclude that together with all the expected benefits of specializing the nursing workforce - for patients, professionals, and health organizations - come a set challenges, as well as direct, indirect and opportunity costs that must be previously evaluated to asses both how can the policy measure be successfully implemented and managed, and if the benefits arising from that investment justify the costs. As so, the evaluation of the main opportunities, difficulties, and of the financial side of the nurse specialization is crucial to ensure both a successful implementation, that the investment is affordable and that economic pressure on the sustainability of the health system is not exacerbated.

\section{Bibliography}

B. T. Ahrens, V. Yancey, and M. Kollef. Improving family communications at the end of life: implications for length of stay. American Journal of Critical Care, 12(4):317-324, 2003.

L. H. Aiken, D. M. Sloane, J. P. Cimiotti, S. P. Clarke, L. Flynn, J. A. Seago, J. Spetz, and H. L. Smith. Implications of the california nurse staffing mandate for other states. Health services research, 45(4):904-921, 2010.

M. Amorim-Lopes, Á. S. Almeida, and B. Almada-Lobo. Handling healthcare workforce planning with care: where do we stand? Human Resources for Health, 13(1):38, May 2015.

T. Bodenheimer, K. MacGregor, and N. Stothart. Nurses as leaders in chronic care. BMJ, 330(7492):612, 2005.

M. Boltz, E. Capezuti, L. Wagner, M.-C. Rosenberg, and M. Secic. Patient safety in medical-surgical units: can nurse certification make a difference? Medsurg Nursing, 22(1), 2013. 
D. K. Boyle, E. Cramer, C. Potter, M. W. Gatua, and J. X. Stobinski. The relationship between direct-care rn specialty certification and surgical patient outcomes. AORN journal, 100(5):511-528, 2014.

D. Brooten, J. M. Youngblut, L. Brown, S. A. Finkler, D. F. Neff, and E. Madigan. A randomized trial of nurse specialist home care for women with high-risk pregnancies: outcomes and costs. The American Journal of Managed Care, 7(8):793, 2001.

R. Bryant. Regulation, roles and competency developmen. Journal of Nursing Regulation, 1(1):44-48, 2005.

J. Buchan and L. Calman. Skill-mix and policy change in the health workforce. nurses in advanced roles. OECD Health Working Papers, 17:65, 2004.

A. H. Cary. Certified registered nurses: Results of the study of the certified workforce. The American Journal of Nursing, 101(1):44-52, 2001.

CNA. Advanced nursing practice a national framework. Canadian Nurses Association, pages $1-53,2008$.

E. A. Coleman, S. K. Coon, K. Lockhart, R. L. Kennedy, R. Montgomery, N. Copeland, P. McNatt, S. Savell, and C. Stewart. Effect of certification in oncology nursing on nursing-sensitive outcomes. Clinical Journal of Oncology Nursing, 13(2), 2009.

K. Cox, S. C. Macleod, C. J. Sim, A. W. Jones, and J. Trueman. Avoiding hospital admission in copd: impact of a specialist nursing team. British Journal of Nursing, 26(3): 152-158, 2017.

S. De Geest, P. Moons, B. Callens, C. Gut, L. Lindpaintner, and R. Spirig. Introducing advanced practice nurses / nurse practitioners in health care systems: a framework for reflection and analysis. Swiss Med WKLY, 138:621-8, 2008.

M. Delamaire and G. Lafortune. Nurses in advanced roles: a description and evaluation of experiences in 12 developed countries. OECD Health Working Papers, 54, 2010. 
A. DiCenso and D. Bryant-Lukosius. Clinical nurse specialists and nurse practitioners in canada. Canadian Health Services Research Foundation, 2010.

A. Dicenso and D. Bryant-Lukosius. Clinical nurse specialists and nurse practitioners in canada: A decision support synthesis. Canadian Health Services Research Foundation, 2010.

DL71/2019. Decreto-lei n. ${ }^{\circ}$ 71/2019. Diário da República n. ${ }^{\circ}$ 101/2019, Série I de 201905-27, 17:2626-2642, 2019.

F. Donald, K. Kilpatrick, K. Reid, N. Carter, R. Martin-Misener, D. Bryant-Lukosius, P. Harbman, S. Kaasalainen, D. Marshall, R. Charbonneau-Smith, E. Donald, M. Lloyd, A. Wickson-Griffiths, J. Yost, P. Baxter, E. Sangster-Gormley, P. Hubley, C. Laflamme, M. Campbell-Yeo, S. Price, J. Boyko, and A. DiCenso. A systematic review of the costeffectiveness of nurse practitioners and clinical nurse specialists: what is the quality of the evidence? Nurse Research and Practice.

L. Fagerström. The impact of advanced practice nursing in healthcare: Recipe for developing countries. Annals of neurosciences, 19(1):1, 2012.

M. Frank-Stromborg, S. Ward, L. Hughes, K. Brown, A. Coleman, C. G. Grindel, and C. M. Murphy. Does certification status of oncology nurses make a difference in patient outcomes? In Oncology nursing forum, volume 29, 2002.

J. S. Fulton and K. Baldwin. An annotated bibliography reflecting clinical nurse specialist practice and outcomes. Clin. Nurse Spec., 18(1):21-39, 2004.

K. B. Gaberson, K. Schroeter, A. R. Killen, and W. A. Valentine. The perceived value of certification by certified perioperative nurses. Nursing Outlook, 51(6):272-276, 2003.

C. J. Goode, M. R. Lynn, C. Krsek, and G. D. Bednash. Nurse residency programs: an essential requirement for nursing. Nursing Economics, 27(3):142-147, 2009.

G. Halcomb, Davidson and Daly. An investigation of barriers and enablers to advanced nursing roles in australian general practice. Human Resources for Health, 13(1), 2008. 
S. Hanneman, A. Bines, and W. Sajtar. The indirect patient care effect of a unit-based clinical nurse specialist on preventable pulmonary complications. American Journal of Critical Care, 2(4):331-338, 1993.

S. Hart, S. Bergquist, B. Gajewski, and N. Dunton. Reliability testing of the national database of nursing quality indicators pressure ulcer indicator. Journal of nursing care quality, 21(3):256-265, 2006.

R. Heale and C. R. Buckley. An international perspective of advanced practice nursing regulation. International Nursing Review, 62:421-429, 2015a.

R. Heale and R. C. Buckley. An international perspective of advanced practice nursing regulation. International Nursing Review, 1(1), 2015b.

ICN. Definition and characteristics of the role. International Council of Nurses, 2002.

ICN. The scope of practice, standards and competencies of the advanced practice nurse. International Council of Nurses, 2008.

ICN. Regulation 2020: Exploration of the present; vision for the future. International Council of Nurses, 2009.

S. M. Kabene, C. Orchard, J. M. Howard, M. A. Soriano, and R. Leduc. The importance of human resources management in health care: a global context. Human resources for health, 4(1):20, 2006.

L. A. Kelly, M. D. McHugh, and L. H. Aiken. Nurse outcomes in magnet $($ and non-magnet hospitals. The Journal of nursing administration, 42(10 Suppl):S44, 2012.

D. Kendall-Gallagher and M. A. Blegen. Competence and certification of registered nurses and safety of patients in intensive care units. American Journal of Critical Care, 18(2): 106-113, 2009.

D. Kendall-Gallagher, L. H. Aiken, D. M. Sloane, and J. P. Cimiotti. Nurse specialty certification, inpatient mortality, and failure to rescue. Journal of Nursing Scholarship, 43(2):188-194, 2011. 
G. Krapohl, M. Manojlovich, R. Redman, and L. Zhang. Nursing specialty certification and nursing-sensitive patient outcomes in the intensive care unit. American Journal of Critical Care, 19(6):490-498, 2010.

D. Litaker, L. C. Mion, L. Planavsky, C. Kippes, N. Mehta, and J. Frolkis. Physiciannurse practitioner teams in chronic disease management: the impact on costs, clinical effectiveness, and patients' perception of care. Journal of interprofessional care, 17(3): 223-237, 2003.

C. B. Maier. The role of governance in implementing task-shifting from physicians to nurses in advanced roles in europe, u.s., canada, new zealand and australia. Health Policy, 119(12):1627-1635, 2015.

R. Martin-Misener, B. Downe-Wamboldt, E. Cain, and M. Girouard. Cost effectiveness and outcomes of a nurse practitioner-paramedic-family physician model of care: the long and brier islands study. Primary Health Care Research E Development, 10(1):14-25, 2009.

A. Martínez-González, R. Tandjung, S. Djalali, F. Huber-Geismann, and S. Markun. Effects of physician-nurse substitution on clinical parameters: A systematic review and meta-analysis. PLOS ONE, 9(2):e89181, 2014a.

A. Martínez-González, R. Tandjung, S. Djalali, F. Huber-Geismann, and S. Markun. Substitution of physicians by nurses in primary care: a systematic review and meta-analysis. Health Services Research, 14, 2014b.

L. J. Mathew, H. Gutsch, N. Hackney, and E. M. Munsat. Promoting quality and costeffective care to geropsychiatric patients. Issues in Mental Health Nursing, 15(2):169$185,1994$.

C. McComiskey, S. Simone, D. Schofield, K. McQuillan, B. Andersen, S. Johannes, and A. Weichold. Professional advancement for advanced practice clinicians. Journal for Nurse Practitioners, 14, 2018. 
L. McKenna, E. Halcomb, R. Lane, N. Zwar, and G. Russell. An investigation of barriers and enablers to advanced nursing roles in australian general practice. Collegian, 22(2): 183-189, 2015.

J. Mousquès, Y. Bourgueil, P. Le Fur, and E. Yilmaz. Effect of a french experiment of team work between general practitioners and nurses on efficacy and cost of type 2 diabetes patients care. Health policy, 98(2-3):131-143, 2010.

NCPDNM. Development of nursing and midwifery a preliminary evaluation of the role of the advanced nurse practitioner. National Council for the Professional Development of Nursing and Midwifery, 2005.

A. Nelson, G. Powell-Cope, P. Palacios, S. L. Luther, T. Black, T. Hillman, B. Christiansen, P. Nathenson, and J. C. Gross. Nurse staffing and patient outcomes in inpatient rehabilitation settings. Rehabilitation nursing, 32(5):179-202, 2007.

R. Newhouse and L. a. Heindel. Advanced practice nurse outcomes 1990-2008: a systematic review. Nurs. Econ., 29(5):1-21, 2011.

R. P. Newhouse, M. Johantgen, P. J. Pronovost, and E. Johnson. Perioperative nurses and patient outcomes-mortality, complications, and length of stay. AORN journal, 81(3): $508-528,2005$

B. Niebuhr and M. Biel. The value of specialty nursing certification. Nursing outlook, 55 (4):176-181, 2007.

M. G. Niezen and J. J. Mathijssen. Reframing professional boundaries in healthcare: a systematic review of facilitators and barriers to task reallocation from the domain of medicine to the nursing domain. Health Policy, 117:151-169, 2014.

OE. Norma para o cálculo de dotações seguras dos cuidados de enfermagem. Ordem dos Enfermeiros, 2014.

J. Pulcini, M. Jelic, R. Gul, and A. Y. Loke. An international survey on advanced practice 
nursing education, practice, and regulation. Journal of Nursing Scholarship, 42(1):3139, 2010a.

J. Pulcini, M. Jelic, and L. A. Gul R. An international survey on advanced practice nursing education, practice, and regulation. Journal of Nursing Scholarship, 42:31-39, 2010 b.

S. Rosen. Specialization and human capital. Journal of Labor Economics, 1(1):43-49, 1983.

C. Savrin. Growth and development of the nurse practitioner role around the globe. Journal of Pediatric Health Care, 23(5):310-314, 2009.

M. Schober. Introduction to advanced nursing practice: An international focus. Springer, 2016.

B. Sheer and F. K. Y. Wong. The development of advanced nursing practice globally. Journal of Nursing Scholarship, 40(3):204-211, 2008a.

B. Sheer and F. K. Y. Wong. The development of advanced nursing practice globally. Journal of Nursing Scholarship, 40(3):204-211, 2008 b.

M. Temido and G. Dussault. How can a country learn from the experience of another? expanding nurses' scope of practice in portugal: Lessons from england. Health Policy, 119(1):475-487, 2015.

A. Tier and G. Hall. The super six model of diabetes care: Implementing and evaluating the diabetes specialist nurse role in portsmouth. Diabetes $\mathcal{E}$ Primary Care, 17:164-174, 2015.

A. Tsiachristas and A. a. de Bont. Costs and effects of new professional roles: evidence from a literature review. Health Policy, 119(9):1176-1187, 2015.

P. A. O. Ulch and M. M. Schmidt. Clinical nurse specialist as community-based nurse case manager: Integral to achieving the triple aim of healthcare. Nurse Leader, 11(3):32-35, 2013. 
C. H. Wade. Perceived effects of specialty nurse certification: a review of the literature. AORN journal, 89(1):183-192, 2009.

E. C. Wheeler. The effect of the clinical nurse specialist on patient outcomes. Critical care nursing clinics of North America, 11(2):269-275, 1999.

E. C. Wheeler. The cns's impact on process and outcome of patients with total knee replacement. Clinical Nurse Specialist, 14(4):159-172, 2000.

D. a. Whitehead. The relationship between specialty nurse certification and patient, nurse and organizational outcomes. 2019.

J. A. Whitty, E. McInnes, T. Bucknall, J. Webster, B. M. Gillespie, M. Banks, L. Thalib, S. R. M. Wallis, J. Cumsille, and W. Chaboyer. The cost-effectiveness of a patient centred pressure ulcer prevention care bundle: Findings from the intact cluster randomised trial. International Journal of Nursing Studies, 75:35-42, 2017.

C. Wiskow, T. Albreht, and C. De Pietro. How to create an attractive and supportive working environment for health professionals. World Health Organization Geneva, 2010.

\section{Appendix 5.A Supplementary material}




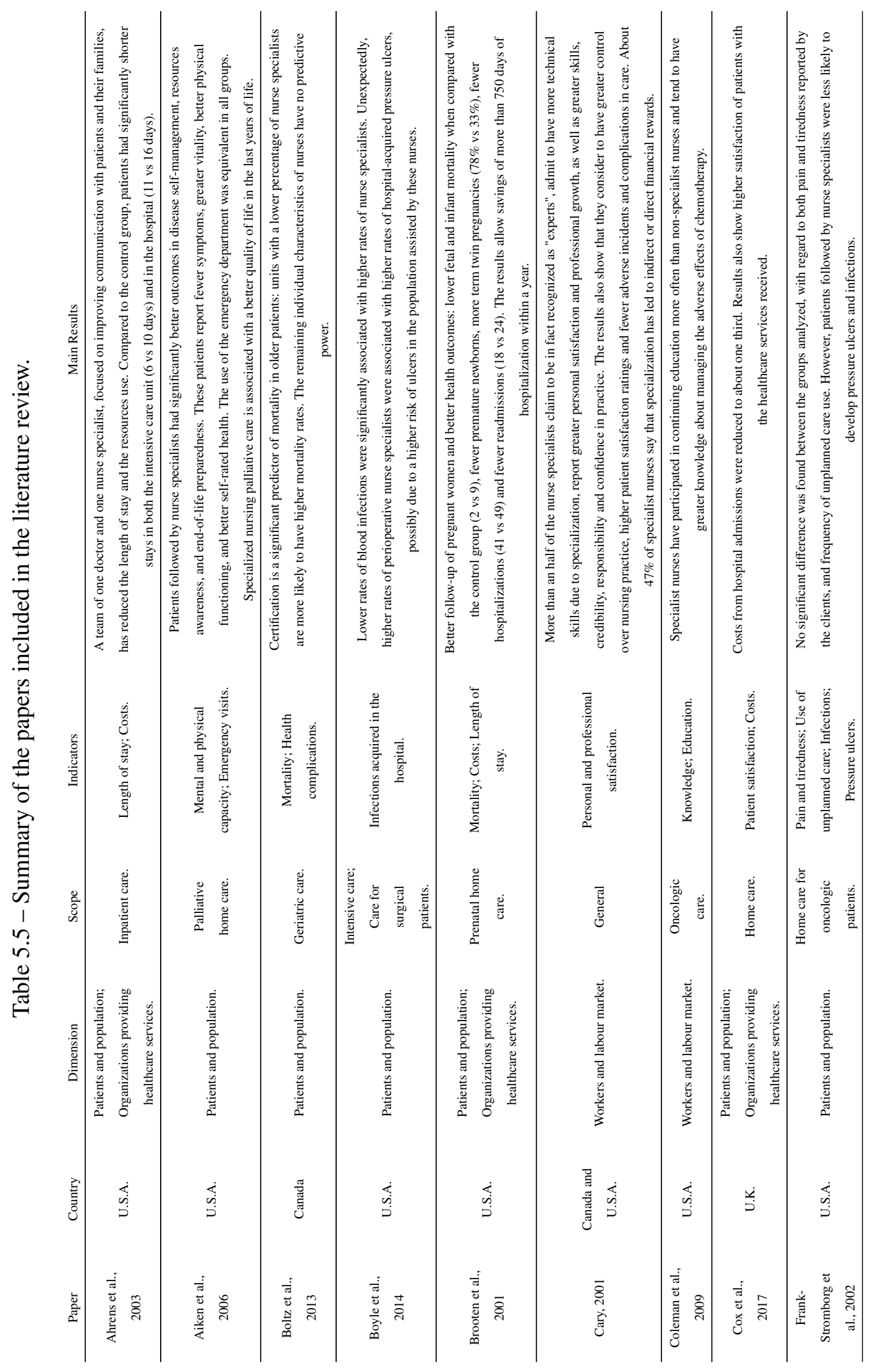




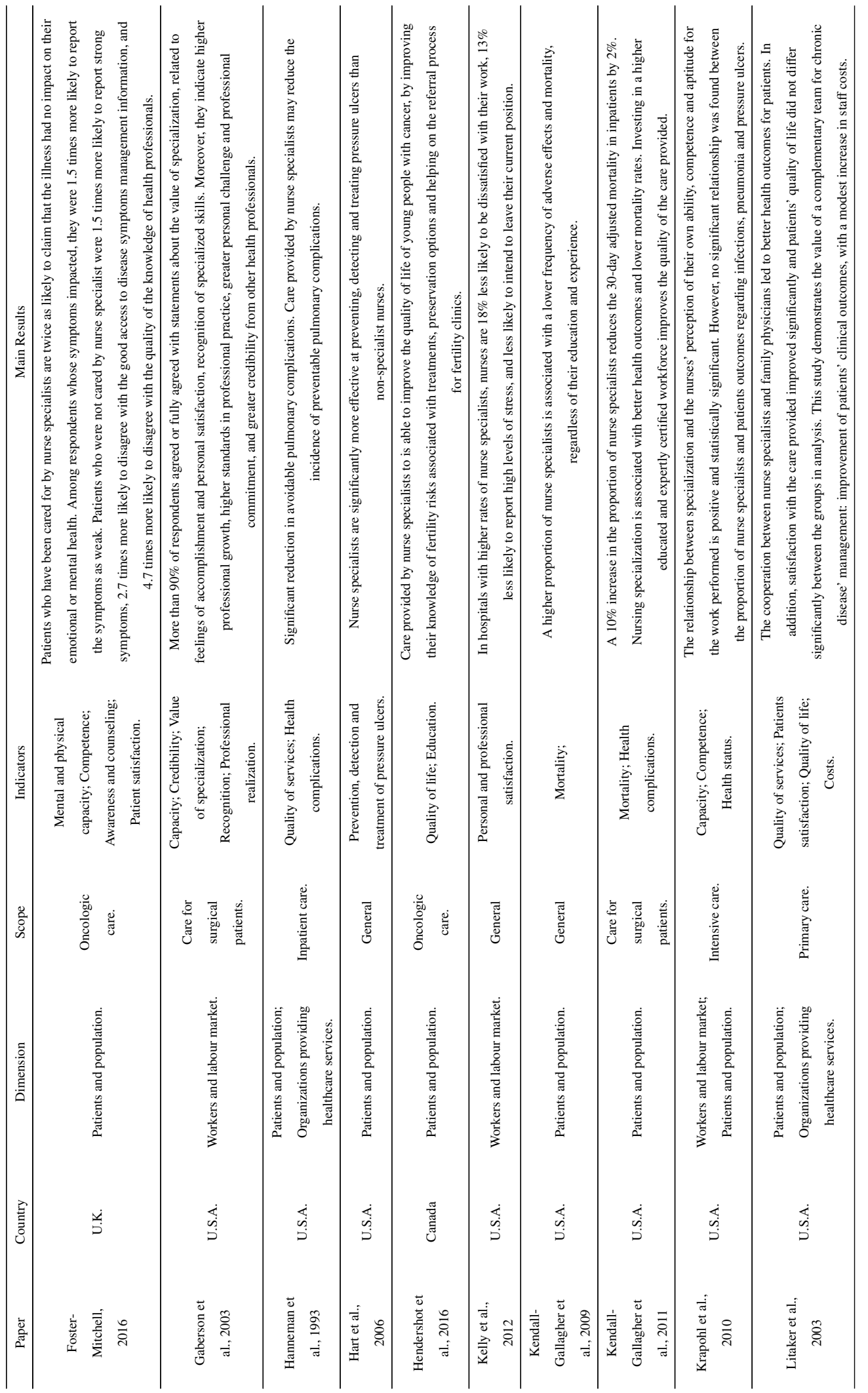




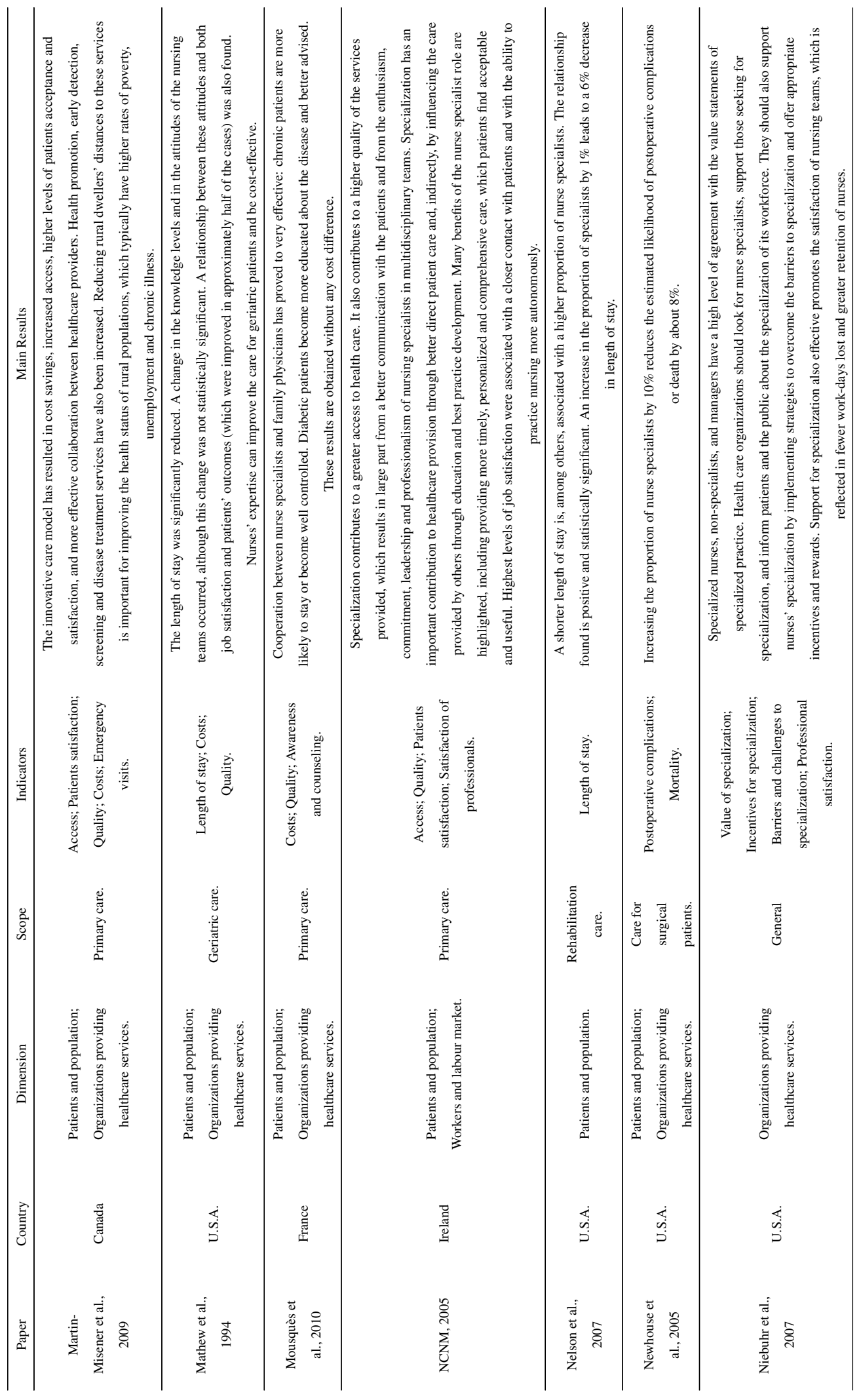




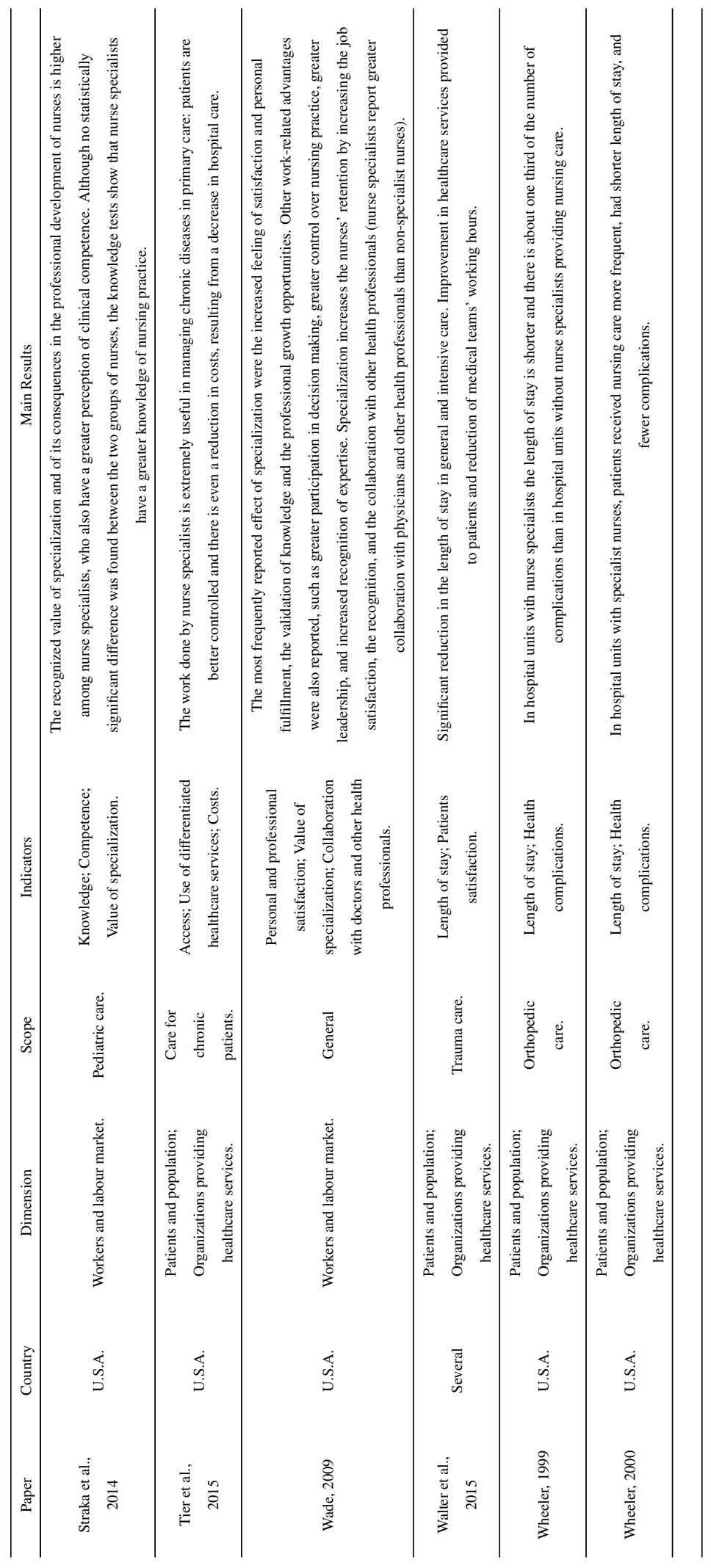




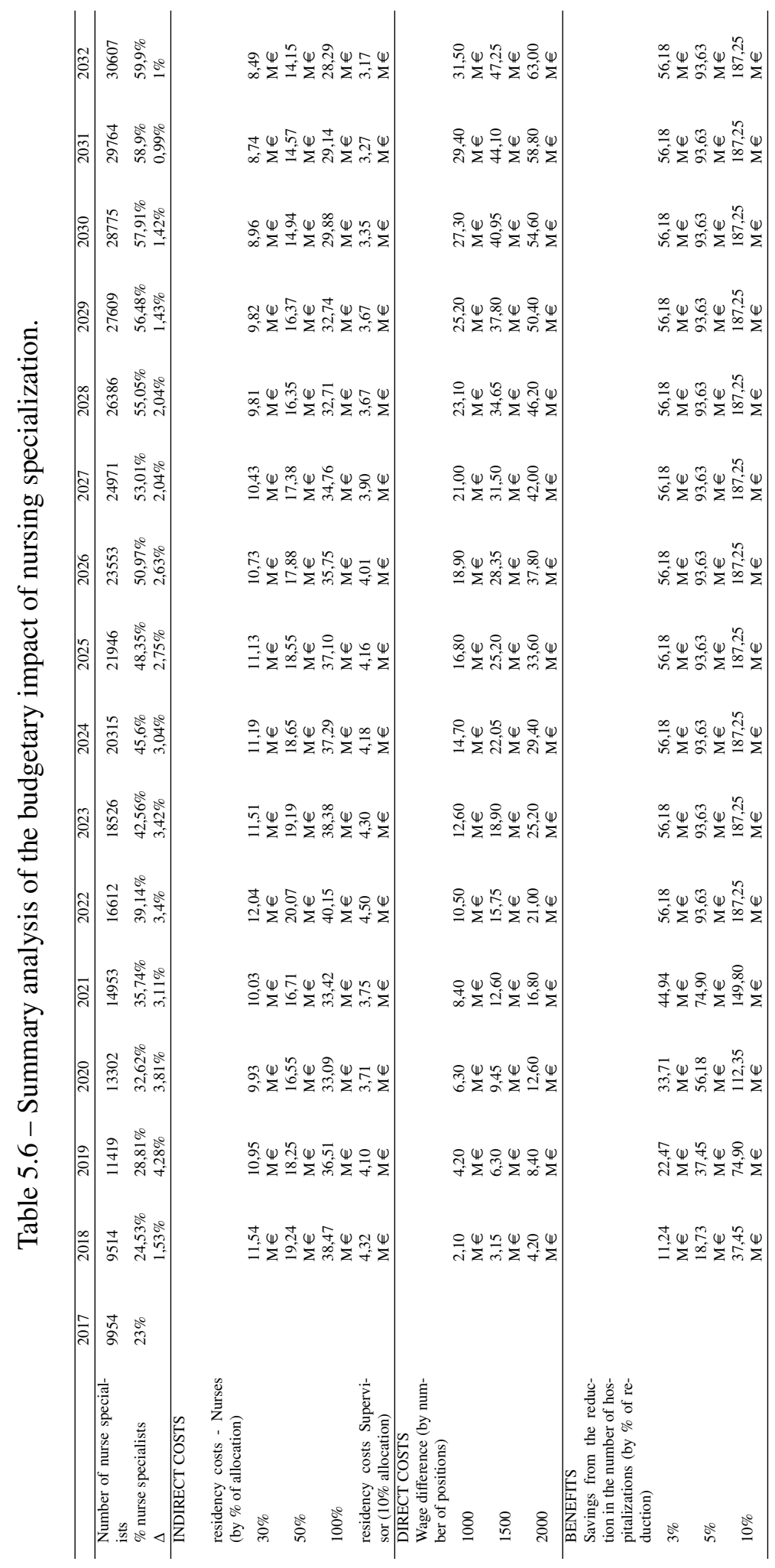


CHAPTER 6

\section{Conclusions and future work}

This thesis is focused on the healthcare demand and delivery problem. The theoretical motivation is discussed in Chapter 2, which presents a literature overview, identifies some research gaps, and proposes an integrated framework for the problem. Chapter 3 focuses on Health Human Resources, where an approach to estimate HHR requirements is presented. An econometric analysis of Health Expenditures is performed in Chapter 4, and in Chapter 5, nurse specialization is discussed and evaluated as a way to deal with the rising volume and complexity of the demand for healthcare.

The main contributions of each chapter are mainly related to the expansion of knowledge on some of the sub-problems identified: Health Human Resources, Health Expenditures, and Healthcare Delivery. This chapter summarizes the contributions of this thesis and discusses relevant future work.

\subsection{Contributions}

This work focused on the demand for and delivery of health care, a topic of increasing relevance in recent years, given the demographic and technological changes, the rising health expenditures, and the enhanced concern about access to quality, timely and sustainable healthcare.

Distinct sub-problems were identified as crucial to ensure that the future demand will be met, at the level desired for the healthcare services delivery: demand for healthcare services, for health human resources, for health expenditures, and healthcare delivery process. This thesis presented both a reflection and a structured analysis of the previously identified sub-problems. It also presented econometric models for quantifying the relationship 
between healthcare services and HHR needed, as well as for exploring the relationship between health expenditures and its drivers. These models were applied to concrete contexts (Portugal and OECD countries), using real dataset. Additionally, different frameworks were proposed to generalize the approaches followed and allow their application to different settings and data.

Overall, the main contributions arising from this thesis go beyond the interesting insights about the concrete context, such as the trade-off of physicians' time between different healthcare services and the effect of technology on physicians' productivity in Portugal, or the main determinants of health expenditures in OECD countries. This work can also be valuable to health researchers, planners or policymakers, mainly for two reasons. First, since the frameworks and models presented allow for a structured comprehension and analysis of the sub-problems introduced. Second, by helping both on planning the needs for HHR and financial resources in healthcare - ensuring that all the needed resources are available and best used - and with the implementation of new ways of delivering healthcare.

The work underlying this thesis instigated several scientific contributions at various levels. The research agenda and the results obtained gave origin to four scientific papers published or submitted in international peer-reviewed scientific journals, two working papers, over ten communications at national and international conferences, and participation in two research projects: HHRPLAN: Foresight and decision support tools for improved healthcare workforce planning and policy analysis (Grant No PTDC/IIMGES/4770/2014), developed in co-authorship and financed by Fundação para a Ciência e Tecnologia (FCT), and bringing together several national and international institutions (Universidade do Porto, Instituto Superior Técnico, Administração Central do Sistema de Saúde (ACSS) and Cardiff University); and ANPCARE: Specialized nursing care in response to changing healthcare needs, financed by the Portuguese Nursing Council and supporting the discussion and negotiation of the implementation of this role in Portugal.

Firstly, Chapter 2 draws attention to the importance of planning the demand for healthcare in the current context, characterized by an increasing number of health and economic concerns related to the demand for healthcare, and presents a published paper: 
1. Cruz-Gomes, S., Amorim-Lopes, M., Almada-Lobo, B., 2019. The Demand for Healthcare Services and Resources: Patterns, Trends and Challenges in Healthcare Delivery, in: Alves, M.J., Almeida, J., Oliveira, J.F., Pinto, A.A. (Eds.), $O p$ erational Research. Springer Proceedings in Mathematics $\mathcal{E}$ Statistics, vol 18, pp. 91-106.

The first highlight of this paper is a literature overview and discussion on the main healthcare demand issues. As we attempted to prove, and despite the undeniable interest of the field and the growing number of studies devoted to these issues, the problem is not closed. By identifying some gaps and pointing out to some research opportunities we hope to stimulate future research focused both on providing a better understanding on the factors driving the demand for healthcare services and resources and on developing models to accurately forecast their expected evolution for the future: the healthcare services that will be demanded by the population, the health human resources that will be required to deliver these services and the financial resources that will be needed for all the inputs that are required to produce them. Moreover, a framework for the demand for healthcare problem is proposed, which integrates the four sub-problems identified: demand for healthcare services, for health human resources and for financial resources, and challenges on assuring healthcare delivery in the future.

Chapter 3 answers to RQ1: 'How to translate healthcare services into HHR requirements in a multi-output context? What has been the impact of labour productivity on healthcare delivery? Which allocation options are available for the current levels of HHR?'. It proposes a method to empirically quantify the relation between healthcare services and Health Human Resources requirements, which is presented in the following paper:

2. Cruz-Gomes, S., Amorim-Lopes, M., Almada-Lobo, B., 2018. A labor requirements function for sizing the health workforce. Human Resources for Health 16, $67-80$. 
The proposed method yields simple yet powerful models to understand and quantify the relation between healthcare services and HHR needed. Estimation of HHR requirements based on these models can be performed as the second step - that aims to translate services to HHR - on the different demand approaches to HHR planning. By empirically quantifying the relation between HHR and healthcare services produced, this method can be used to complement several other existent approaches aiming to translate healthcare services in HHR, which require the use of service standards as an input, to further estimate the HHR requirements. Additionally, the proposed approach also provides several interesting insights that can be very useful to health managers and policy-makers, such as: 1) the variation in the number of physicians that is required to meet fluctuations in the demand for healthcare; 2) the proportion of time spent by physicians in each type of care provided; 3) the possible allocations of the available physicians between different healthcare services, based on the opportunity cost of physicians' labor; 4) the effect of the HHR concentration in hospitals; and 5) the evolution of labor productivity in hospitals. Overall, this method can be used to enable a more informed sizing and allocation of human resources and to achieve a better HHR management in hospitals, to inform on the right scale of health facilities and HHR concentration, and to foster a deeper knowledge on the evolution of the labor productivity and on the opportunity costs of labor in different healthcare services.

Chapter 4 answers to RQ2: 'Out of the main supply-and demand-side drivers of healthcare expenditures identified in the literature, which are the most significant for the OECD countries? What are the shapes of long-and short-run relationships among health care expenditures and these drivers? Which are the most suitable models for detecting the existence of long-run relationships among healthcare spending and its determinants? Do the different methodologies most commonly applied lead to similar results and conclusions?'. It describes the econometric approach to tackle the sub-problem of health expenditures, resulting in the following paper: 
3. Cruz-Gomes, S., Amorim-Lopes, M., Almada-Lobo, B.. Health Expenditures in OECD countries: An Econometric Analysis. Submitted to Health Economics.

This paper starts by synthesizing the methodological advances that have been guiding the macro studies of health expenditures from simple cross-country or time-series analysis to most advanced panel studies, an by exposing the contradictions on previous literature regarding the factors driving health expenditures. Using a recent and long panel on OECD countries, we studied the main characteristics of the data, and compare different models and estimation methods used in recent works exploring the relationship between health expenditures and its drivers. Results confirm the existence of a long-run relationship between health expenditures and the considered drivers, and the comparison of the results arriving from different methodological approaches shows that the conclusions on the relevance of each driver are highly influenced by the methods applied. We show that studying the characteristics of the data is essential and that these insights should be taken into account so that the models and estimation methods selected are appropriate and, consequently, the inference is reliable. As so, we propose a framework for the selection of macro panels models, according to the main characteristics of the data, to help researchers on the choice of the adequate approach.

In Chapter 5 we answer to RQ3: 'Can nursing specialization help with the main challenges arising from the recent changes in the demand for healthcare? What is the theoretical rationale supporting the specialization of nurses? Do the main empirical results reported by countries where nursing specialization was implemented support this rationale? How to roll-out nursing specialization in a specific country? What can be the expected budgetary impact of implementing specialized nursing roles?'. The last paper tackles the nursing specialization as an alternative mode of delivering care that can help to ensure the quality, access, and sustainability of healthcare delivery: 
4. Cruz-Gomes, S., Amorim-Lopes, M., Almada-Lobo, B.. The impact of specialized nursing care in Portugal: an economic evaluation and a policy analysis. Submitted to International Journal of Nursing Studies.

The main contributions of this paper follow two directions. On the one hand, the international trends are presented, and the empirical evidence regarding the impact of nursing specialization is reviewed, informing on the expected effects of nursing specialization for the several stakeholders: patients, professionals, and health organizations.

On the other hand, this paper proposes a policy framework for rolling-out nurse specialist roles, also presenting the analysis and results for the real-context application, which aims to shed some light on the several relevant topics, informing other countries that may be considering the implementation of these nursing roles. The framework for the application and governance of such role provides insights regarding the main barriers and enablers that may hinder or facilitate the implementation of the measure; the regulation guiding the main aspects of both the implementation and governance; the specialized nursing workforce estimation and planning; the education and training processes that are required to perform the role of nurse specialist; the payment policies defining the financial rewarding of a specialized workforce; and the economic impact of both the specialization process and maintenance of a specialized workforce in the health system, to ensure the feasibility and sustainability of the measure in the financial context of a specific country.

\subsection{Future work}

In the course of this thesis, we faced many challenges, and some questions remain unanswered, either due to time constraints or to the limitations of the empirical data. Overall, this research can lead to several relevant directions for future work, such as:

- A deeper analysis of the interacting influences that lead to the demand for healthcare services. In a context of rising coexistence of multiple health conditions, epidemiological factors are incredibly relevant on driving the decision to seek for care, as 
a higher prevalence of multiple conditions increases the demand for healthcare services and heightens its complexity.

- Further work on HHR productivity, to provide a better understanding of the main factors driving the changes in productivity that were found in Chapter 3.

- The comparison between country-specific models with the panel models presented in Chapter 4.

- The forecast of health expenditures through both these types of models, in the light of the insights provided in Chapter 4 regarding health expenditures determinants.

- The integration of the developments provided for each of the sub-problems identified as constituting the problem of the demand for healthcare, making use of the integrated framework proposed in Chapter 2 to assess and plan the future needs for healthcare services and resources.

- Further analysis of other alternative ways to deliver healthcare, which may help to deal with the increasing demand for health services and resources and subsequent concern on the continuity and sustainability of healthcare delivery.

We are already tackling some of the issues arising from this thesis. Regarding the study of the determinants of healthcare services demand, we are currently working on an agentbased simulation model to study epidemiology and the demand for healthcare. Using data from the Portuguese Diagnostic Related Groups database, we aim to infer about the probabilities and patterns on the evolution of health conditions, through their association with the co-occurrence of other current or previous chronic and non-chronic conditions, as well as of other relevant factors, such as age, gender, economic conditions, risk and lifestyle factors, and residence location. Moreover, we aim to simulate how illness and morbidity may evolve and the subsequent demand for healthcare, using projections for some relevant variables (e.g., demographic) and considering specific 'what if' scenarios (e.g., change in the prevalence of a particular condition). We also aim to use the results on the expected 
healthcare demand to infer whether the current physical capacity will be enough to provide the expected volume of healthcare services and for the assessment of eventual regional asymmetries.

Moreover, a country-specific Vector Error Correction (VEC) model of health expenditures is being developed for Portugal. This multi-equation econometric time-series model is used to explore and describe both the long-run relationships and the short-run dynamics between the health expenditures and its demand and supply drivers. This model will be further compared against the ones here presented for OECD countries (cf. Chapter 4). Moreover, both types of models (country-specific and panel models) will be used to forecast health expenditures and to provide insights on its expected evolution and subsequent sustainability of healthcare in the future. 
